\title{
Morphometric analysis of the gull Larus (Aves:Laridae) with implications for small theropod diversity in the Late Cretaceous
}

by

Michel Haché

A thesis submitted to the Faculty of Graduate and Postdoctoral Affairs in partial fulfillment of the requirements for the degree of

Master of Science

in

Earth Science

Carleton University

Ottawa, Ontario

(C) 2016, Michel Haché 


\section{Abstract}

This project analyzed morphological diversity in the modern gull (Aves:

Charadriiformes) genus Larus. Measurements of the post-cranial skeletons were made on specimens from six species of Larus and analyzed using Principal Component Analysis (PCA). Similar analyses were conducted on a series of theropod taxa. Landmark-based geometric morphometric analysis was also conducted on select skulls of gulls and analyzed using PCA. The results show that most of the gull species are very similar for the morphological parameters analyzed, only differing in overall body size, and, thus cannot be easily distinguished based on their skeletal morphology. These results were used as a modern analogue for inferring species diversity in the theropod fossil record. The implications of this study suggest that skeletal morphology, without the addition of soft tissue and behavior data available for modern birds, may not be able to distinguish closely related species of interbreeding, non-avian theropods in the fossil record. This suggests that the species diversity of extinct non-avian theropods was likely higher than can be of determined from their skeletal remains. 


\section{Acknowledgements}

I would like to thank my supervisors, Dr. Michael Ryan and Dr. Tim Patterson for their support over the past two years. I would like to thank Elizabeth Anderson for her patience and for helping me with writing this thesis. I would also like to thank Michel Goselin and the staff of the Canadian Museum of Nature for helping me with my data collection and allowing me access to the museum's collection. I would like to thank Mark Peck for helping me with the data collection of the specimens at the Royal Ontario Museum. I also want to thank Dr. Phil Currie for providing me with his database of theropod measurements. I want to thank everyone in the Patterson Research Group for their help and support. A special thank you to all my friends and family for all the support they've given in the past three years. This research was, in part, supported by a NSERC Discovery Grant to Tim Patterson. 


\section{Table of Contents}

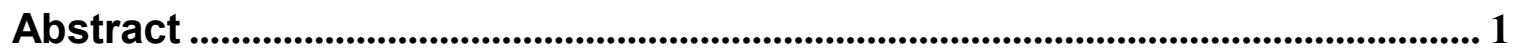

Acknowledgements .................................................................................................................. 2

Table of Contents..................................................................................................................... 3

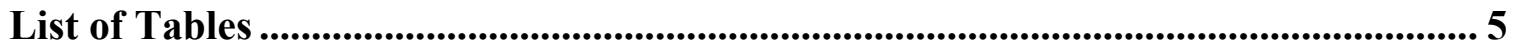

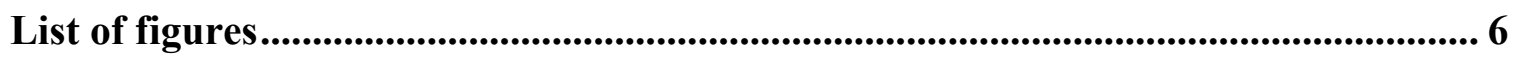

Chapter 1: Introduction ...................................................................................... 7

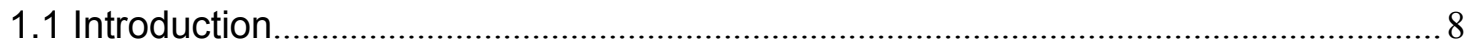

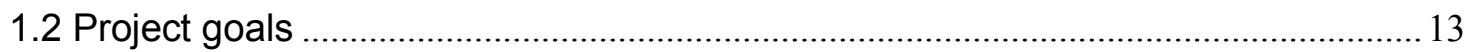

1.3 Gulls

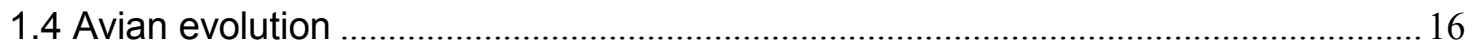

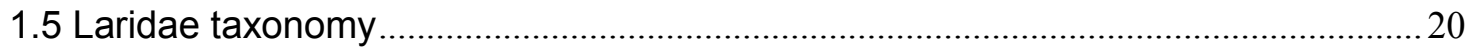

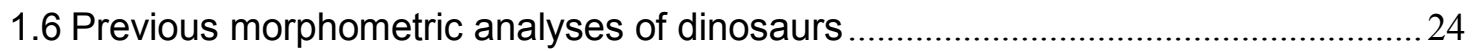

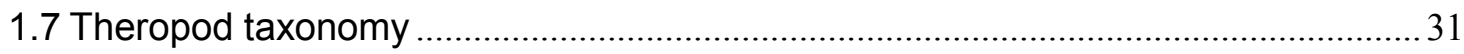

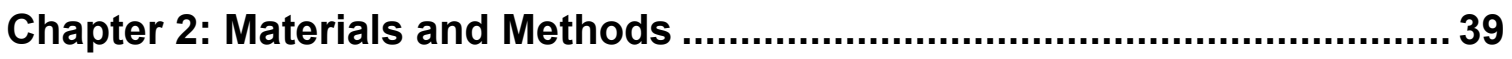

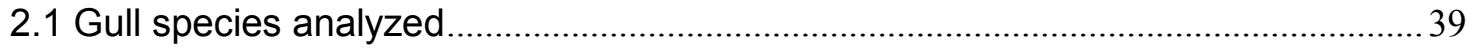

2.2 Theropod taxa analyzed .................................................................................... 43

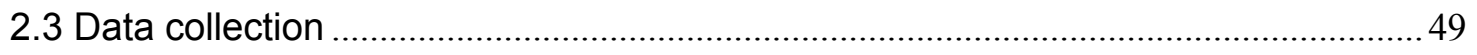

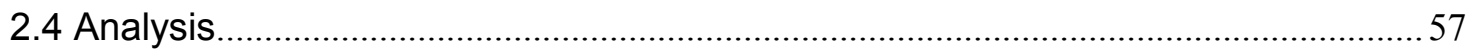

3.1 Gull postcranial morphometric analysis …………………………........................59

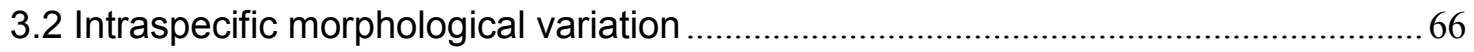

3.3 Gull cranial morphometric analysis .................................................................... 76

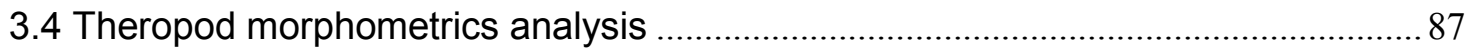


Chapter 4: Discussion

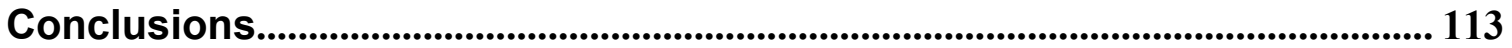

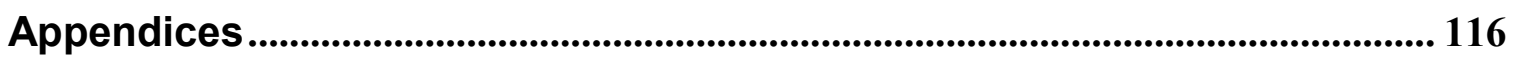

Appendix A Averaged measurements for the gull specimens ...................................116

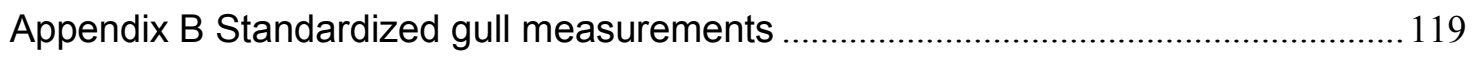

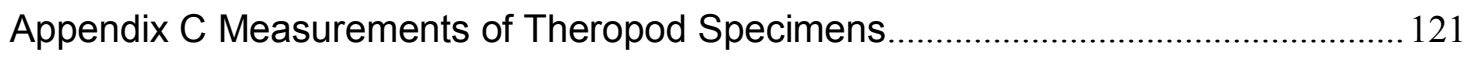

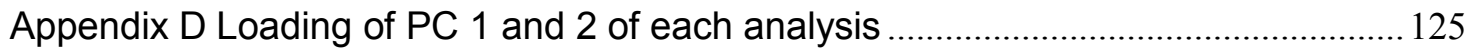

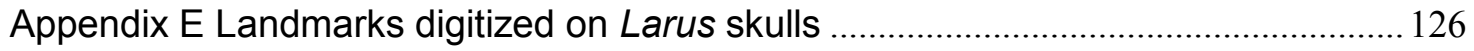

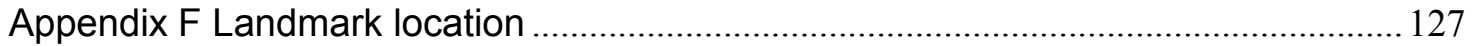

References ....................................................................................................................... 128 


\section{List of Tables}

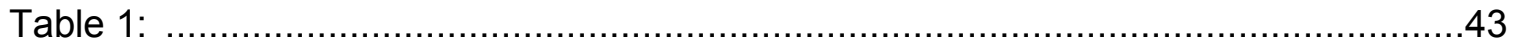

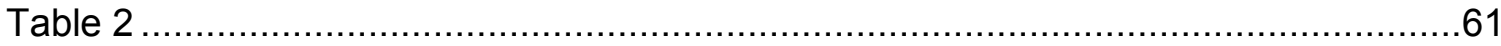

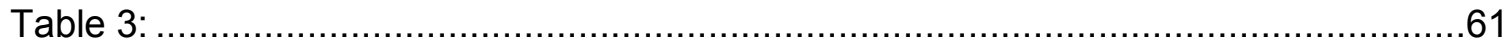

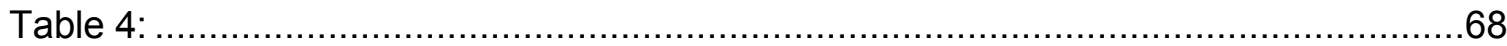

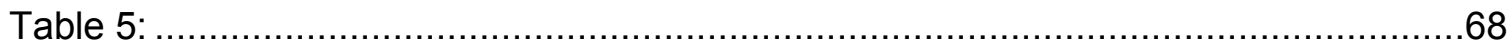

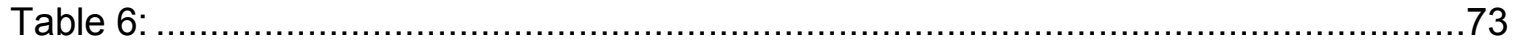

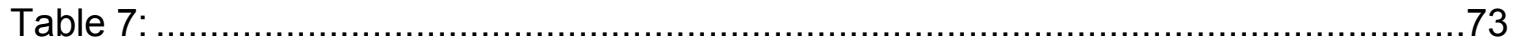

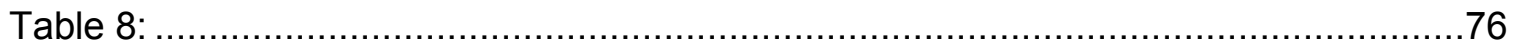

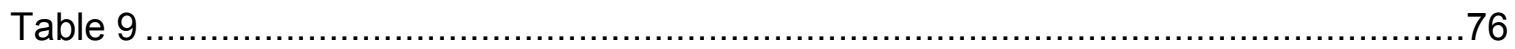

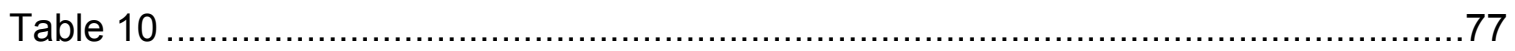

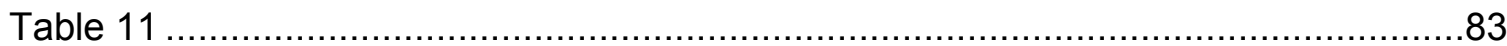

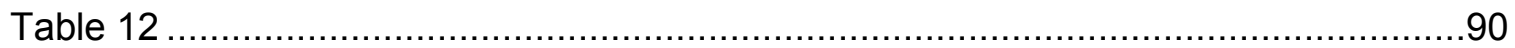

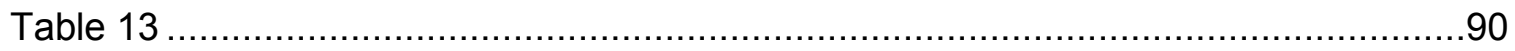

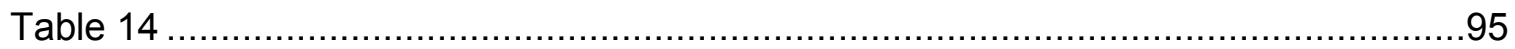

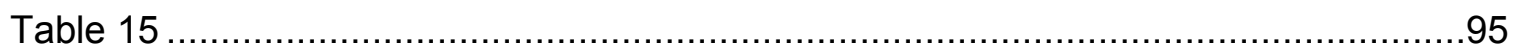

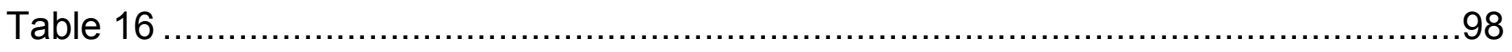

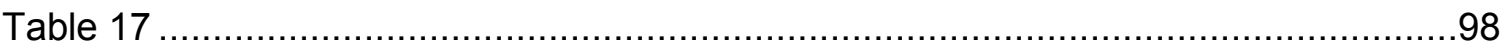




\section{List of figures}

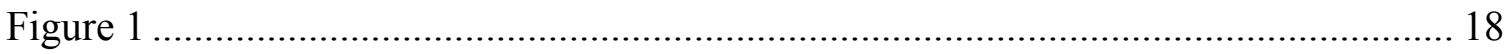

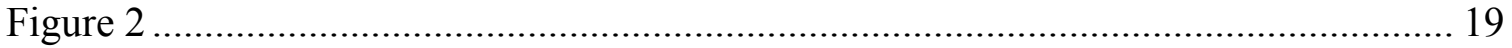

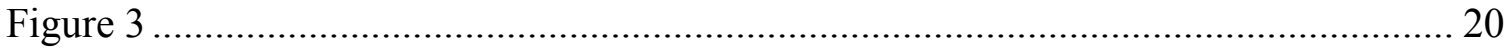

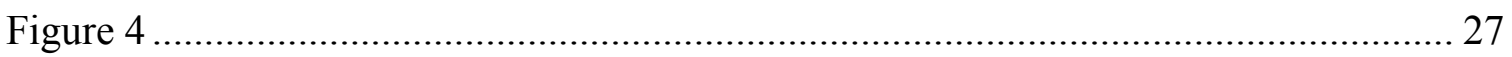

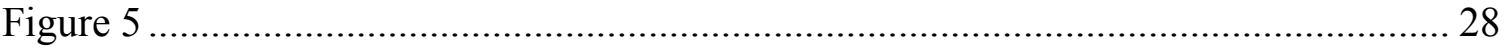

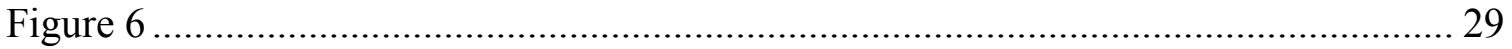

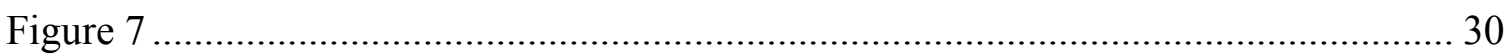

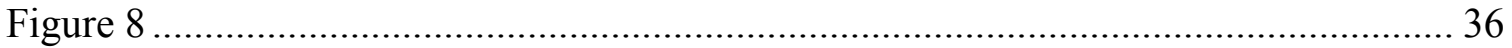

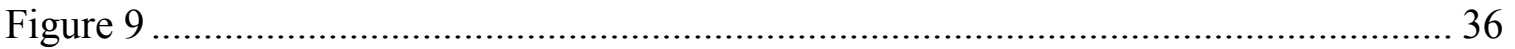

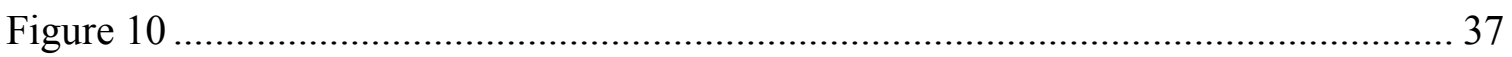

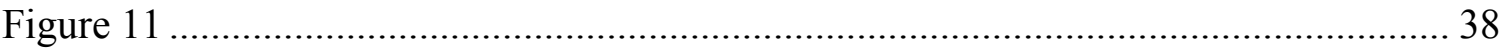

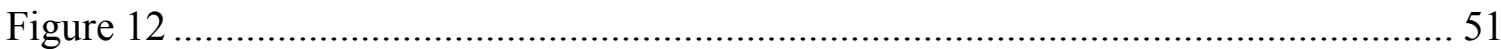

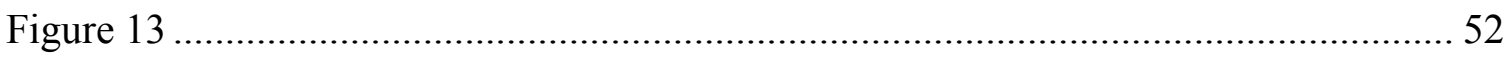

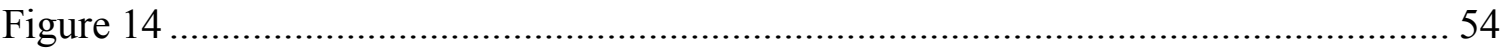

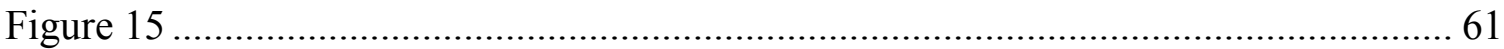

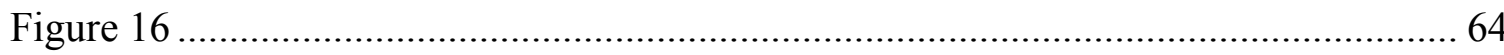

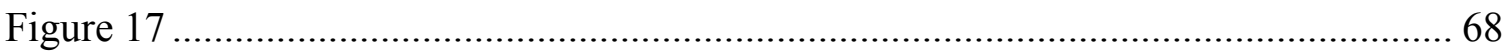

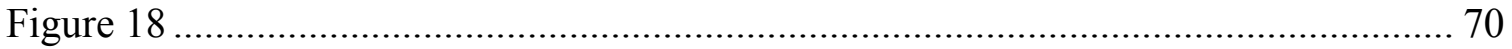

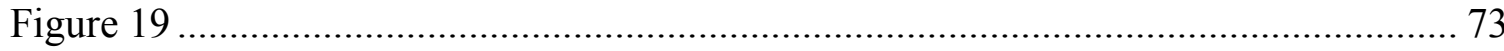

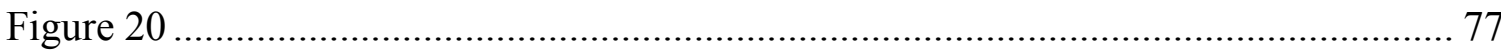

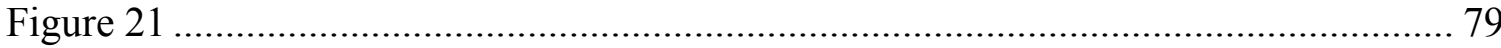

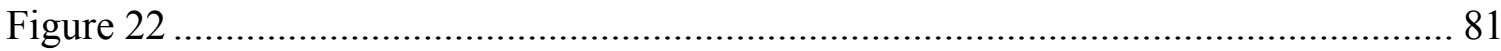

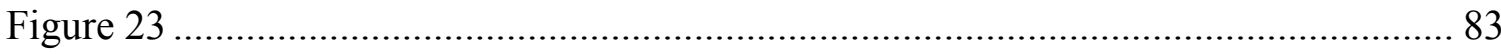

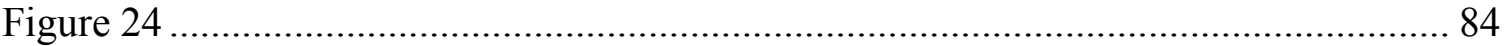

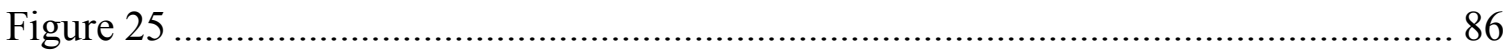

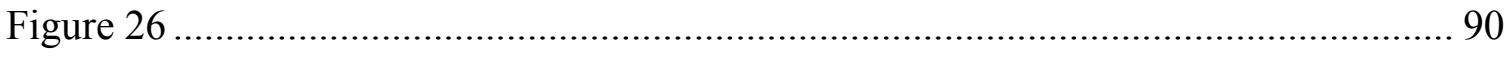

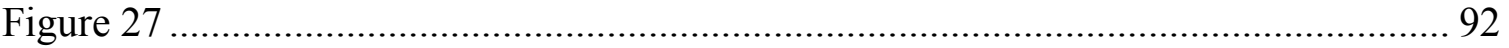

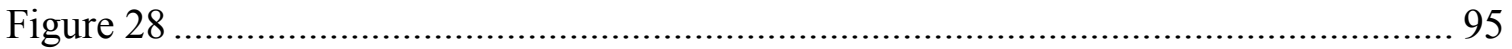

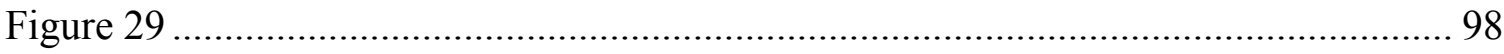

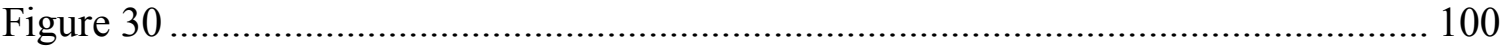




\section{List of Appendices}

Appendix A Averaged measurements for the gull specimens ................................... 116

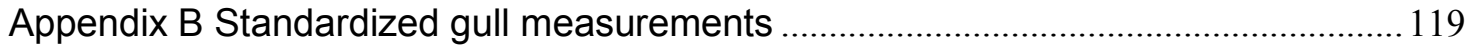

Appendix C Measurements of Theropod Specimens................................................ 121

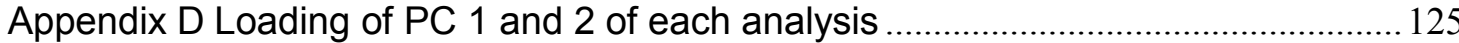

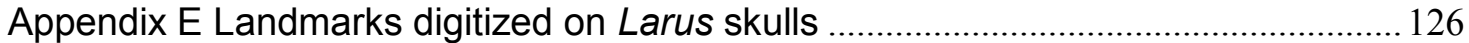

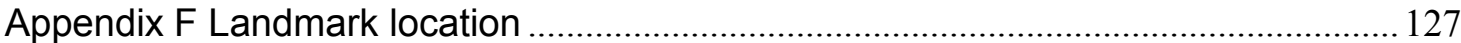




\section{Chapter 1: Introduction}

\subsection{Introduction}

All living birds are dinosaurs belonging to the clade Avialae, a branchbased clade that includes modern birds and all species more closely related to them than to deinonychosaurs (Naish, 2012, Gauthier, 1986). Small-bodied theropods (Dinosauria: Theropoda) are among the most studied dinosaurs, with multiple new taxa being described every year, (e.g., Benson and Carrano, 2010; Ryan et al., 2012), but our understanding of their rich natural history is affected by preservation and the completeness of their fossil record that frequently only preserves fragmentary specimens, especially for material derived from North American deposits (e.g.: Ryan et al., 2012; Larson, 2008). Taphonomic size biases ensure that larger-bodied taxa are commonly more complete as fossils, and will preserve more readily than smaller-bodied taxa (e.g., Brown 2013). Theropods are typically diagnosed based on hard tissue characters (skeletal elements and teeth) and soft tissues are only rarely preserved in some taxa (e.g., Ji et al., 2001, Longrich, 2006, Xu et al., 2012). There are rare cases of exceptional preservation where soft tissues are preserved, such as the Solnhofen limestones of Germany (e.g., Archaeopteryx) or the Jehol fauna from the Liaoning deposits of China (containing multiple complete skeletons from birds and small theropods) that can preserve feathers and stomach contents (e.g., Zhang, et al. 2010; Bada, et al. 1994). Many of these, such as the recently discovered Zhenyuanlong suni (Hu et al., 2009, Zanno, 2010, Lü and Brusatte 
2015), provide new insights into the evolutionary history of modern birds through the description of new anatomical details. However, since almost all small theropod taxa are described exclusively based on their skeletal characteristics, this has resulted in most genera being monospecific.

By contrast, species recognition of modern animals is not uniquely based on skeletal features, but uses molecular, behavioural and morphological data, such as integument type and colour and general body size (e.g., Griffiths et al., 1998; Haddrath and Baker 2001; Hebert et al., 2004). The only skeletal related character that is frequently used to diagnose extant birds is size, which has limited utility in fossil taxa where the effects of ontogeny can rarely be fully considered (e.g., Dwight, 1925).

Extant Aves are described either exclusively, or primarily, on soft-tissue features (i.e., feather colour and patterning), behavior (i.e., mating behaviour and songs (Emlen, 1972; Slabbekoorn and Smith, 2002), and genetic differences (mDNA and chromosomal differences, e.g., Prum, et al., 2015). These characters allow for a level of taxon discrimination unavailable for fossils such that for the vast majority of modern birds genera, multiple species are recognized, with many having overlapping geographical occurrences (e.g., Kubetzki and Garthe, 2003; Norell and Makovicky, 2004). Recent work in molecular phylogeny has further suggested that the number of species within some groups should at least be doubled because morphologically and behaviorally identical taxa have proven to be genetic distinct (e.g., Jetz et al., 2012, Lemme and Erbacher, 2013). 
Despite the limitations of the fossil record, there are currently $\sim 1100$ valid non-avian dinosaurs known from the 186 million years of the Mesozoic, with 527 genera currently described (Starrfelt and Liow 2016). By comparison, there are more than 10,600 (Hoyo et al., 2013) modern dinosaurs (Aves) alive today. If we can assume that every bird taxa has a 1 million year time span, and that bird diversity for the Jurassic and Cretaceous was similar to what it is today, then we can estimate that approximately 1.4 million species have existed since the end of the Triassic, If dinosaur diversity in the Jurassic and Cretaceous matched that of modern birds, then we can estimate that only $0.1 \%$ of the dinosaur species that actually existed after the end of the Triassic are currently known. When we acknowledge that most living theropod (bird) species are only recognized based on non-fossilizing features, then we can hypothesize that the fossil material that is known for extinct, non-avian theropods cannot capture the diversity we would expect for any diagnosed genera. 


\section{$\underline{\text { Species concepts }}$}

The ability to recognize and diagnose species in fossilized taxa has been an on-going debate in biology ever since Linnaeus formalized a system of taxonomic nomenclature and the concept of a dichotomously branching 'tree' to represent the relationships between taxa (Queiroz, 1997, Reece et al., 2009). In such a system, the lengths of the 'branches', and the distance between them, were rough indications of the implied evolutionary relationships between groups (Reece et al., 2009). Mayr (1942) formulated the biological species concept as follows: "Species are groups of actually or potentially interbreeding natural populations, which are reproductively isolated from other such populations". he later revised this basic definition in 1969 and 1982 by omitting the "actually and potentially" interbreeding clause. He also added that species "occupy a specific niche in nature" (Mayr 1982). The key to the biological species concept is that species are not defined based on their appearance, but on their breeding potential (Mayr 1942, Mayr, 1957; Mayden, 1997).

Recognizing the difficulty in determining interbreeding potential in the fossil record, Simpson (1951) defined the evolutionary species concept as "...a lineage (an ancestral-descendent sequence of populations) evolving separately from others and with its own unitary evolutionary role and tendencies". This concept does not consider the breeding potential of a species or it's ecological niche (Mayden 1997). Multiple additional definitions have been coined, including the phylogenetic species concept, the genetic species concept, the morphological species concept, all of which have varying systematic utility 
depending on the group being investigated and the questions of relationships being asked. Some of the other species concepts are summarized below:

Morphological Species Concept: This concept groups species based on morphological and anatomical criteria (Reece et al., 2011). It typically uses skeletal morphology to infer taxonomic relationships. It is also used to characterize species that do not reproduce sexually, or for species that are known only as fossils (Mayr et al 1963).

Phylogenetic/cladistic species concept: This concept considers the evolutionary relationships among organisms. It relies on evolutionary history and common ancestry to define species (Reece et al., 2011). Since paleontologists lack access to the breeding potential and most soft tissue features of the fossils that they study, they typically use hard tissue characters to construct hypotheses of relationships relative to a common ancestor, thus incorporating, in part, the morphological species concept when describing fossil organisms. Geographic, stratigraphic, and ontogenetic considerations can also be incorporated as characters in these analyses.

Genetic Species Concept: This concept defines species based on their genetic similarity or distance. Genetic analyses can uncover cryptic species, which cannot be distinguished using morphological analyses. This concept incorporates the biological species concept by assuming that a species is a group of 
genetically compatible, interbreeding natural populations that are genetically isolated from other populations (Baker and Bradley, 2006).

Paleontologists lack access to assessing the breeding potential of the fossils that they study, so they typically implicitly use the phylogenetic species concept (Reece et al., 2011). The inferred relationships within the phylogenetic hypotheses illustrated by phylograms are generated almost exclusively on hard tissue characters.

In the modern era of paleontology, inferences of relationships between taxa based on the cladistical method developed by Hennig (1965) which categorizes organisms based on shared, derived characters, and illustrated using branching diagrams called cladograms. Under this system, discrete characters are compared within a group assumed to have a common evolutionary ancestry. The analytical methods of cladistics have been refined using complicated mathematical algorithms that can be run using specific computer software (e.g., NTSSYS-pc, PHYLIP, PAUP etc.) on powerful computing systems, and can incorporate a range of characters including morphologic, genetic, geographic and stratigraphic.

\subsection{Project goals}

This project assumes that modern birds can be used as analogues for their related non-avian theropod relatives (based on the extant phylogenetic bracketing methodologies of Bryant and Russell, 1992; and, Witmer, 1995), and that inferences made about the skeletal basis for recognizing modern species 
can be applied to build hypotheses about recognizing species, and thus, species diversity, in the fossil record. The goal of this research is to analyze the morphological diversity within one multispecific bird genus to determine if these species can be distinguished exclusively on a select set of skeletal parameters alone. If they cannot be distinguished, this will suggest that, perhaps, within small, non-avian theropods there may be a hidden diversity that also cannot be determined without access to soft-tissue and behavioral data.

To examine this question, I analyzed species within one genus (Larus) of the most common group of shorebirds, the gulls (Aves: Charadriiformes) for a limited number of characters of the skull and postcrania to determine if they can be distinguished morphologically. Since the species to be studied are well established, I will test the null hypothesis $\left(\mathrm{H}_{\circ}\right)$ that the species cannot be distinguished morphologically. If rejected, I will accept the alternative hypothesis $\left(\mathrm{H}_{1}\right)$ that the species can be distinguished morphologically using morphometrics analyses. I will also conduct analyses of the post crania for the best available data set of small maniraptoran dinosaurs to determine if they can be distinguished $\left(\mathrm{H}_{\mathrm{o}}\right)$ by the same parameters. If they cannot, I will not reject the null hypothesis (Ho); I can then infer, that like the modern birds examined, the fossil sample set may contain more species than is currently recognized.

\subsection{Gulls}

Gull phylogenetic relationships used in this research are based on the cladistic analysis of Chu (1998). His analysis was based on morphological 
characters of the skeleton and integument. Gulls (or seagulls) are among some of the best-studied shorebirds, with a worldwide distribution. They are genetically and behaviorally diverse but very similar morphologically (see: Chu 1998; Baker et al., 2007; Thomas et al., 2004a, Thomas et al., 2004b), making them an excellent group on which to explore the utility and limitations of morphological characters in identifying species (Chu 1998). Laridae (gulls) is the sister clade to Sternidae (terns) within the clade Lari in the clade (order) Charadriiformes (Chu 1998, Cane 1994, Wetmore 1960). Charadriiformes is diagnosable by the following shared characters: schizognathous palate (having the maxilla-palatine bones separate from each other and from the vomer, which is pointed in front) and further similarities in syrinx and leg tendons (Brooke and Birkhead 1991). They are distantly related to auks, skimmers and waders (Chu 1998, Crochet et al., 2000, Livezey 2010). They have medium-to-large sized bodies that are typically white to grey in integument colour, often with black tipped wings and/or heads, long bills and webbed feet. Their unhinged jaws allow them to feed on large prey items of fish and marine invertebrates (Colewell 2010). Gulls are typically coastal animals. They nest in large, densely packed colonies of between 50 to hundreds of individuals. They lay two to three eggs in nests composed of vegetation (Burger 2006).

Most taxa take two years to develop adult plumage, going through several plumage states during their lifespan (Olsen and Larsson, 2010), although medium and large-sized gulls may take three or four years, respectively to reach maturity (Olsen 2010). Plumage is used to assess age in the field. 


\subsection{Avian evolution}

The gull Larus was chosen because it is a large $(\sim 1.5 \mathrm{~kg})$ genus - making it easy to measure parameters - with multiple species. Ideally, a flightless bird taxon would have been chosen as, lacking well-developed tails and being flightless, it more closely resemble their non-avian theropod ancestors; however, most flightless taxa are monospecific, and they are poorly represented in museum collections, making it difficult to amass a statistically significant data set. Birds evolved from small-bodied maniraptoran dinosaurs during the mid- to late Jurassic with the earliest accepted bird being Archaeopteryx lithographica (Padian, 2004). Most of the features that characterize birds first evolved in smallbodied maniraptorans, such as feathers, sternum, furcula and hollow limb bones, and are now generally considered to be adaptations for fast running (Padian, 2004, Holtz, 2012). During the Late Cretaceous, birds diversified very rapidly with most of the major clades evolving within the short span of 0.5 to 5 million years (McCormack et al., 2013).

Gauthier (1986) coined the term Avialae for the branch-based clade that includes modern birds and all species more closely related to them than to deinonychosaurs (Naish, 2012, Gauthier, 1986), with the term 'Aves' being used to describe the crown group of birds. Modern birds (Neornithes), are divided into three major groups: Paleognathae (Tinamous and flightless ratites), Galloanserae (gamebirds and waterfowls) and Neognathae (other modern birds) (Naish, 2012, Prum, 2015). Neognathae includes the clade Neoaves which 
represents the majority of all avian diversity (about $95 \%$ of all species) (Mayr and Clarke, 2003). Paleognathae and Neognathae form the group Neornithes (Naish, 2012; Padian, 2004; Mayr and Clarke, 2003).

Sibley and Ahlquist (1990) made major advances in bird taxonomy when they applied DNA hybridization to determine the degree of similarity between taxa. This technique compares the entire genome of species to determine how closely related various species are. Hackett (2008) conducted a phylogenomic analysis of 169 species of birds to determine their evolutionary history (fig 1). His analysis showed support for much of the previously established clades of birds (like land birds, charadriiformes, water birds and galloanserae).

A recent comprehensive phylogenetic analysis of Neornithes (Prum et al. 2015) refined the proposed relationships between major clades and defined the synapomorphies that support them (fig 2 and 3 ). They erected the new clade Aequorlitornithes within Neoaves, which includes the majority of waterbirds, including Charadriiformes (waders and shorebirds, including gulls), Mirandornithes (flamingos and grebes) and Ardeae (Eurypygimorphae and Aequornithes).

The sister group of the shorebirds is the 'land birds', which is an informal name for a large and diverse group supported only by molecular characters (Hackett et al., 2008, Ericson et al., 2006). This group contains most (but not all) of the familiar land birds, including the Passeriformes (a group that includes more than half of all bird species) (Hackett et al., 2008). 


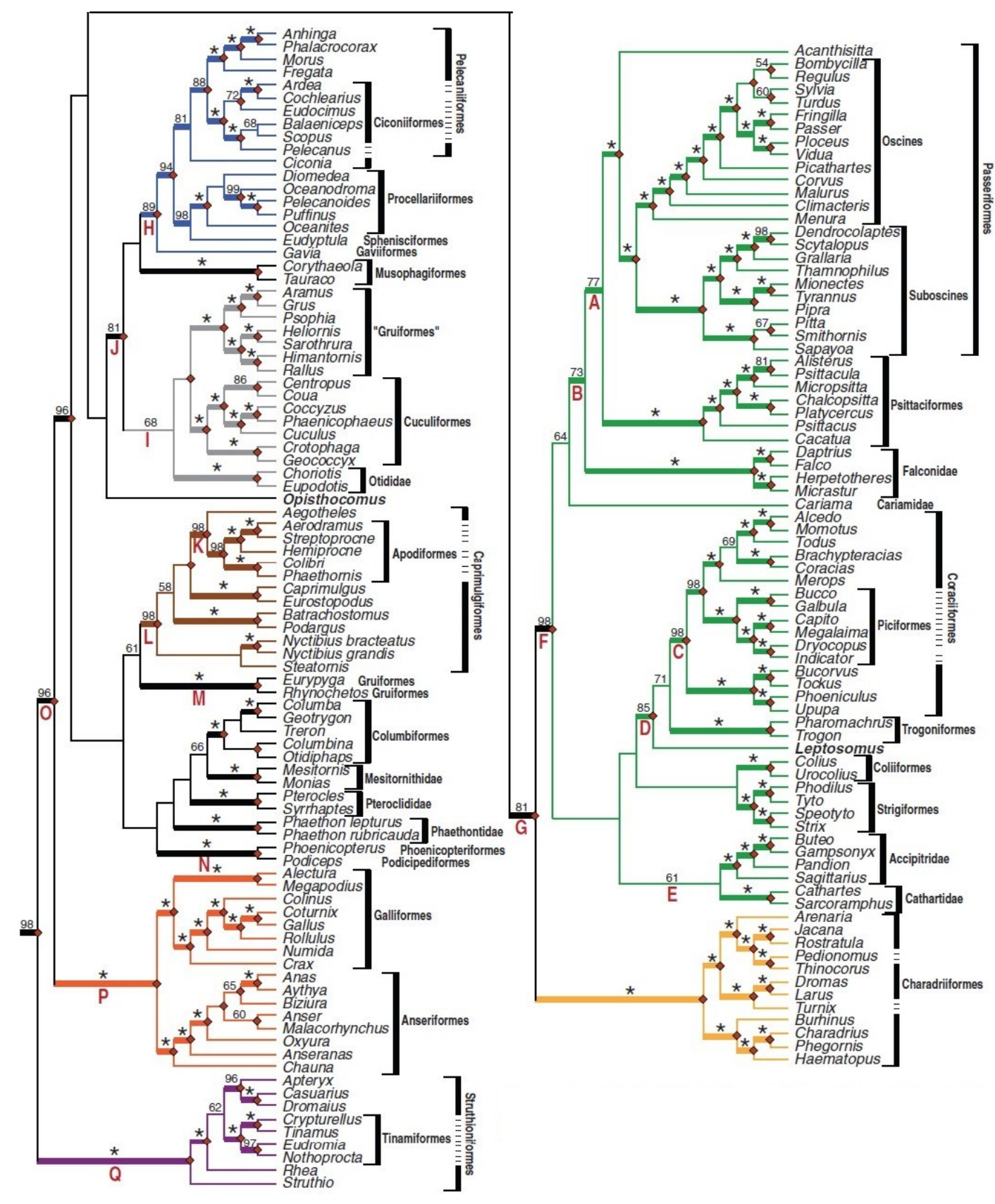

Figure 1: Fig. 2 from Hacket et al., 2008 showing avian taxonomy 


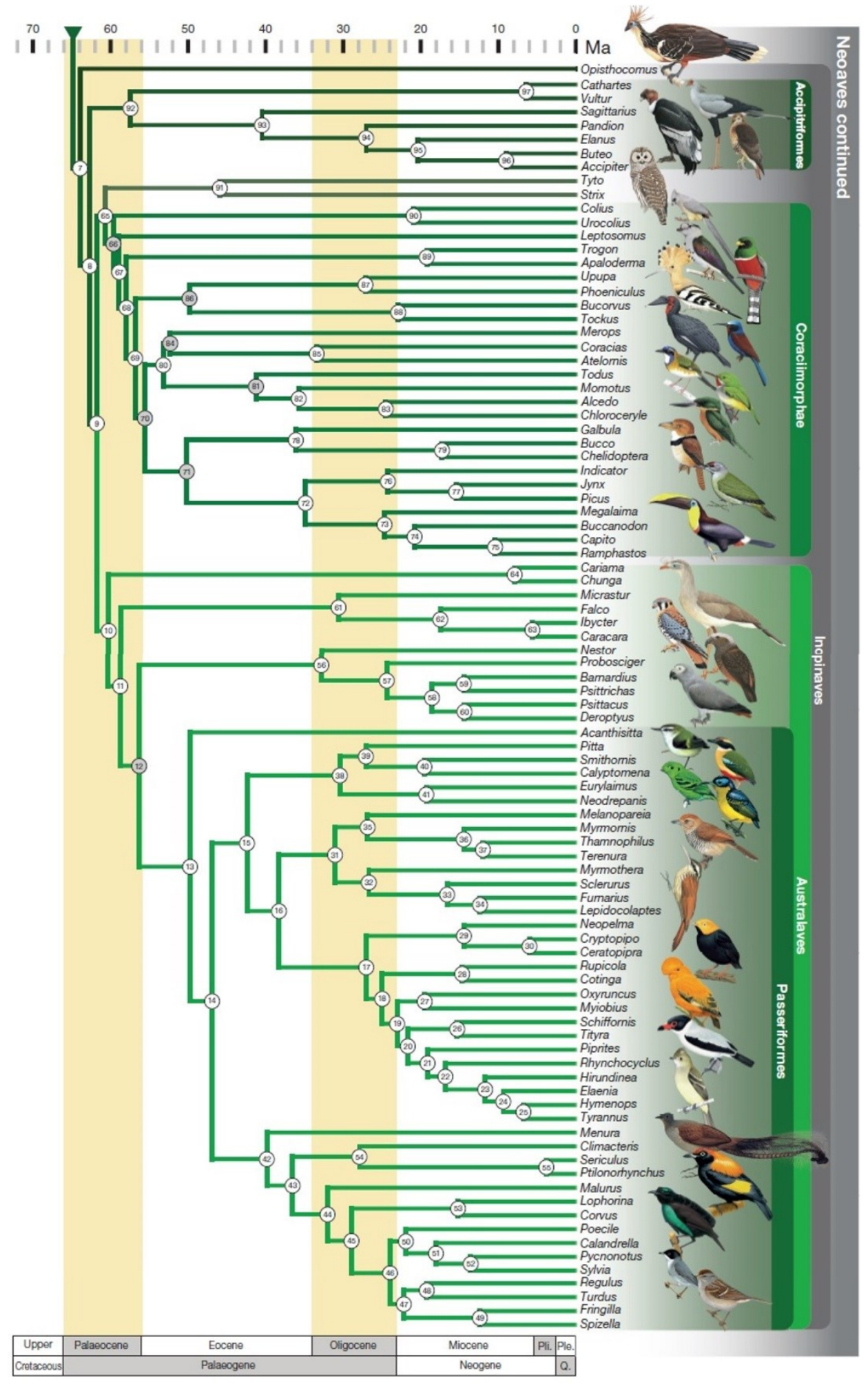

Figure 2: Taxonomy of the birds based on Prum et al., 2015 pt. 1 


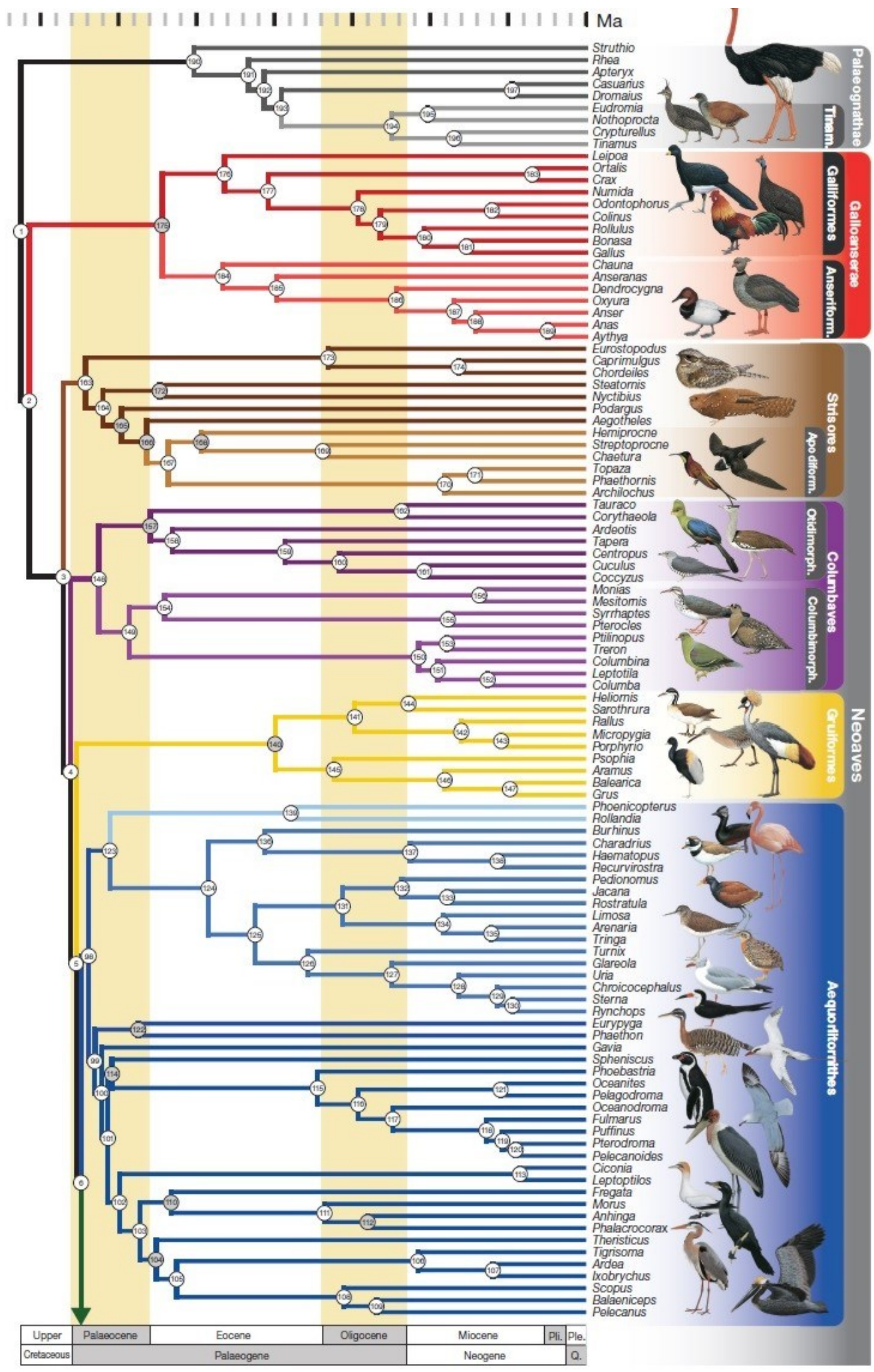

Figure 3: Avian taxonomy based on Prum et al., pt. 2 


\subsection{Laridae taxonomy}

The systematics of Laridae (comprising skuas, terns, gulls and skimmers) have been studied for more than a century, beginning with early $19^{\text {th }}$ century nonphylogenetic studies (Coues,1862). Most previous morphological analyses carried out on species within the genus Larus (gulls) were based on nonmorphometric data. Typically, the data used focused on external characters, such as plumage coloration. One of the first avian analyses to include gulls obtained poor resolution within 'gulls' and could not distinguish between gull species (Dwight, 1925; fig. 1). Dwight grouped the gulls into two genera, Larus and Hydrocoloeus with four and five species, respectively. He further subdivided the largest bodied species into subspecies. The first hypothesis of gull systematics based on qualitative morphological features (plumage and bill coloration) and display behavior was proposed by Moynihan (1959; fig. 4). He recognized 10 genera of gulls comprised of 9 species.

Hudson et al. (1969) conducted a non-cladistical numerical analysis of shorebirds using characters of the appendicular musculature of gulls. Their results supported the recognition of gulls as a monophyletic group, but had poor resolution. Schnell (1970) conducted a principal component analysis and a phenetic study of Lari (gulls, skuas, terns and skimmers) using a combination of skeletal and integumentary data to generate over a dozen phenograms that he used to differentiate skimmers and terns from gulls and skuas by characters of the bill. However, only one of Schnell's analyses (using external characters of the 
feathers) was able to cluster all the gulls together to the exclusion of all other shorebirds.

Hoffman (1984) also performed a qualitative analysis of the postcranial skeleton, but he could not resolve their relationships (Fig. 5). Cane (1994) analyzed the ontogeny of bill shape and hind limbs in a variety of shorebirds that indicated a close relationship between gulls and skuas (Fig. 6B and 6C). Chu (1998) conducted an analysis of gulls using 117 skeletal and 64 integumentary characters and obtained one best, fully resolved tree (Fig. 7), although the recovered clades are poorly supported statistically. Chu's results suggest that the genus Larus is not monophyletic. In order to make nomenclature reflect the phylogeny that he generated, Chu suggested subdividing the gulls into six genera; Larus, Xema, Rissa, Pagophila, Hydrocoloeus and Chroicocephalus.

Chu (1998) also compared the utility of osteological vs. integumentary characters in his analysis of the gulls using a total-evidence analysis. The totalevidence methodology uses character congruence to look for the best fitting phylogenetic hypothesis for all the available characters (Eernisse and Kluge, 1993). Chu analyzed 117 qualitative characters from the skeleton and scored them according to character states (e.g., presence/absence of the character). $\mathrm{He}$ did several analyses using, 1 ., only the osteology, 2., using only integuments, and then, 3., using thevcombiined osteology and integument data. The osteology-only data set recovered $25 \%$ of the most parsimonious trees using a total evidence approach, while the integument-data set only had $30 \%$ congruence. Chu found that in the gull groups, osteological change is minimal 
compared to other groups of birds (e.g., the auks). If only the gulls are considered, then the osteology-only data set included approximately $7 \%$ of the clades. This suggests for gulls, osteology is important in reconstructing higherlevel phylogenies, but the integument is more useful for lower-level phylogenetic reconstructions.

The gulls constitute a well-studied group of birds that include over 28 extant species within a single genus (Sibley and Ahlquist 1990). Support for what is now considered to be the natural gull group has been the outcome of several studies (e.g. Hudson et al., 1969; Schnell, 1970; Hoffman, 1984; Hackett, 1989; Sibley and Ahlquist, 1990; Crochet et al., 2000), and continues to be refined within the context of both more detailed analyses (e.g., Laridae; Pons et al., 2005), and broader analyses of all Aves (e.g., Livezey et al., 2007). This ongoing research uses a variety of data types, including morphological analysis (e.g., Chu, 1998), comparative parasitology (Timmermann, 1957; Hugot et al., 1991), protein electrophoresis and DNA-DNA hybridization (Hackett, 1989, Sibley and Ahlquist, 1990), and behavioural analysis (Burger and Gochfeld, 1990). Some of these analyses have produced differing in-group relationships for Laridae (e.g., Chu, 1998, Hacket, 1984) and different sister group relationships within Aves. Laridae is currently placed as a sister clade to Sternidae (terns) within the clade Lari in the order Charadriiformes (Pons et al., 2005). 


\subsection{Previous morphometric analyses of dinosaurs}

There have been numerous morphometric (shape) analyses conducted on dinosaurs to investigate such functions as cranial kinesis (e.g., Holliday and Witmer, 2008), jaw and neck mechanics (e.g., Snively and Russell, 2007) and locomotion (e.g., Gatesy and Middleton, 1997). Foth and Rauhut (2013) used geometric morphometrics to evaluate theropod cranial diversity and its relation to phylogeny, ecology and function, but not species level recognition. Some

morphometrics of teeth have been used to recognize dinosaur taxa (e.g. Smith et al 2005, Larson 2008).

Dodson (1993) conducted some of the first dinosaurian morphometric analyses when he compared the cranial morphology of several species of ceratopsians. In 1993, he used 16 specimens from 12 taxa to test whether phyletics produced similar clustering results as cladistics. Dodson digitized 21 landmarks on each skull specimens and His analysis determined that specific diagnostic characters can be found on all parts of the skull and that they are not sexually dimorphic. His analysis was also recovered the clade Ceratopsidae clade indicating that morphometrics is a valid method for recovering and recognizing higher level dinosaur clades.

Hedrick and Dodson (2013) conducted 3D geometric morphometric analysis on Psittacosaurus specimens to understand their individual and taphonomic variations. They sampled 30 skulls from three species of Psittacosauridae (P. lujiatunensis, P. major, and Hongshanosaurus houi) from the Lujiatun beds of the Yixian Formation. Their results showed that most of the 
variation between the species results from individual and taphonomic variation. They concluded that there is only one species of Psittacosaurus within the Lujiatun beds and that the three species previously identified represent different taphomorphotypes of $P$. Iujiatunensis. This implies that the range of variation found in other dinosaurian groups may also be related to taphonomic distortion, rather than interspecific variation (Hedrick and Dodson, 2013).

Maiorino et al. (2013) conducted geometric morphometrics on Triceratops and Torosaurus to determine whether these taxa are congeneters. They examined the cranial morphology of 28 skulls and 36 squamosals of Nedoceratops hatcheri, Triceratops sp. and Torosaurus $s p$. using landmarkbased morphometrics. Their results showed that Torosaurus is a distinct and valid taxon, whether looking at the entire skull, the skull without the frill, frill alone, or squamosals separately. Torosaurus has different morphologies and distinct allometric trajectories compared to Triceratops. These results indicate that extinct dinosaur taxa can be recognized using morphometric analyses.

Maiorino et al., (2013) also c geometric morphometrics to investigate the shape change in the squamosals of 155 ceratopsian specimens, representing 27 species of Chasmosaurinae and Centrosaurinae. The results indicate that the ceratopsian squamosal is highly constrained in phylogeny. There is an evolutionarily significant allometric signal between the two clades, but not within each clade. Chasmosaurines, compared to centrosaurines, show a more derived squamosal morphology, with a trend towards a blade that is strongly expanded 
dorsoventrally and with a narrower angle between the infratemporal process and the caudoventral margin (Maiorino et al. 2013). 


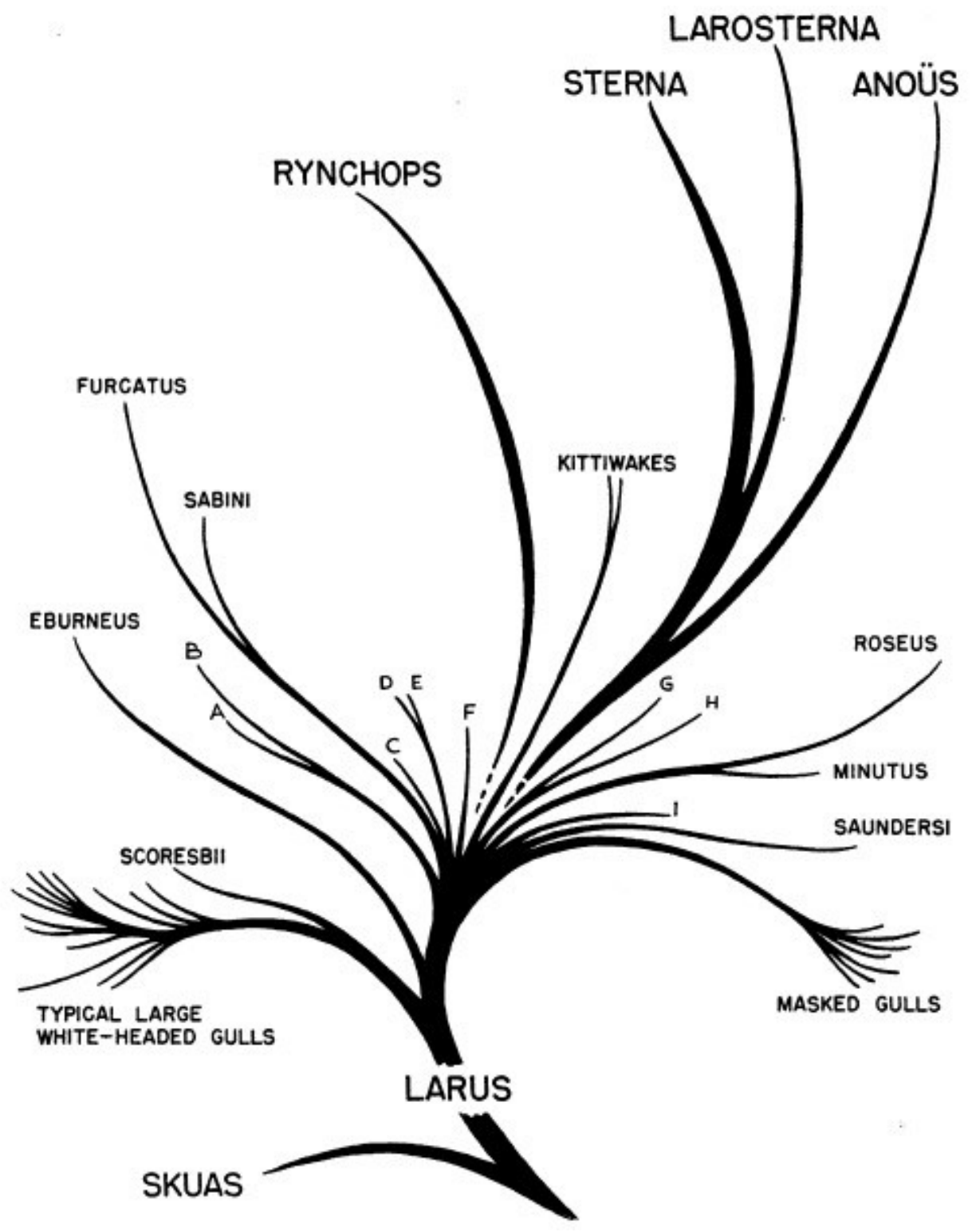

Figure 4: a rough family tree generated by Moyniham (1959) showing the inferred releationship between each gull taxa. A: Larus heermanni, B: Larus modestus, C: Larus fuliginosus, D: Larus hemprichi, E: Larus leucopthalmus, F: Larus atricilla, G: Larus ichtyaetus, H: Larus pipixcan, I: Larus melanocephalus. A: Larus heermanni, B: Larus modestus, C: Larus fuliginosus, D: Larus hemprichi, E: Larus leucopthalmus, F: Larus atricilla, G: Larus ichtyaetus, H: Larus pipixcan, I: Larus melanocephalus. 


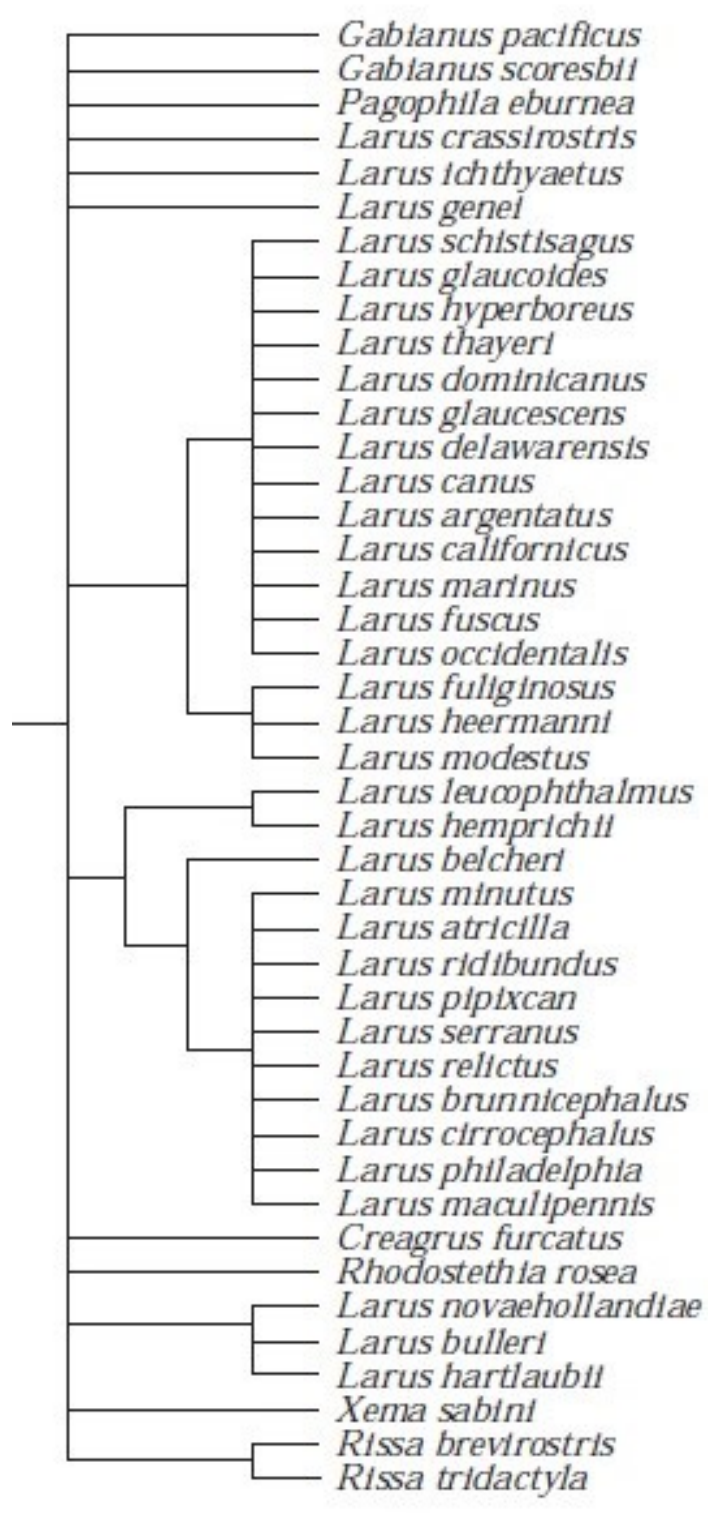

Figure 5: Hoffman's (1984) phylogeny of the gulls showing the relationships of each gull taxa. 

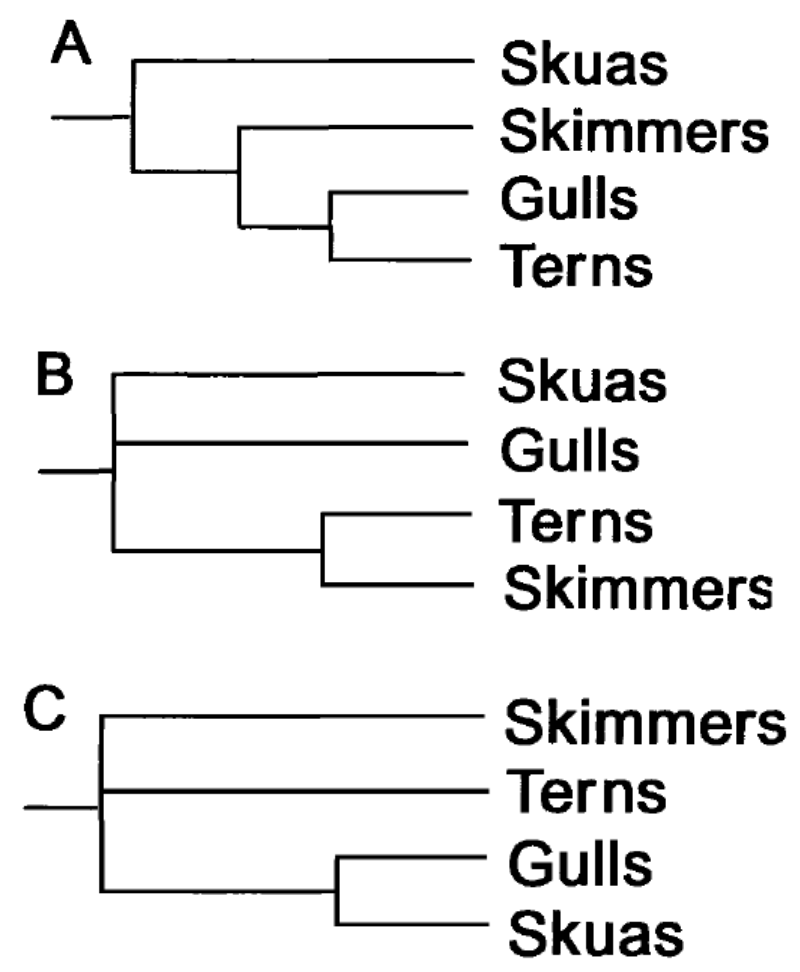

Figure 6: Three common theories on shorebird taxonomy, A being the one that is currently accepted (from Cane 1994). A) Terns and gulls are more closely related to each other than to skimmers and skuas. These relationships are supported by molecular analyses (ex: Hackett 1989). B and $C$ have been suggested by comparative parasitology (Timmermann 1957 ) and analyses of skeletal morphology (Strauch 1978) 


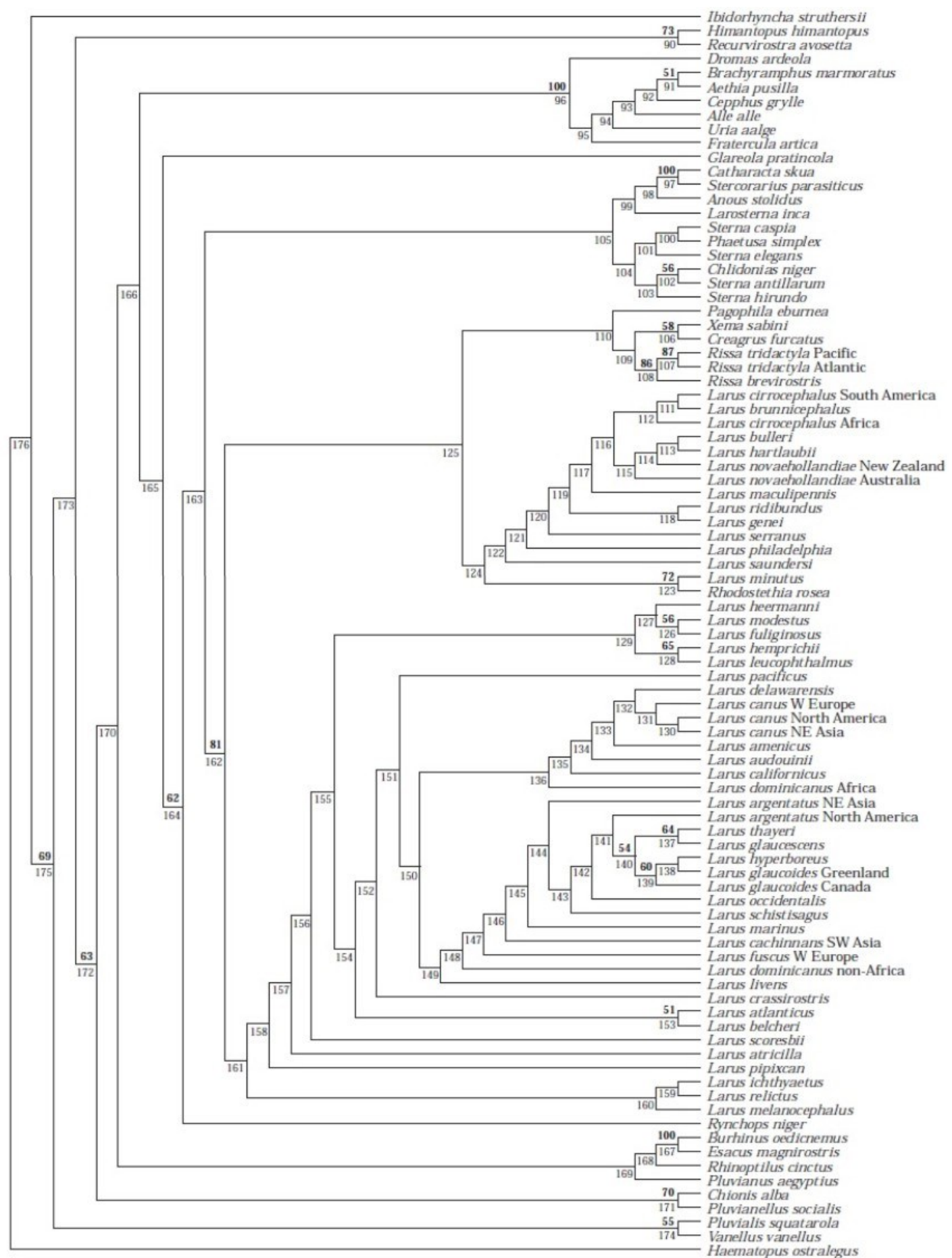

Figure 7: Phylogeny of gulls as proposed by Chu (1998). 


\subsection{Theropod taxonomy}

Theropoda ("beast-footed ones") are some of the most well-studied dinosaurs and various hypotheses regarding their phylogenetic relationships are illustrated in Figs. 8 - 11. They are a diverse and globally distributed group of saurischian dinosaurs comprised of some of the largest terrestrial carnivores ever to exist, such as Spinosaurus, Tyrannosaurus and Giganotosaurus. Other theropods were quite small, such as Microraptor and Epidendrosaurus (Holtz, 2012). Theropods represent the most successful group of dinosaurs in that their descendants, the birds, survived the terminal extinction at the end of the Cretaceous (Cooper and Penny, 1997; Holtz, 2012).

The earliest theropod-bearing deposits are found in the upper Triassic Ischigualasto formation of Argentina, (Sereno et al. 1993; Sereno ,1997; Benton, 2004; Irmis, 2010; Benton, 2012). The closest outgroups to Dinosauria are found in South-America, suggests that dinosaurs originated in South-America (BrettSurman et al. 2012).

Theropoda is defined as Passer domesticus (the European house sparrow) and all taxa sharing a more recent common ancestor with it than with Cetiosaurus oxoniensis (Holtz and Osmólska, 2004). A recent revision has suggested replacing Passer domesticus with Allosaurus fragilis (Kischlat, 2000). There are several characters that unite Theropoda, including: prezygapophyses in the distal caudals extending one quarter or more the length of the previous caudal; the humerus is shorter than $60 \%$ of the length of the femur; the proximal ends of the metacarpals are joined to each other (but don not overlap); the shaft 
of metacarpal IV is much more slender than the other metacarpals; the fifth digit of the hand does not have phalanges (Benton, 2012).

Most theropods belong to the clade Averostra (=Neotheropoda sensu Bakker, 1986) and belong to one of two major clades, Ceratosauria and Tetanurae (Benson, 2009, Brusatte and Sereno, 2008, Langer et al., 2014, Carrano et al., 2012). Since the theropods of interest to this project are within Tetanurae, the phylogeny of ceratosaurs will not be discussed. For a complete discussion of Ceratosauria phylogeny, see Carrano and Sampson (2008).

\section{Tetanurae systematics}

Tetanurae ("stiff tails") is composed of three major clades; Megalosauroidea, Carnosauria and Coelurosauria (Fig. 11), with the last two comprising Avetheropoda (Holtz, 2012). The coelurosaurs originated during the Middle Jurassic (Holtz. 2000, Rauhut. 2003), or earlier (e.g., Barrett. 2009) and include the Maniraptora and all living birds (Avialae; Holtz, 2012). Some of the characteristics of tetanurans include having teeth restricted to the front of the jaws, proportionally larger hands, and interlocking tail vertebrae in the distal half of the tail (Holtz, 2012).

Maniraptoriformes, which includes famous groups such as the dromaeosaurs and birds, is a group of theropods characterized by a reduction of skull size relative to body size; a reduction in tooth size; an increase in tooth count, an increase in brain size (based on skull size); elongated forelimbs; a large, bony sternum for the attachment of the muscles that pull the arms inward; 
and a semilunate carpal (a pulley-shaped block of wrist bones that allowed greater folding motion while sacrificing motion in the other plane).

Eumaniraptora (often synonymized with Paraves) is one of the last major groups of extinct theropods to have radiated and includes Deinonychosauria and Avialae, and is defined by the following synapomorphies: greatly reduced prefrontals; margin of the external antorbital fenestra on the craniolateral surface of the descending ramus flattens out and is not continued on the surface of the jugal; vertical columnar process is present on the retroarticular process; vertebral centra of caudal vertebrae I - V are box-like with increased mobility; glenoid articulation of the pectoral girdle is oriented laterally in basal dromaeosaurids, basal troodontids and basal birds; coracoid is subrectangular; coracoid forms a sharp angle at the point of articulation with the scapula; pubic tubercle is spine-or crest-like and points cranially; distal articular surface of the tibia is rectangular and more than three times as wide transversely as craniocaudally (Holtz and Osmólska, 2004).

Avialae is the group of theropods that includes Archaeopteryx and modern birds (Neornithes). Current taxonomy shows that birds evolved within Maniraptora, approximately 150 million years ago (Padian 2004). The earliest divergence within Neornithes occurred between Neognathae (fowls, ducks and most modern birds) and Paleognathae (emus, ostriches and relatives) (Tuinen 2009, Edwards et al., 2005). Avialans are distinguished from other vertebrates by a number of features, including: an elongate prenarial portion of the premaxilla; the breaking down of the postorbital bar; absence of dental serrations and the 
presence in the teeth of a characteristic constriction; enlargement of the cranial cavity; caudal tympanic recess opening within the columnar recess; presence of a caudal maxillary sinus; fewer tail vertebrae, with the prezygapophyses reduced distally; ossified uncinate processes on the edge of their vertebral ribs (Witmer 2002). Other features of birds include a keeled sternum; furcula; hollow limb bones and double-condyled quadrates that articulate with the prootic (Padian, 2004). Many of these features first evolved in small maniraptorans as adaptations for fast running and ground dwelling. Feathers were originally thought to be an avian synapomorphy for at least Coelosauria, but are now recognized as a symplesiomorphy (an ancestral trait shared by two or more taxa or group). This is due, in part, to the presence of a feather-like integument in a number of non-theropod dinosaur groups, including Psittacosaurus and Tianyulong (an Early Cretaceous heterodontosaurid) (Norell and Xu. 2005, Godefroit et al. 2014, Zheng et al. 2009).

Archaeopteryx represents one of the earliest eumaniraptorans and one of the earliest members of Avialae. It is the sister taxon to Deinonychosauria+Avialae (Mayr et al., 2005). Anchiornis from the Late Jurassic of China was originally described as a basal bird older than Archaeopteryx, but has more recently been identified as a non-avian troodontid by Hu et al. (2009). Archaeopteryx is represented by seven skeletons and isolated feathers, all of which were discovered in the Solnhofen limestone in Germany. Even though they retained the long tail and teeth of reptiles, the fossils were recognized as early 
birds because of the fact that they retained feathers, a boomerang-shaped furcula, and hollow bones (Padian 2004).

Avialae (sensu Gauthier, 1986) is defined as a stem group to encompass living birds and maniraptorans closer to them than to Deinonychus. Defining characters of Avialae include: enlarged brains; long slender, tridactyl manus; curved chevrons making the distal part of the tail slender and long; and narrow metatarsals (Holtz, 2012, Larsson et al. 2000). The term "birds" is still used to encompass Archaeopteryx and all the more derived members of Avialae (with Neornithes considered the crown taxon) (Padian, 2004, Gauthier, 1986).

Our understanding of the evolution and radiation of early birds has been growing exponentially in recent years. This is due in part to the discovery of several early bird fossils that have come out of China, including the Archaeopteryx-like Xiaotingia zhengi and Jeholornis prima (O'Connor and Zou 2015, Xu et al., 2011). Ever since the discovery of Archaeopteryx, very few new avian fossil have been discovered until quite recently (Fountaine et al., 2005). With these recent additions more than 70 genera of Mesozoic fossil birds are known from sites distributed globally (Chiappe and Dyke 2002). 


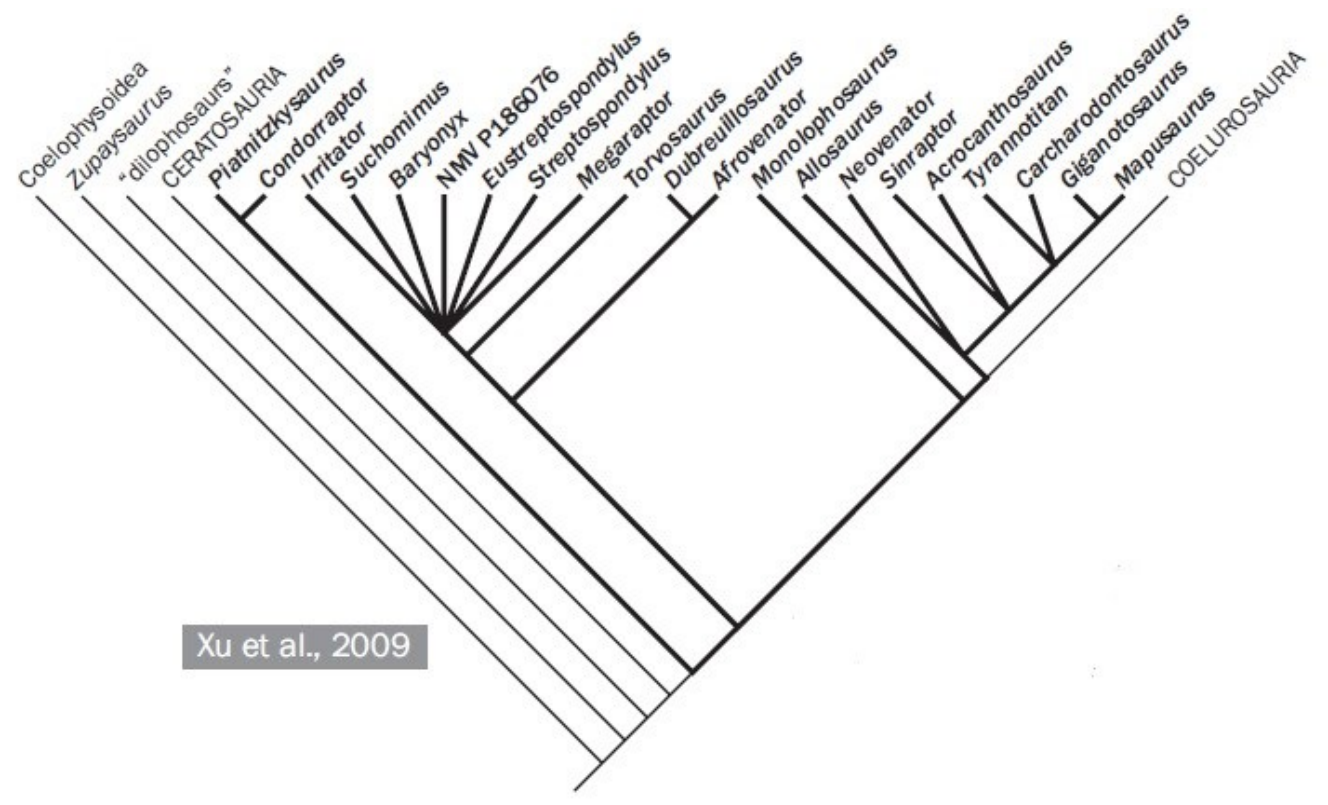

Figure 8: Phylogeny of theropods as proposed by Xu et al., 2009.

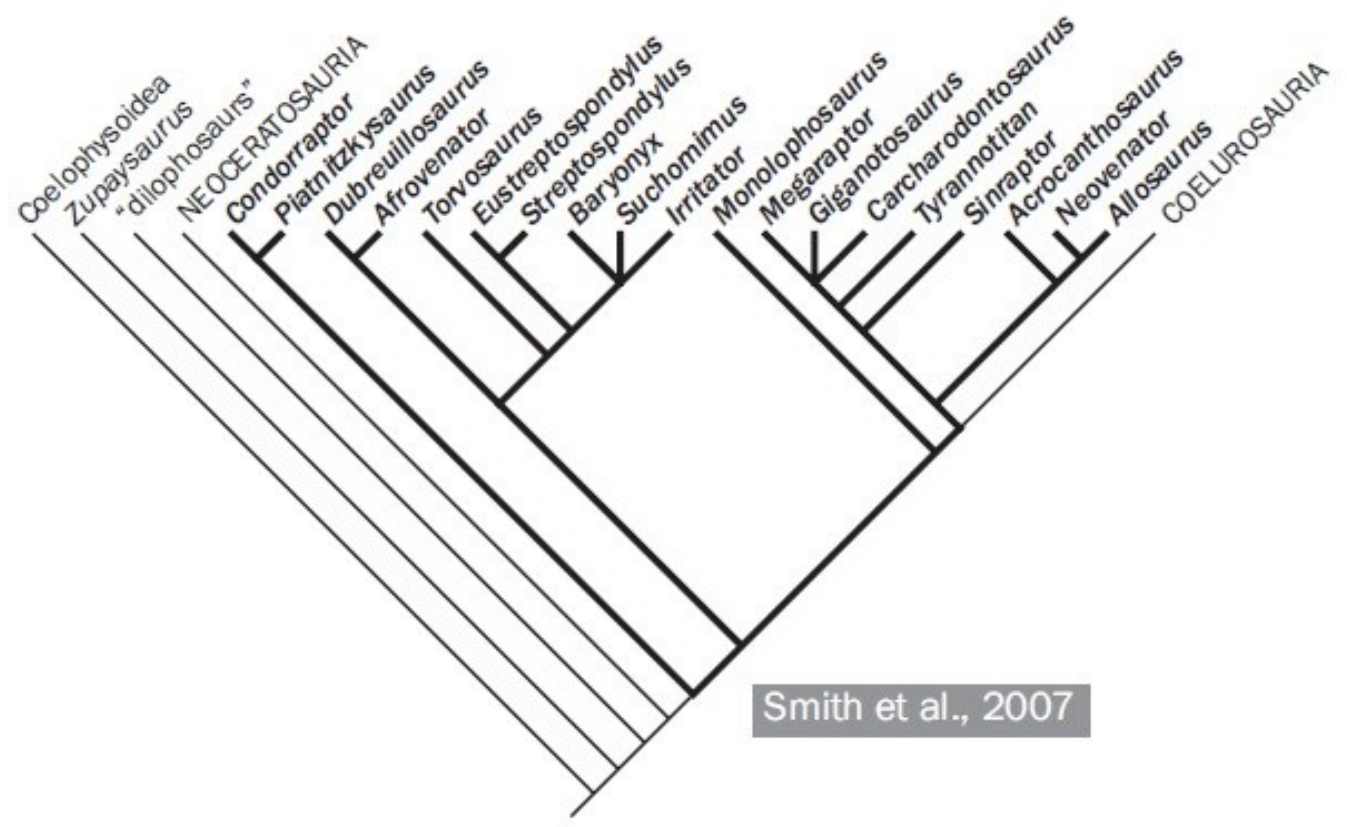

Figure 9: Phylogeny of theropods as proposed by Smith et al., 2007. 


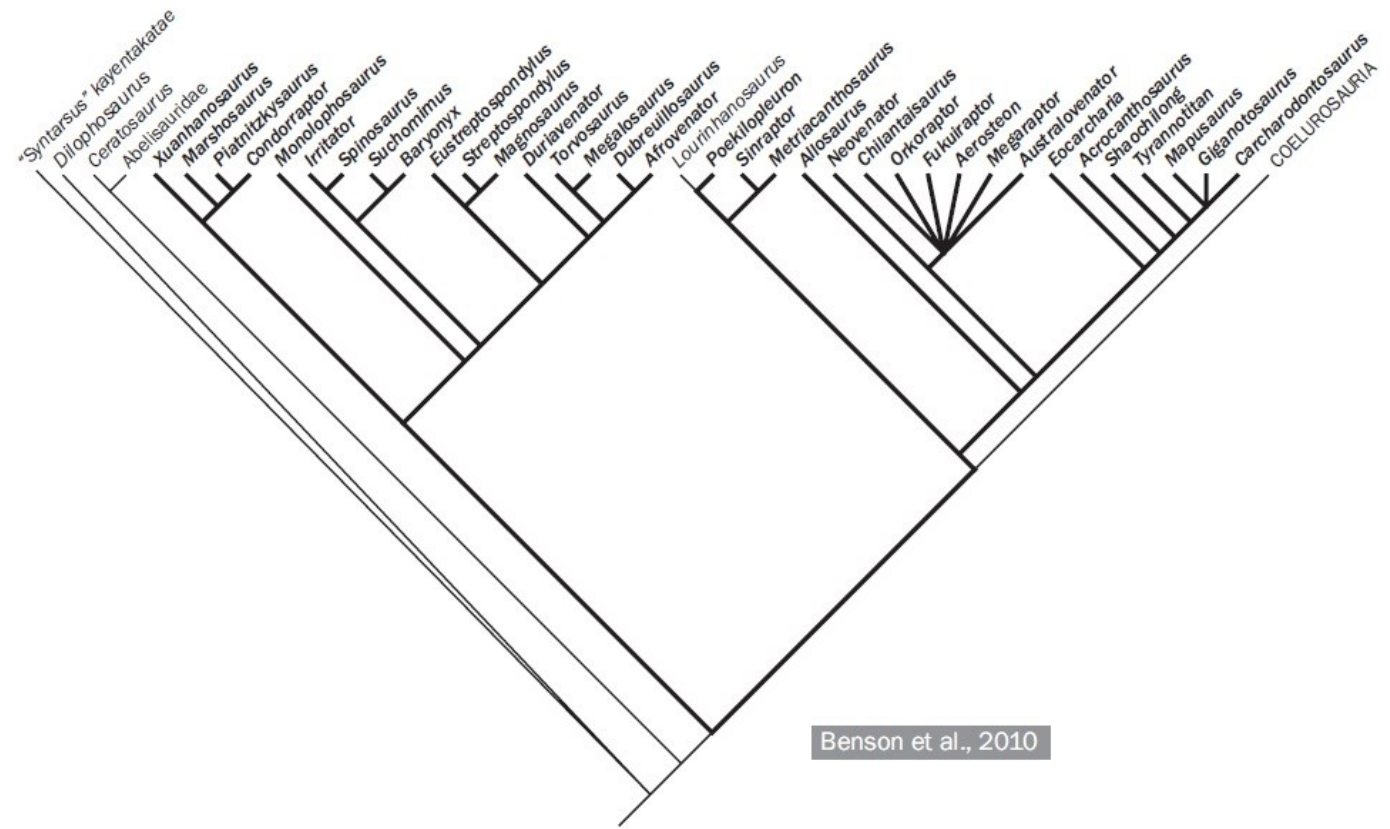

Figure 10: Phylogeny of theropods as proposed by Benson et al., (2010) 


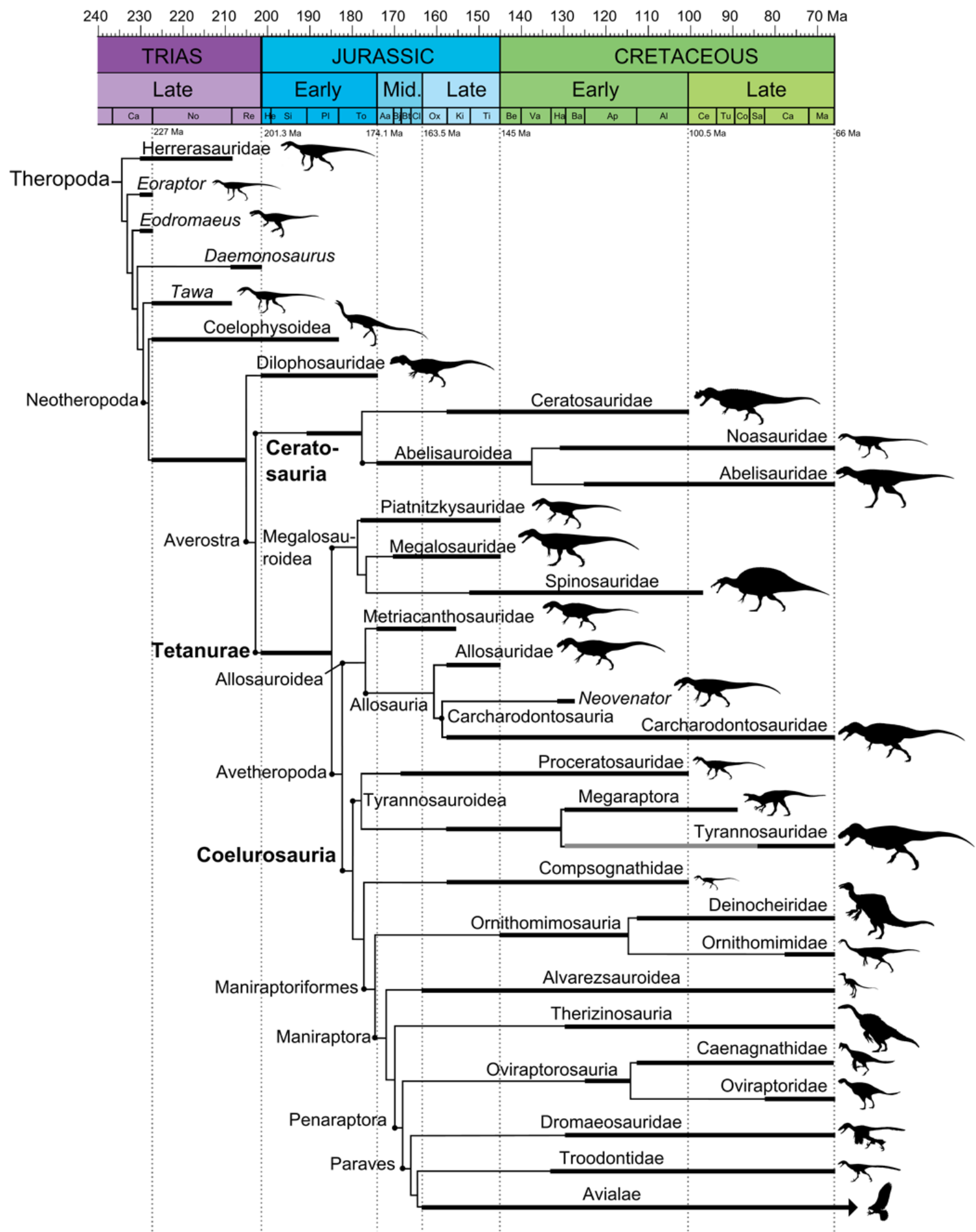

Figure 11: Theropod phylogeny from Hendrickx et al., 2015. 


\section{Chapter 2: Materials and Methods}

\subsection{Gull species analyzed}

Gulls are part of the family Laridae and are defined by several characteristics, including: exposed culmen (the upper part of a bird's beak) is less than one and a quarter times as long as the tarsus; tarsus is more than onetenth as long as the wing; tail is usually truncate or rounded, rarely forked, and sometimes wedge shaped or graduated (Ridgeway and Friedmann, 1919, p. 561). The genus Larus is distinguished by the following characteristics: medium to very large Laridae with well-developed hallux entirely free from the inner toe; tibia has at least the lower half unfeathered; tarsus is longer than the middle toe without claw; tail is truncate or very slightly rounded; in adults, the tail and under belly is almost entirely white; and the bill is shorter than the head (Ridgeway and Friedmann, 1919, p. 581). The original description of Larus was made by Linneaus (1758): Bill straight, sharp edged and hooked at the tip; lower mandible convex below the tip; nostrils linear, broader near the fore-part and placed in the middle of the bill. The original description of Larus was made by Linnaeus (1758): the bill is straight, with sharp edges and hooked at the tip; the lower mandible convex bellow the tip; nostrils linear, broader near the fore-part and placed in the middle of the bill

A short description of each gull species analyzed based on field guides is included in Table 1. The gull species analyzed during this project include: 
Larus delawarensis (Ring-billed gull): Their most defining feature is the black ring around their bills (Rideway and Friedmann, 1919).

Larus argentatus (European Herring gull) (Pontoppidan 1763): The original description roughly translates to: Larus argentatus has a black spot on the end of the outer wing. There is a red dot on the lower beak (Pontoppidan 1763). Most of the defining characters of $L$. argentatus are integumentary in nature (refer to Table 1).

Larus glaucoides (Iceland gull) (Meyer 1822): The original description roughly translates to: the beak is yellow, with the base greenish gray. The lower jaw has a bright red spot. The beak is slightly shorter than in $L$. argentatus. The feet are yellow. The shoulder and wing coverts are pale blue gray, the edge of the wings are white. The Flight feathers are white without black (Meyer 1822).

Larus glaucescens (Glaucous-winged gull) (Naumann 1840): They are mostly defined based on their feather coloration (refer to Table 1). Their bills are yellow, whitish at the tip with a subterminal red spot on the lower mandible.

Larus hyperboreus (glaucous gull) (Gunnerus 1767): This species is typically larger in size compared to other gull species (Ridgeway and Friedmann 1919, P. 581) (refer to Table 1 for description). 
Larus thayeri (Thayer's gull) (Brooks 1915): described as being about the size of Larus kumlienis, but differeing primarily in the color of the mantle, primary flight feathers and having a larger and heavier bill. The color of its mantle is intermediate between L. kumlieni and L. argentatus (see Table 1) (Brooks 1915, p.373). 
Table 1: description of each Larus species analyzed during this project (from Hayman et al 1986 and Sibley 2003

\begin{tabular}{|c|c|c|c|}
\hline Species & $\begin{array}{l}\text { Size }(M=\text { males, } \\
\mathrm{F}=\text { females) }\end{array}$ & Physical description & Geographic range \\
\hline $\begin{array}{l}\text { Larus } \\
\text { argentatus }\end{array}$ & $\begin{array}{l}\text { Length } \\
\text { M: } 60-66 \mathrm{~cm} \\
\text { F: } 56-62 \mathrm{~cm} \\
\text { Weight } \\
\text { M: } 1000-1250 \mathrm{~g} \\
\text { F: } 800-980 \mathrm{~g}\end{array}$ & $\begin{array}{l}\text { Both sexes have similar plumage. First } \\
\text { year young have all brown plumage. } \\
\text { Yellow beak with red spot on lower } \\
\text { mandible. Beak is long and slender with } \\
\text { peak on rear crown. Pink or flesh coloured } \\
\text { legs. Wing feathers are black with white } \\
\text { spots. Long narrow wings. Eyes are } \\
\text { golden with yellow ring of skin. }\end{array}$ & $\begin{array}{l}\text { Entire northern } \\
\text { hemisphere. Native } \\
\text { to Nearctic and } \\
\text { palearctic regions. } \\
\text { Live in coastal } \\
\text { regions near body } \\
\text { of water. }\end{array}$ \\
\hline $\begin{array}{l}\text { Larus } \\
\text { delawarensis }\end{array}$ & $\begin{array}{l}\text { Length } \\
\text { M: } 46-54 \mathrm{~cm} \\
\text { F: } 43-50 \mathrm{~cm} \\
\text { Weight } \\
\text { M: } 400-700 \mathrm{~g} \\
F: 300-700 \mathrm{~g}\end{array}$ & $\begin{array}{l}\text { Adults have an average wingspan of } \\
127 \mathrm{~cm} \text {. Pale bluish back with white heads. } \\
\text { White wings and their belly is white. They } \\
\text { have a narrow black band around their } \\
\text { bills. Their bill is fairly short and slim. First } \\
\text { year young have whitish feathers with } \\
\text { brown flecks. Morphologically similar to } \\
\text { herring gulls. }\end{array}$ & $\begin{array}{l}\text { Ranges from the } \\
\text { southern shores of } \\
\text { Alaska to the gulf } \\
\text { coast to Cuba. } \\
\text { Found in inland } \\
\text { waterways }\end{array}$ \\
\hline $\begin{array}{l}\text { Larus } \\
\text { glaucoides }\end{array}$ & $\begin{array}{l}\text { Length } \\
55-64 \mathrm{~cm} \\
\text { Wingspan } \\
125-130 \mathrm{~cm} \\
\text { Weight } \\
557-863 \mathrm{~g}\end{array}$ & $\begin{array}{l}\text { Relatively small with round head and short } \\
\text { bill. Round bodies with short bills, short } \\
\text { legs and relatively broad but pointed } \\
\text { wings which create an overall stocky } \\
\text { appearance. }\end{array}$ & $\begin{array}{l}\text { Breeds in arctic } \\
\text { regions of Canada } \\
\text { and Greenland. } \\
\text { Winters in the } \\
\text { northernmost } \\
\text { states of the USA, } \\
\text { in Iceland and on } \\
\text { the coast of } \\
\text { Norway }\end{array}$ \\
\hline $\begin{array}{l}\text { Larus } \\
\text { hyperboreus }\end{array}$ & $\begin{array}{l}\text { Length } \\
64-77 \mathrm{~cm} \\
\text { Weight } \\
1070-1820 \mathrm{~g} \\
\text { Wingspan } \\
132-142 \mathrm{~cm}\end{array}$ & $\begin{array}{l}\text { As large as the Great Black Backed gull. } \\
\text { Plumage is lighter in coloration, light gray } \\
\text { in coloration. Back and wings are pale } \\
\text { blue-gray, belly and wingtips are white. } \\
\text { Often confused with the similar, but } \\
\text { smaller, Iceland Gull. Their heads are } \\
\text { flatter, back of their head us less rounded. } \\
\text { Legs more pinkish. }\end{array}$ & $\begin{array}{l}\text { Lives in the arctic } \\
\text { regions of the } \\
\text { northern } \\
\text { hemisphere, } \\
\text { Northern Europe } \\
\text { and Asia. }\end{array}$ \\
\hline Larus thayeri & $\begin{array}{l}\text { Length } \\
56-69 \mathrm{~cm} \\
\text { Weight } \\
846-1152 \mathrm{~g} \\
\text { Wingspan } \\
130-140 \mathrm{~cm}\end{array}$ & $\begin{array}{l}\text { White headed with pale gray mantle. Bill is } \\
\text { yellow with red gonydeal spot. Legs are } \\
\text { dark pinkish. Some scientists consider it to } \\
\text { be a subspecies of herring gull. It is } \\
\text { considered as its own species in this } \\
\text { project. }\end{array}$ & $\begin{array}{l}\text { Breeds in high } \\
\text { arctic of Canada. } \\
\text { Found on the } \\
\text { western coast of } \\
\text { the united states } \\
\text { and Canada. }\end{array}$ \\
\hline $\begin{array}{l}\text { Larus } \\
\text { glaucescens }\end{array}$ & $\begin{array}{l}\text { Length } \\
61-69 \mathrm{~cm} \\
\text { Weight } \\
900-920 \mathrm{~g} \\
\text { Wingspan } \\
130-142 \mathrm{~cm}\end{array}$ & $\begin{array}{l}\text { Males larger than females. Adults are } \\
\text { white with pale gray backs. Wings pale } \\
\text { gray with small white patches. Large body } \\
\text { and large bill, but extremely variable: } \\
\text { some are more slender than others. }\end{array}$ & $\begin{array}{l}\text { Lives near salt or } \\
\text { brackish water } \\
\text { along coasts and } \\
\text { bays. Nests on } \\
\text { rocky cliffs of the } \\
\text { coastal northern } \\
\text { pacific, from Alaska } \\
\text { to the Aleutians }\end{array}$ \\
\hline
\end{tabular}




\subsection{Theropod taxa analyzed}

All the theropod measurements were taken from a database of measurements provided courtesy of Dr. Philip J. Currie. The database contains over 2000 theropod specimens from 150 genera including seven tyrannosaurids, six maniraptorans and the earliest birds Archaeopteryx lithographica and Confuciusornis sanctus. They range in size from very large theropods to smallbodied birds. Only the most complete specimens, a total of 52 , were analyzed. The species listed below and described subsequently were analyzed during this project:

Tyrannosauridae (large-bodied theropods)

- Albertosaurus sarcophagus

- Daspletosaurus torosus

- Gorgosaurus liberatus

- Raptorex kriegsteini

- Tarbosaurus bataar

- Nanotyrannus lancensis

- Tyrannosaurus rex

Eumaniratpora: Dromaeosauridae (small to medium-sized theropods)

- Sinosauropteryx prima

- Bambiraptor feinbergi

- Deinonychus antirrhopus

- An unidentified dromaeosaurid

- Velociraptor mongoliensis

- Saurornitholestes langstoni

Aves ('basal birds') (small-bodied theropods)

- Archaeopteryx lithographica

- Confuciusornis sanctus 


\section{Tyrannosauridae}

Tyrannosauridae (Albertosaurinae+Tyrannosaurinae) is a derived clade of large-bodied theropods that lived at the end of the Cretaceous in North America and Asia. They are characterized by large skulls with a highly specialized heterodont dentition, a derived squamosal-quadratojugal flange, and a highly pneumatic basicranium. They also have greatly reduced forelimbs (both in size and in number of digits) and elongated hindlimbs. The hindlimbs have a pinched third metatarsal (the arctometatarsus) (Holtz, 2004).

\section{Albertosaurinae}

Albertosaurus sarcophagus (Osborne 1905): Occurs in the early Maastrichtian Horseshoe Canyon Formation of Alberta (Tanke and Currie, 2010; Russell, 1970; Currie and Eberth, 2010; Holtz, 2001). It is smaller than tyrannosaurids from the Late Maastrichtian (i.e., Tarbosaurus and Tyrannosaurus) (Holtz, 2004).

Gorgosaurus libratus (Lambe, 1914): Occurs in the Dinosaur Park Formation of Alberta, with referred specimens coming from the Two Medicine and Judith River formations of Montana (Holtz, 2004, Erickson et al. 2006). 
Tyrannosaurinae:

Daspletosaurus torosus (Russell, 1970): Occurs in the Campanian Oldman and Dinosaur Park formations of Alberta, and the Two Medicine Formation of Montana (Holtz, 2004).

Tarbosaurus bataar (Maleev, 1955): Occurs in the Late Cretaceous (?Maastrichtian) of Mongolia, with referred material from China (Holtz, 2004).

Raptorex kriegsteini (Sereno et al., 2009): A nomen dubium of uncertain provenience that is probably a juvenile Tarbosaurus (Fowler et al., 2011).

Nanotyrannus lancensis (Bakker et al., 1988): The holotype (CMNH 754) comes from the Hell Creek Formation of Montana (Larson, 2013).

Compsognathidae:

Sinosauropteryx prima (Ji and Ji, 1996): Sinosauropteryx was a small-bodied compsognathid discovered in China. It is the first nonavialan dinosaur discovered to have integumentary structures (Holtz et al., 2004; Ji and Ji, 1996). Given the phylogenetic position of compsognathids, the structures found on Sinosauropteryx are interpreted as the precursors to feathers (Holtz et al., 2004; $\mathrm{Ji}$ and Ji, 1996). It is known from the Yixian Formation in the Liaoning province of North East China (Holtz, 2004). Sinosauropteryx is comparable in size to Compsognathus (Currie and Chen, 2001). Both species share several 
morphological characters that indicate a close relationship (Currie and Chen, 2001).

\section{Eumaniratpora: Dromaeosauridae}

Dromaeosaurs are a group of highly diverse, small to mid-sized maniraptorans that are characterized by the presence of a recurved claw on the second pedal digit (the raptorial claw) as well as a stiffened tail (Gianechini and Apesteguia, 2011). Dromaeosaurs are closely related to the group Avialae.

Bambiraptor feinbergi: Bambiraptor is a Late Cretaceous bird-like dromaeosaurid theropod from the Two Medicine Formation of Montana. The holotype specimen consists of the well preserved skeleton of a juvenile individual. It has several features that are more birdlike than those of other dromaeosaurids (Holtz 2004, Burnham, 2000). Most of those features might be due to the fact that the specimen is a juvenile and not a fully developed adult. The species highly resembles Saurornitholestes and only differs in aspects of the frontal bone (Holtz, 2004).

Deinonychus antirrhopus: Deinonychus is a species of carnivorous dromaeosaurid from the late-Aptian to middle-Aptian (Early Cretaceous) (Norell and Makovicky, 2004; Ostrom, 1969). It was approximately 1 meter tall and nearly 3 meters in total length. It was first discovered in the Cloverly Formation of Montana and Wyoming. It shares several features of dromaeosaurine dinosaurs, 
such as laterally compressed, serrated teeth, a raptorial manus, a raptorial second pedal digit, and a long tail stiffened by hypertrophied prezygapophyses and chevron processes (Ostrom 1969; Brinkman et al., 1998). Several specimens have been collected in assemblages that contained several disarticulated specimens, which leads paleontologists to believe that Deinonychus was a gregarious pack hunter (Norell and Makovicky, 2004; Brinkman et al., 1998).

Velociraptor mongoliensis: Velociraptor is probably the best-known dromaeosaurid dinosaur. More than a dozen articulated specimens have been recovered. It lived approximately 71 to 75 million years ago during the later part of the Cretaceous period (Osborn, 1924, Norell and Makovicky, 1997). It shares several features with other dromaeosaurids, such as a caudolateral process on the squamosal, an enlarged quadrate foramen, elongated cranial processes on the prezygapophyses of the distal caudals and chevrons and a raptorial second pedal digit (Norell and Makovicky, 2004; Norell et al., 1997). It was originally discovered in 1923 in the Gobi by an expedition from the American Museum of Natural History. The taxon is known from the Djadokhta Formation of Mongolia and the Minhe Formation of China (Norell and Makovicky, 2004).

Sinornithosaurus millenii: Sinornithosaurus is a genus of dromaeosaurid dinosaur from the Early Cretaceous period (early Aptian). It is found in the Yixian Formation of China and is one of the smallest dromaeosaurids known from a 
near complete skeleton (Xu et al., 1999). Xu et al (1999) recovered Sinornithosaurus millenii as the sister taxon to the velociraptorinedromaeosaurine group. The specimen preserves elongated integumentary structures associated with the skeleton (Norell and Makovicky 2004).

\section{Aves}

The definition of birds used for this project will follow that of Padian (2004): birds comprise Archaeopteryx and all its living descendents. Data from only two early birds were available for this project:

Archaeopteryx lithographica: Archaeopteryx is considered the first commonly accepted true bird (e.g., Padian 2004; Longrich et al., 2012; Martin et al., 1998). . The first discovery of Archaeopteryx (a feather) was made in 1860, and all subsequent skeletons have come from the Late Jurassic Solnhofen limestones of Germany (Padian, 2004)Archaeopteryx lithographica shares multiple synapomorphies with modern birds, including: elongated, narrow and pointed premaxillae, with long nasal processes; the double condyled quadrate articulates with the prootic; the teeth are reduced in size and are not serrated; the coracoid has a pronounced sternal process; the forelimbs are nearly as long as, or longer, than the hindlimbs; in the pelvis, the cranial process of the ischium is reduced or absent; the caudal margin of the naris nearly reaches or overlaps the rostral border of the antorbital fossa (Padian 2004).

Confuciusornis sanctus: Confuciusornis (Hou et al., 1995) is a species of early crow-sized bird from the Early Cretaceous of China. Similar to modern birds, 
Confuciusornis has a toothless beak and has a pygostyle. The specimen is well represented by hundreds of specimens collected from the Lower Cretaceous beds of Northeastern China. In certain specimens, there is a pair of blade-like rectrices that have been interpreted as an early example of sexual dimorphism (Feduccia 1996).

\subsection{Data collection}

\section{Measurements of specimens}

A total of 72 specimens from the collections of the Canadian Museum of Nature (Gatineau, QC) and the Royal Ontario Museum (Toronto, ON) were examined and measured from 6 species (Appendices A and B); L. argentatus (18 specimens), L. delawarensis, (15 specimens); L. thayeri (18 specimens); $L$. hyperboreus (10 specimens); L. glaucescens (5 specimens); L. glaucoides (2 specimens). All the specimens were measured using a Vernier Digital Caliper and photographed using a Nikon 8200 series camera.

The following linear measurements were taken on each specimen; femur (total length, proximal, distal, and midshaft width), tibiotarsus (total length, proximal and distal widths), tarsometatarsus (total length, proximal and distal widths), and the total lengths of humeri, radii, ulnae; these are diagrammed in figures 12 and 13. Each measurement was taken three times and an average value calculated. This was done to reduce the potential error in the measurements. The sex, age, location and year of collection for each specimen, and all measurements taken are recorded in Appendix A. Measurements of the 
theropods were obtained by Dr. Phil Currie and include: femur length, tibiotarsus length, length of third metatarsus, length of radius, length of ulna and length of humerus. Only length measurements were used, because most of the width measurements were missing or incomplete.

Thirty-five skulls from $L$. argentatus, $L$. delawarensis and $L$. glaucescens were selected for landmark-based geometric morphometrics to determine whether there are any morphological differences between the gull species. Each skull was photographed in dorsal and ventral views using the camera mounted on a Zerene stackshot rail and remotely operated using a computer to eliminate any movement that could be caused by manual release of the shutter. The camera was mounted approximately $50 \mathrm{~cm}$ away from each specimen. The specimens were placed on a semi-transparent "photo table" and illuminated using a series of LED spotlights. In each orientation, between five to eight photographs were taken at different focal points which were then processed in the "zerene stacker" program to generate a completely in-focus photograph of each specimen. These were then used for the geometric morphometric analyses. 


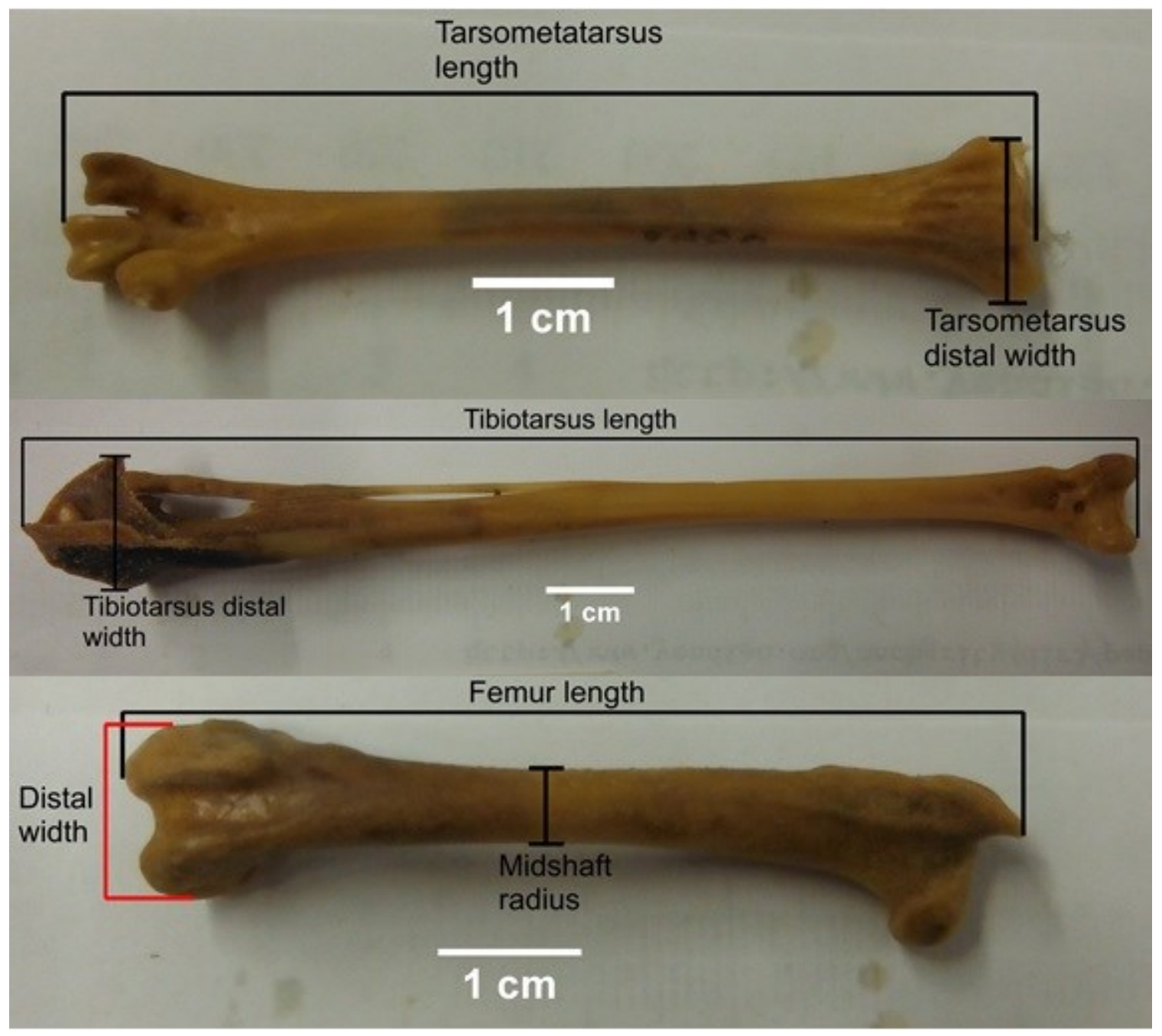

Figure 12: photograph depicting measurements taken on each skeletal element of the gull specimens 


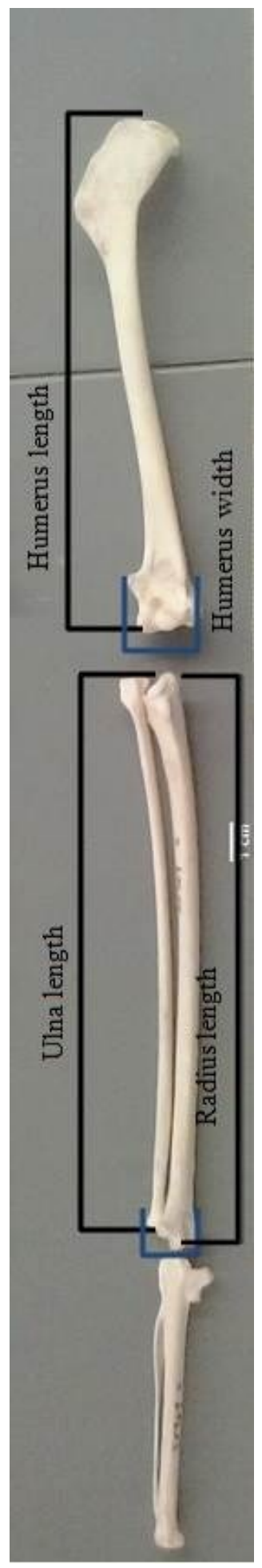

Figure 13: measurements taken on the forelimb elements of each gull specimen 


\section{Landmark selection}

Consistent landmarks (e.g., at sutural junctions or discrete morphological features) that would best represent the shape of the skull were indentified and plotted on each of the photograph. Fourteen landmarks were selected on the dorsal view and 15 on the ventral following the methodology of Cullen (2014) and using some of the methodology suggested by Webster and Sheets (2010). These landmarks were then used to conduct shape-based analyses to determine morphological differences between the specimens. Appendix E illustrates the location of the landmarks that were digitized on each skull. All landmarks were digitized using TPSdigs. Prior to analyzing the landmarks, pocrustes superimposition was performed on the landmarks using the Coordgen8 This was done to reduce the effects of overall size differences while also aligning the coordinates. The data were then analyzed using PCA to identify major trends in the morphological data. The superimposed landmark data was imported into PCAgen8 and deformation grids were extracted for each component to visualize the change in shape of the skulls. 


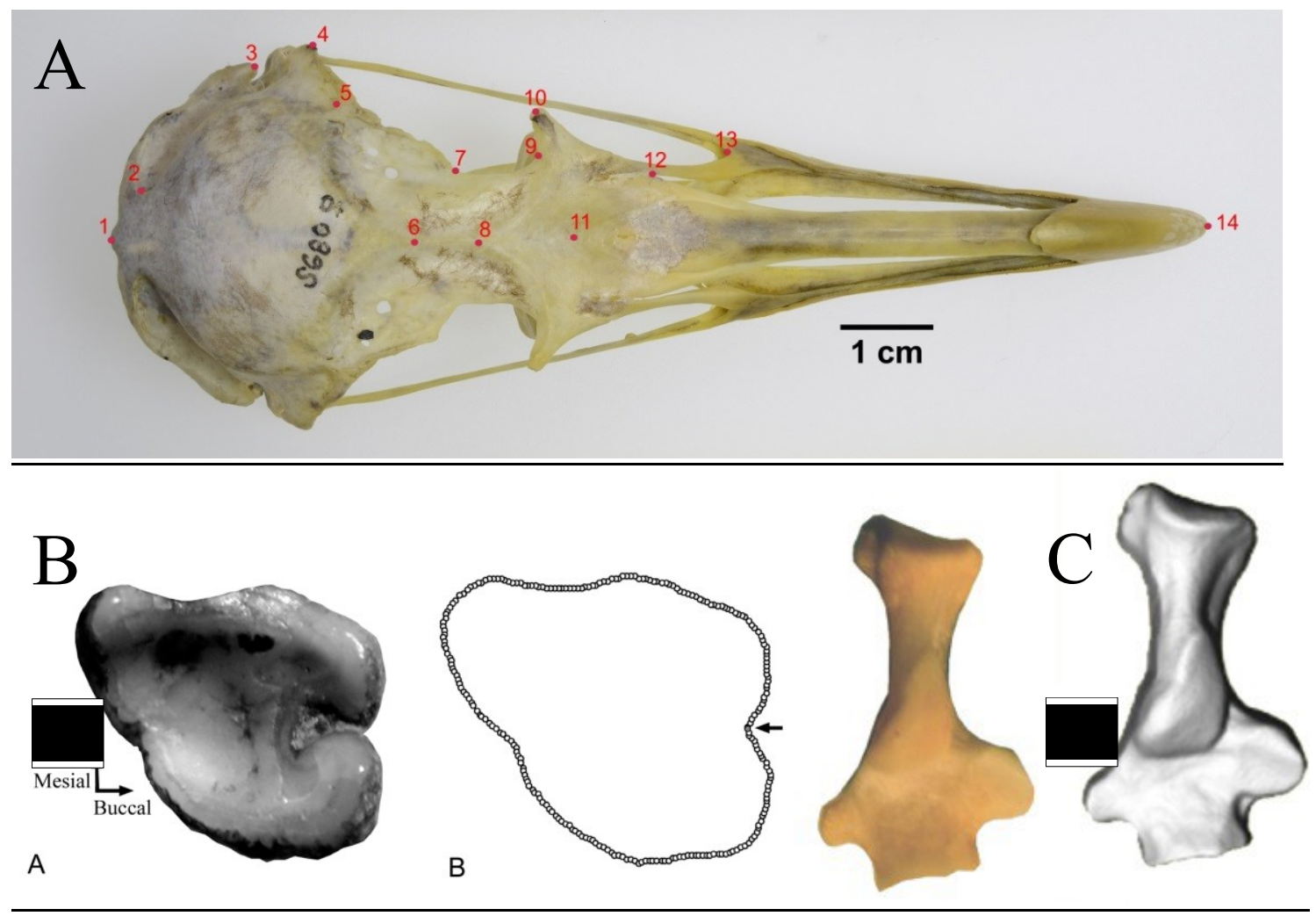

Figure 14: types of landmarks. A) 2-dimensional landmarks, B) semilandmarks, C) 3-dimensional surface 


\section{Geometric Morphometric Analysis}

Morphometrics are any quantitative analysis of morphological form, size and/or shape (e.g., Rohlf and Marcus, 1993, Webster and Sheets, 2010). There are three types of morphometric analyses: 1 , traditional morphometrics use linear measurements along with multivariate statistics to compare shapes (Marcus 1990, Webster and Sheets 2010), 2, geometric morphometric uses landmark configurations to summarize shape variations, and, 3, morphometric analysis is frequently used in biology to describe organisms (e.g.,Gunduz et al 2007). Outline-based geometric morphometrics summarizes the shape of open or closed curvatures (perimeters) (Webster and Sheets, 2010).

An inherent problem with traditional morphometric is that it doesn't adequately capture the overall shape and is sometimes hard to interpret. Landmark-based morphometrics typically capture more of the shape variation and can be easier to visualize. In geometric morphometrics, landmarks are any points described with Cartesian coordinates ( $\mathrm{x}, \mathrm{y}$ and sometimes $\mathrm{z})$ that are used to describe a shape. Figure 14 illustrates the differences in landmark types. Typically, landmarks are placed on a biologically or geometrically homologous point or structures. Semi-landmarks are points placed using algorithms, usually by defining endpoints at biologically homologous points and by placing semilandmarks between them, e.g., placing two points at either end of a limb bone and then placing a set number of points around the bone (Bookstein 1997, Webster and Sheets, 2010). 
Outline-based geometric morphometrics involves summarizing the shape of an object mapping landmarks on the perimeter of the object, typically without using fixed landmarks.

There are three types of landmarks:

Type I: a mathematical point whose claimed homology from case to case is supported by the strongest evidence, such as local patterns of tissue overlap, or small patches of unusual histology (Zelditch, 2004).

Type II: a mathematical point whose claimed homology from case to case is only supported by geometric evidence, not histology (e.g., the sharpest curvature of a structure) (Zelditch, 2004),

Type III: a landmark that has at least one deficient coordinate, for example: either ends of a longest diameter or the bottom of a concavity. Type III landmarks characterize more than one region of the shape (Zelditch, 2004). 


\subsection{Analysis}

Data processing/statistical analysis:

The measurements were standardized by subtracting its mean from that variable and dividing it by its standard deviation:

$$
Z_{i j}=\frac{X_{i j}-\bar{x}_{j}}{s_{j}}
$$

Where:

$X_{i j}=$ data for variable $j$ in sample unit $i$

$\bar{x}_{j}=$ Sample mean for the variable $j$

$S_{j}=$ Sample standard deviation for variable $j$

This is done so that variables that have higher variance will not have more emphasis than the variables that have less variance.

Principal Component Analyses (PCA) were conducted on the standardized measurements of the gulls and the theropods. PCA is a multivariate method used to emphasize variation and show patterns in a dataset. PCAs maximize variation while reducing dimensionality in a dataset. It works by converting a set of observations of possibly correlated variables into a set number of linearly uncorrelated variables called principal components (PC) (Wold et al., 1987). The PCAs were run using a variance-covariance matrix. Twelve PC $\left(\mathrm{PC}_{g}\right)$ were extracted for the gull analysis and 6 for the theropod analyses. All PCAs were 
conducted using minitab. The components are plotted against each other to show the morphological variation between each species. In a PCA, specimens that clump together will show similar trends. Two sets of PCAs were conducted on the gull postcrania: one included all the species of gulls, the second only analyzed individual specimens from $L$. argentatus, $L$. delawarensis and $L$. thayeri. The analyses of individual species were conducted to analyze the extent of intraspecific morphological variations. Two sets of analyses were conducted on the theropod postcranial data: one included all specimens available, the other excluded the tyrannosaurs.

For the cranial analysis of the gulls, the coordinates of the digitized landmarks were analyzed in CoordGEN8. The data were then rotated using partial Procrustes superimposition to remove size difference between landmark configuration (Webster and Sheets, 2010). This makes comparison of landmark configuration easier by removing variation associated with differences in their location, orientation and size (Webster and Sheets, 2010). PCA deformation grids were generated for each quadrant of the PCA plots using PCAgen8. These grids use the information in the landmark coordinates to help visualize shape changes (Webster and Sheets, 2010). 


\section{Chapter 3: Results}

\subsection{Gull postcranial morphometric analysis}

The PCA results for the postcranial skeletal elements of the gulls are shown in figures $15-17$. The figures are scatter plots generated with the PCA using standardized data. Table 2 provides the loading of each principal component $\left(\mathrm{PC}_{\mathrm{g}}\right)$. Table 3 provides the eigenvalues and percent of variance of each $\mathrm{PC}_{\mathrm{g}}$. The first component explains most of the variation in the analysis (Table 2). $\mathrm{PC}_{\mathrm{g}} 1$ shows high and positive loading for all of the variables (Table 2, appendix $\mathrm{D})$. This suggests that $\mathrm{PC}_{\mathrm{g}} 1$ represents a size variation. $\mathrm{PC}_{\mathrm{g}} 2$ is highly and positively correlated with the tibiotarsus length, tibiotarsus distal width and tarsometatarsus length. It is also negatively correlated with the humerus length, humerus distal width, ulna length and ulna distal width. This suggests an inverse correlation between elements of the hindlimb and elements of the forelimb (Table 2, Appendix D). As the forelimb elements increase in size, the hindlimb elements decrease in size (Fig. 15). This suggests that specimens with larger hindlimbs will have relatively smaller forelimb elements. 
Table 2: eigenvalues and percent variance of the components

\begin{tabular}{|c|c|c|}
\hline $\mathrm{PC}_{\mathrm{g}}$ & Eigenvalue & $\begin{array}{l}\% \\
\text { variance }\end{array}$ \\
\hline 1 & 11.0511 & 93.426 \\
\hline 2 & 0.24198 & 2.0457 \\
\hline 3 & 0.168343 & 1.4232 \\
\hline 4 & 0.114514 & 0.9681 \\
\hline 5 & 0.06964 & 0.58873 \\
\hline 6 & 0.057711 & 0.48789 \\
\hline 7 & 0.045269 & 0.3827 \\
\hline 8 & 0.028761 & 0.24315 \\
\hline 9 & 0.02415 & 0.20416 \\
\hline 10 & 0.014902 & 0.12598 \\
\hline 11 & 0.008444 & 0.071382 \\
\hline 12 & 0.003918 & 0.03312 \\
\hline
\end{tabular}

Table 3: loadings of each principal component

\begin{tabular}{|l|r|r|r|r|}
\hline & \multicolumn{1}{|l|}{$\mathbf{P C}_{\mathrm{g}} \mathbf{1}$} & $\mathbf{P C}_{\mathrm{g}} \mathbf{2}$ & \multicolumn{1}{|c|}{$\mathbf{P C}_{\mathrm{g}} \mathbf{3}$} & $\mathbf{P C}_{\mathrm{g}} \mathbf{4}$ \\
\hline left femur length & 0.29554 & 0.019803 & -0.1924 & -0.20311 \\
\hline left femur distal width & 0.29582 & 0.01209 & -0.2091 & -0.18222 \\
\hline left femur midshaft radius & 0.27903 & -0.15339 & 0.007996 & 0.45266 \\
\hline left tibiotarsus length & 0.29727 & 0.23656 & -0.05962 & -0.06968 \\
\hline left tibiotarsus distal width & 0.28398 & 0.12954 & -0.63438 & 0.37949 \\
\hline left tarsometatarsus length & 0.27491 & 0.74524 & 0.17756 & -0.33297 \\
\hline $\begin{array}{l}\text { left tarsometatarsus distal } \\
\text { width }\end{array}$ & 0.2893 & -0.16404 & -0.31193 & -0.09115 \\
\hline left humerus length & 0.29234 & -0.04565 & 0.23429 & 0.18763 \\
\hline left humerus distal width & 0.29196 & -0.26858 & 0.16919 & -0.03481 \\
\hline left radius length & 0.28566 & -0.01121 & 0.39478 & 0.27399 \\
\hline left ulna length & 0.293 & 0.01681 & 0.37734 & 0.18201 \\
\hline left ulna distal width & 0.28436 & -0.49626 & 0.051237 & -0.55495 \\
\hline
\end{tabular}


- Larus argentatus

- Larus delawarensis

$\nabla_{\text {Larus thayeri }}$

* Larus hyperboreus

¿ Larus glaucoides

+ Larus glaucescens

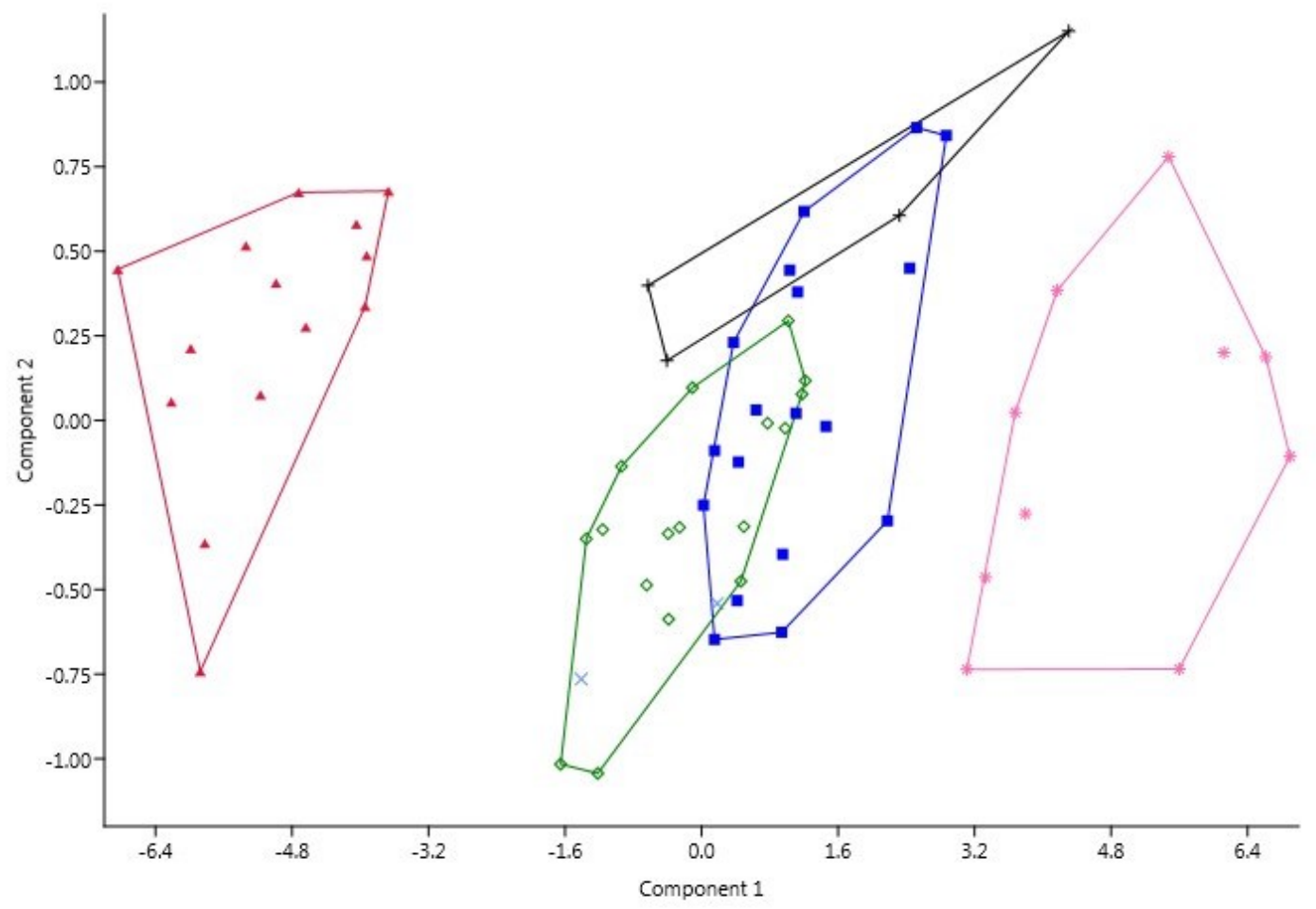

Figure 15: scatter plot showing the results of the post cranial PCA analysis. Components 1 and 2 are shown. 
Figure 15 shows the resulting scatter plot for the first two components of the analysis. Principal component $\left(\mathrm{PC}_{\mathrm{g}}\right) 1$ accounts for approximately $93 \%$ of the total variance in the analysis. $\mathrm{PC}_{\mathrm{g}} 2$ accounts approximately $2 \%$ of the total variance. Specimens plotting on the left side of graph will be smaller than those plotting on the right side of the graph. For example, the Larus delawarensis specimens plot as a group on the left section (Fig.15), suggesting that they are smaller compared to the other species. L. hyperboreus plots on the far right of the graph, suggesting it is larger compared to all other species. L. delawarensis, being the smaller species, plots on the left hand side of the scatter plot. The other species of gulls, being of similar size, plot in a seemingly uniform group near the center of the plot. $\mathrm{PC}_{\mathrm{g}} 2$ shows an inverse relationship between elements of the forelimb and elements of the hindlimb. Specimens plotting higher on $\mathrm{PC}_{\mathrm{g}} 2$ (the $\mathrm{Y}$ axis in Fig.15) will have larger hindlimb and smaller forelimb elements. The specimens lower on the $\mathrm{Y}$ axis will have relatively larger forelimb elements.

There is less variation along the second axis of the analysis. There is one noticeable outlier in Fig. 15. Specimen CMNAV S-484 (see appendix B) plotted away from all the other specimens and was also outside of the $95 \%$ confidence ellipse. The information on the specimen card did not specify the age of the specimen. Because juvenile gulls are noticeably smaller compared to adults, it is possible that any juvenile measured in the analysis would potentially plot far away from all the other specimens. Since it cannot be confirmed whether the specimen is juvenile or not, the specimen is considered to be an experimental or 
measurement error and will not be considered in the analysis. The other outlier in the analysis was an immature female CMNAV S-1785 (see Appendix B). The immature nature of the specimen could explain why it is plotting outside of the $95 \%$ confidence ellipse as an outlier. 


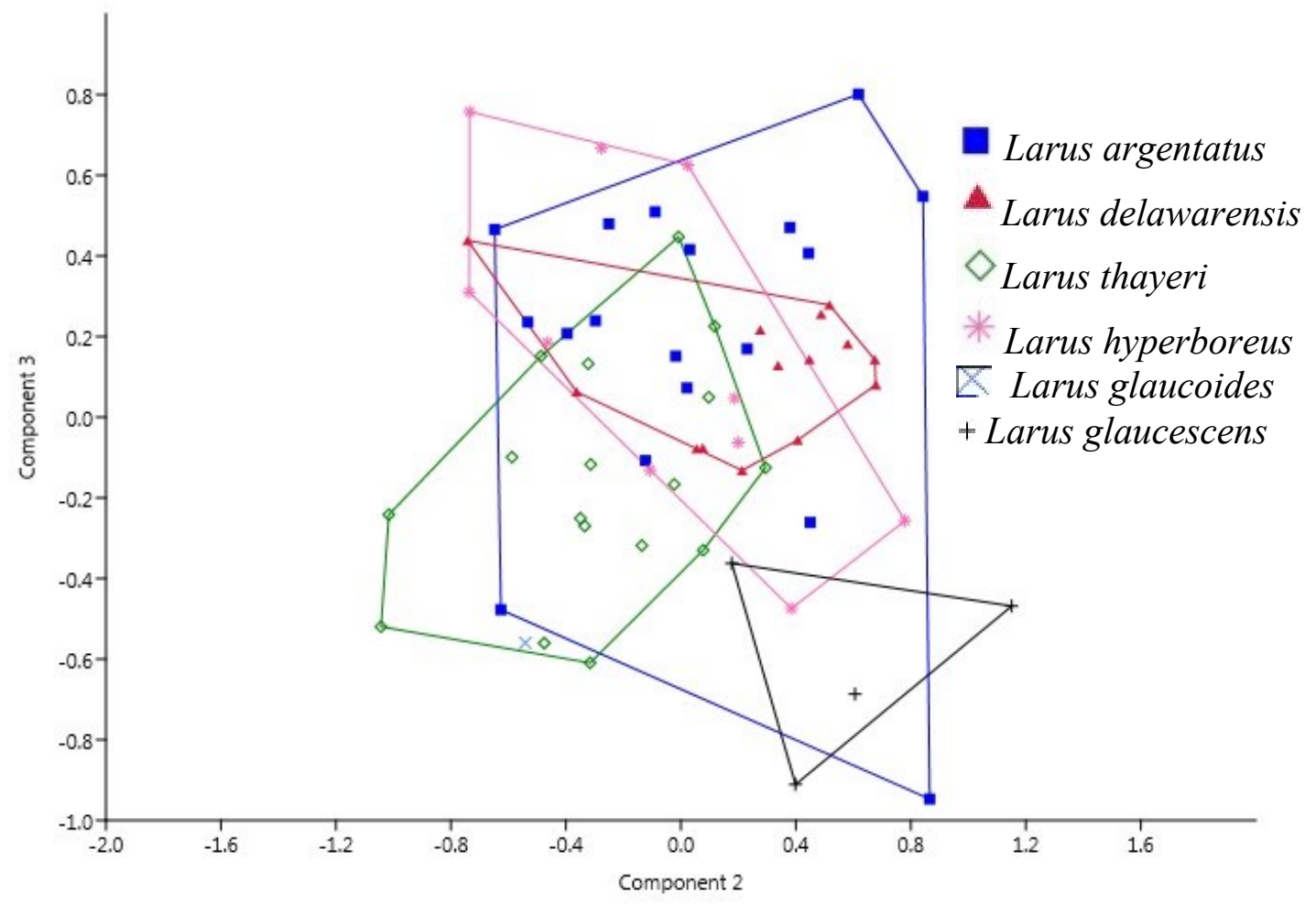

Figure 16: Scatter plot of the post cranial skeleton showing components 2 and 3. 
The PCA results for the $\mathrm{PC}_{\mathrm{g}} 2$ and $\mathrm{PC}_{\mathrm{g}} 3$ are shown in Figure 16. The graph was plotted with a 95\% confidence ellipse. The samples are all grouping in the center of the graph. $\mathrm{PC}_{\mathrm{g}} 2$ accounts for approximately $2 \%$ of total sample variance. $\mathrm{PC}_{\mathrm{g}} 3$ represents approximately $1 \%$ of the total sample variance. The variance in $\mathrm{PC}_{g} 3$ (Table 2) is characterized by positive loadings of tarsometatarsus length, ulna length and distal width, humerus length and distal width, radius length and ulna length and distal width. $\mathrm{PC}_{\mathrm{g}} 3$ also shows strong negative correlation with tibiotarsus distal width and tarsometatarsus length (Table 2).

In a typical morphometric analysis, comparing PC 2 and PC 3 will show the shape variation within the dataset. Considering that PC 2 and PC 3 only account for a total of $3 \%$ of the sample variance, shape variation is not significant in these species of gulls. What little shape variation is present is seen most notably in the tibiotarsus and tarsometatarsus, as these have the highest loading on $\mathrm{PC}_{\mathrm{g}} 2$ and 3 (Table 2). Because of the inverse relationship between tarsometatarsus length and distal width, specimens plotting on the right side of the graph will have longer and narrower tarsometatarsus. 


\subsection{Intraspecific morphological variation}

Individual scatter plots were generated to analyze the morphological variation within each individual species. Only the species with a significant number of specimens were used for the analysis. The results are shown in Figures 18 through 20 as bivariate plots generated from the PCA. 
Table 4: eigenvalues and percent variance of the $L$. argentatus PCA.

\begin{tabular}{|c|c|c|}
\hline PC & Eigenvalue & $\begin{array}{l}\% \\
\text { variance }\end{array}$ \\
\hline 1 & 0.934015 & 61.382 \\
\hline 2 & 0.257388 & 16.915 \\
\hline 3 & 0.136616 & 8.9781 \\
\hline 4 & 0.08678 & 5.703 \\
\hline 5 & 0.038666 & 2.5411 \\
\hline 6 & 0.030332 & 1.9934 \\
\hline 7 & 0.01607 & 1.0561 \\
\hline 8 & 0.008219 & 0.54014 \\
\hline 9 & 0.005695 & 0.37426 \\
\hline 10 & 0.004837 & 0.31786 \\
\hline 11 & 0.001992 & 0.13091 \\
\hline 12 & 0.001041 & 0.068396 \\
\hline
\end{tabular}

Table 5: loadings on the PC of the $L$. argentatus analysis

\begin{tabular}{|l|r|r|r|}
\hline & PC 1 & \multicolumn{1}{|l|}{ PC 2 } & \multicolumn{1}{l|}{ PC 3 } \\
\hline left femur length & 0.29987 & 0.067409 & -0.21213 \\
\hline left femur distal width & 0.33657 & -0.22746 & 0.044216 \\
\hline left femur midshaft radius & 0.23067 & 0.17003 & 0.66941 \\
\hline left tibiotarsus length & 0.31356 & 0.068144 & -0.27531 \\
\hline left tibiotarsus distal width & 0.35246 & -0.22045 & -0.00611 \\
\hline left tarsometatarsus length & 0.58341 & 0.302 & -0.36811 \\
\hline $\begin{array}{l}\text { left tarsometatarsus distal } \\
\text { width }\end{array}$ & 0.25583 & -0.70771 & 0.16969 \\
\hline left humerus length & 0.10819 & 0.17399 & 0.12799 \\
\hline left humerus distal width & 0.10241 & 0.038671 & 0.32915 \\
\hline left radius length & 0.1435 & 0.35481 & 0.24569 \\
\hline left ulna length & 0.15996 & 0.2788 & 0.23576 \\
\hline left ulna distal width & 0.21644 & -0.18471 & 0.15533 \\
\hline
\end{tabular}




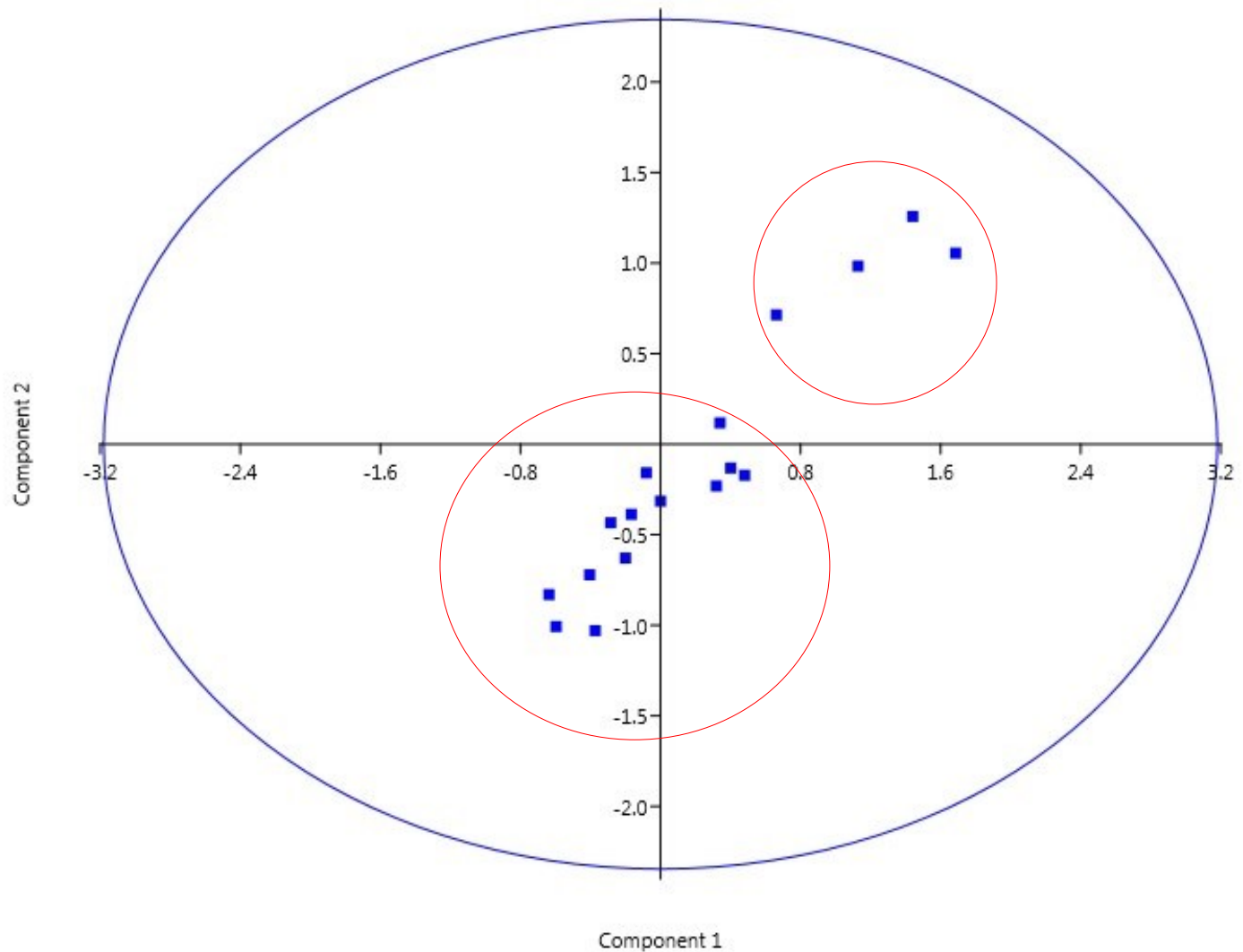

Figure 17: PCA scatter plot for Larus argentatus that shows two different grouping of specimen. The lower left specimens are females and the upper right specimens are all males. 
Figure 17 shows the PCA results for Larus argentatus. PC1 accounts for $61.4 \%$ of the sample variation (Table 5). All the variables are positively correlated in PC1 (Table 4). The tarsometatarsus length has the highest loading on PC 1, followed by the femur length and distal width and the tibiotarsus length and distal width. Elements of the forelimbs (humerus, radius and ulna) show lower loading on PC1 than elements of the hindlimbs. Specimens plotting on the right side of the graph (far right on the $\mathrm{x}$ axis) will therefore be larger in their hindlimbs and forelimbs. PC2 accounts for $16.91 \%$ of the total variation (Table 5). The tarsometatarsus distal width has a high and negative loading on component 2. The ulna, tibiotarsus and femur distal width are weakly negatively correlated with PC2. The radius and ulna lengths have a strong positive correlation on PC2 (Table 4). Specimens plotting on the upper part of the graph (positive on the $y$ axis) will have longer and narrower skeletal elements. Those plotting lower on the graph (negative on the $y$ axis) have shorter, broader skeletal elements.

The specimens plot in two separate groups. This graph demonstrates that $L$. argentatus specimens exhibit sexual size dimorphism. The females plot on the lower central part of the graph and the males plot in the upper right quadrant of the graph. 


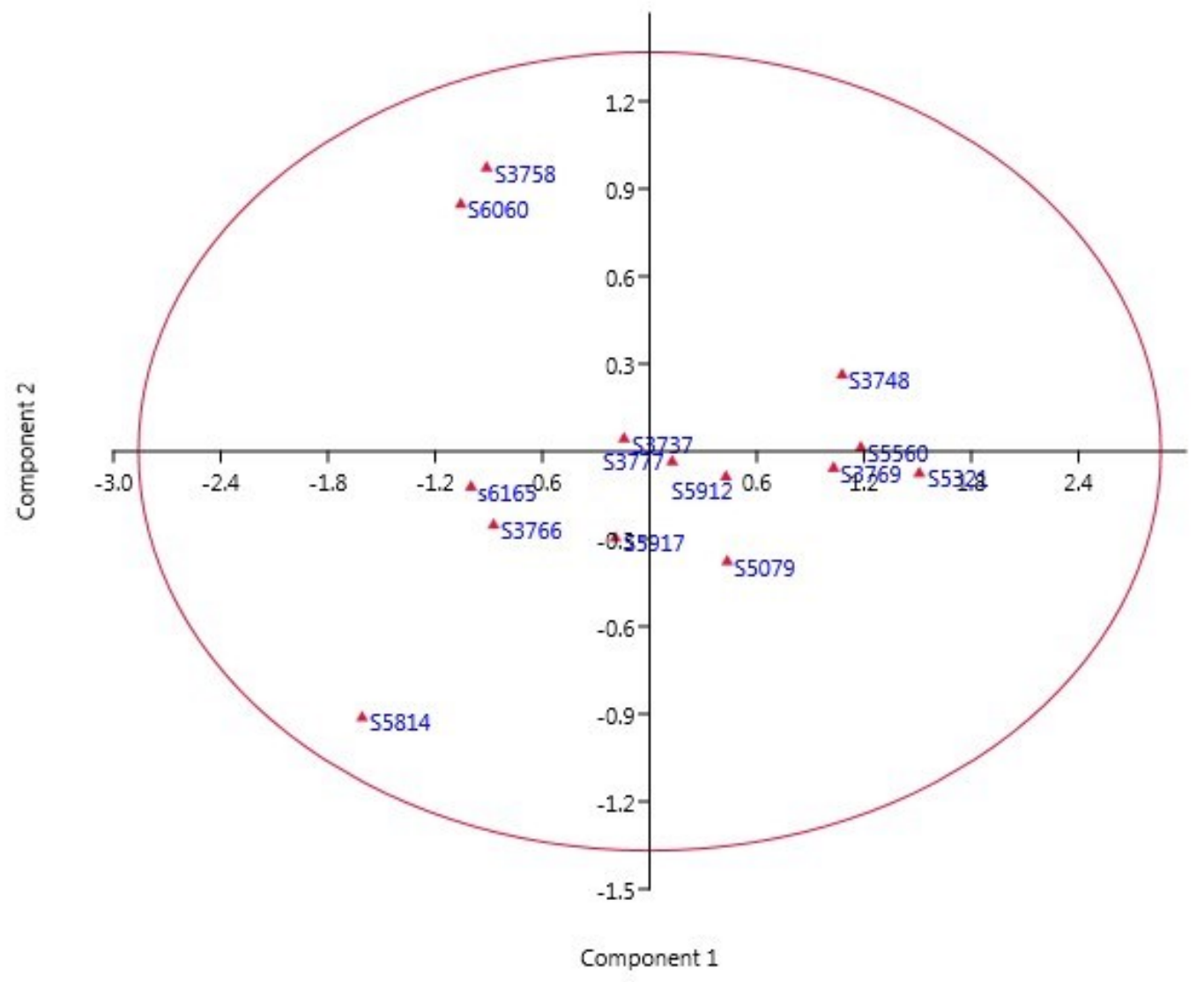

Figure 19: PCA scatter plot for $L$. delawarensis species showing Components 1 and 2. 
Figure 18 shows the PCA results of the $L$. delawarensis species. Component 1 explains $70.8 \%$ of the total variance in the dataset. Component 2 explains $16.2 \%$ of the variance (Table 7 ). PC1 is positively correlated with all the variables. The strongest loading is in the tarsometatarsus length. The weakest loading is shown in the ulna width. All other elements show similar, positive loadings on PC1 (Table 6). PC2 is strongly and positively correlated with the distal width of the ulna. The tarsometatarsus width, humerus width and ulna length are weakly and positively correlated with PC2. The femur width and midshaft radius, tibiotarsus length and width and tarsometatarsus length all have weak and negative loading on PC2. Components plotting on the upper portion of the graph will exhibit wider ulnae, narrower femora, short and narrow tibiotarsi and short, wider tarsometatarsi. There doesn't appear to be sexual dimorphism in PC 1 and 2. 
Table 6: loading of each component of the $L$. delawarensis PCA

\begin{tabular}{|l|r|r|}
\hline & PC 1 & PC 2 \\
\hline left femur length & 0.28053 & 0.028659 \\
\hline left femur distal width & 0.33811 & -0.07357 \\
\hline left femur midshaft radius & 0.29989 & -0.11865 \\
\hline left tibiotarsus length & 0.31431 & -0.08553 \\
\hline left tibiotarsus distal width & 0.2466 & -0.06894 \\
\hline left tarsometatarsus length & 0.4683 & -0.14581 \\
\hline $\begin{array}{l}\text { left tarsometatarsus distal } \\
\text { width }\end{array}$ & 0.21486 & 0.11516 \\
\hline left humerus length & 0.27767 & -0.06942 \\
\hline left humerus distal width & 0.28829 & 0.0654 \\
\hline left radius length & 0.22965 & 0.018625 \\
\hline left ulna length & 0.25315 & 0.074326 \\
\hline left ulna distal width & 0.12228 & 0.95819 \\
\hline
\end{tabular}

Table 7: Eigenvalue and percent variance of the $L$. delawarensis PCA

\begin{tabular}{|r|r|r|}
\hline PC & Eigenvalue & \multicolumn{1}{l|}{$\begin{array}{l}\text { variance } \\
\text { var }\end{array}$} \\
\hline $\mathbf{1}$ & 1.0299 & 70.766 \\
\hline $\mathbf{2}$ & 0.236285 & 16.236 \\
\hline $\mathbf{3}$ & 0.076184 & 5.2348 \\
\hline $\mathbf{4}$ & 0.038037 & 2.6136 \\
\hline $\mathbf{5}$ & 0.025673 & 1.7641 \\
\hline $\mathbf{6}$ & 0.021264 & 1.4611 \\
\hline $\mathbf{7}$ & 0.009453 & 0.6495 \\
\hline $\mathbf{8}$ & 0.008863 & 0.60898 \\
\hline $\mathbf{9}$ & 0.005889 & 0.40464 \\
\hline $\mathbf{1 0}$ & 0.002281 & 0.15672 \\
\hline $\mathbf{1 1}$ & 0.001362 & 0.093558 \\
\hline $\mathbf{1 2}$ & 0.000162 & 0.011165 \\
\hline
\end{tabular}




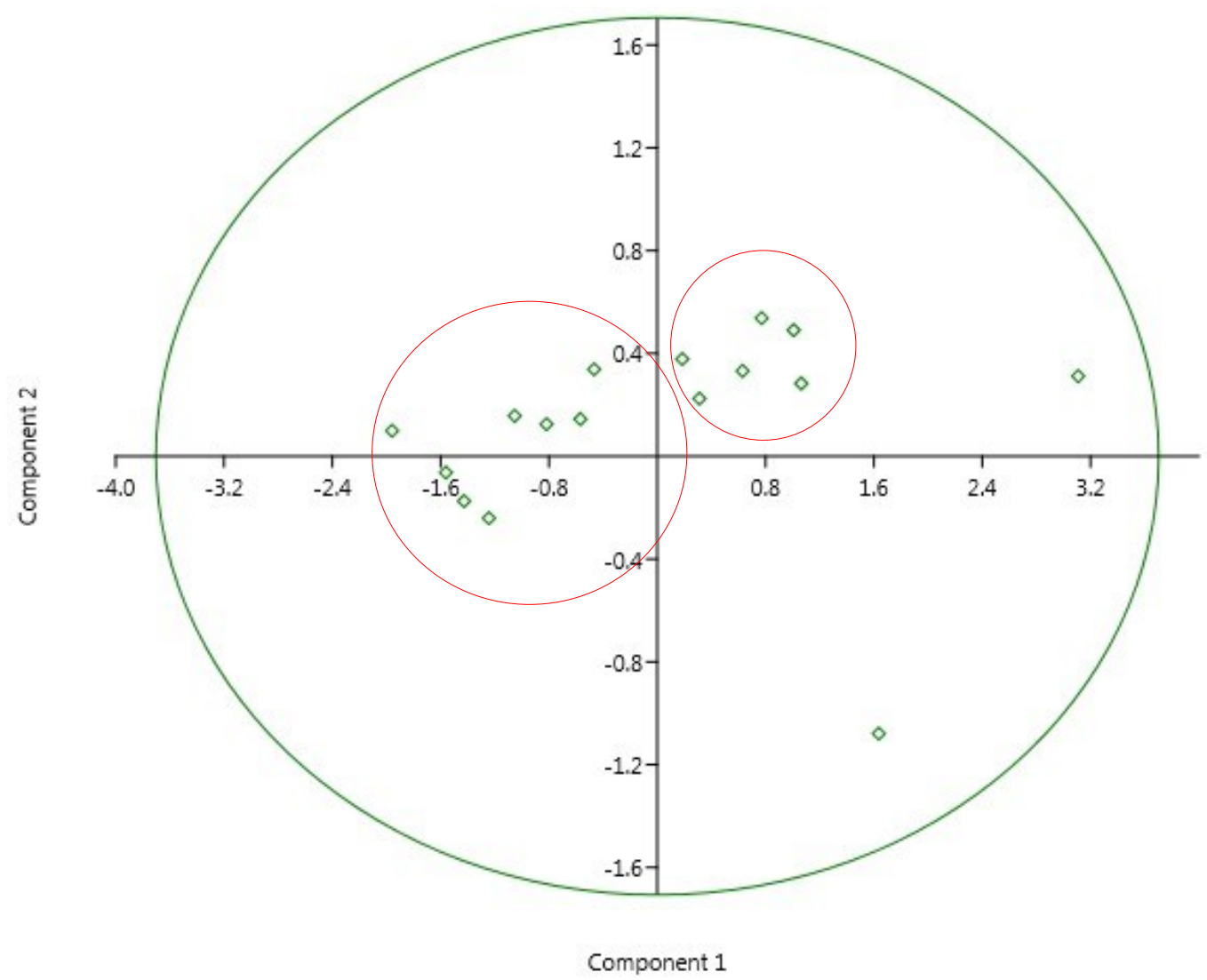

Figure 19: PCA scatter plot for Larus thayeri showing the first and second components of the PCA. 
Figure 19 shows the scatter plot result for the Larus thayeri PCA. PC1 accounts for $75.0 \%$ of the variance and PC2 accounts for $8.5 \%$ (Table 9). PC 1 is strongly and positively correlated with the tarsometatarsus length. The other variables have an even and positive loading on PC1 (Table 8). Specimens on the right side of the graph will exhibit larger skeletal elements (with proportionally longer tarsometatarsus) than the ones on the left side (Fig. 20). PC 2 is strongly and positively correlated with the tibiotarsus width. The femur width and tarsometatarsus width have a positive loading on PC2. The tarsometatarsus length is strongly and negatively correlated with PC2 (Table 8). Specimens plotting on the upper part of the graph will exhibit wider tibiotarsus, femurs and short, wide tarsometatarsus. The graph shows two groups of specimens, which appear to be grouped based on the sex of the specimens. The females are plotting in the left group and the males plot in the right side group, suggesting that males will have longer, wider skeletal elements than females. There are two specimens of undefined sex and age that plot outside of either group (but are still within the $95 \%$ confidence interval). 
Table 8: Loadings on PC 1 and 2 of the $L$. thayeri PCA

\begin{tabular}{|l|l|r|}
\hline & PC 1 & PC 2 \\
\hline left femur length & 0.23684 & -0.03124 \\
\hline left femur distal width & 0.22752 & 0.16949 \\
\hline left femur midshaft radius & 0.16808 & 0.32765 \\
\hline left tibiotarsus length & 0.28747 & -0.10218 \\
\hline left tibiotarsus distal width & 0.32046 & 0.69335 \\
\hline left tarsometatarsus length & 0.53972 & -0.49719 \\
\hline $\begin{array}{l}\text { left tarsometatarsus distal } \\
\text { width }\end{array}$ & 0.17204 & 0.31603 \\
\hline left humerus length & 0.27423 & -0.05442 \\
\hline left humerus distal width & 0.25359 & 0.053689 \\
\hline left radius length & 0.29769 & -0.08644 \\
\hline left ulna length & 0.30443 & -0.09718 \\
\hline left ulna distal width & 0.19194 & -0.04405 \\
\hline
\end{tabular}

Table 9: Eigenvalues and percent variance of each component of the $L$. thayeri

\begin{tabular}{|c|c|c|}
\hline PC & Eigenvalue & $\begin{array}{l}\% \\
\text { variance }\end{array}$ \\
\hline 1 & 1.03007 & 75.017 \\
\hline 2 & 0.117041 & 8.5238 \\
\hline 3 & 0.082964 & 6.0421 \\
\hline 4 & 0.062398 & 4.5443 \\
\hline 5 & 0.035736 & 2.6025 \\
\hline 6 & 0.019041 & 1.3867 \\
\hline 7 & 0.013863 & 1.0096 \\
\hline 8 & 0.005431 & 0.39554 \\
\hline 9 & 0.003536 & 0.25755 \\
\hline 10 & 0.002201 & 0.16026 \\
\hline 11 & 0.000763 & 0.055595 \\
\hline 12 & $6.38 \mathrm{E}-05$ & 0.004648 \\
\hline
\end{tabular}




\subsection{Gull cranial morphometric analysis}

Figures 20 through 22 show the PCA results of the cranial morphometrics analysis for the dorsal view of the gull skulls. The analysis was conducted on four species of gulls using the dorsal photos taken. The PCA analysis was conducted using the landmark coordinates on two different views of the skull (dorsal and ventral). Appendix $\mathrm{D}$ shows the landmarks digitized on the ventral side of each skull. Component 1 explains $35.4 \%$ of the total variance. PC 2 explains $18.7 \%$ of variance. PC 3 explains $14.3 \%$ and PC 4 explains $6.9 \%$ of variance.

Table 10: percent variance of the each component of the dorsal geometric morphometric analysis

\begin{tabular}{|c|c|c|}
\hline PC & Eigenvalue & $\begin{array}{l}\% \\
\text { variance }\end{array}$ \\
\hline 1 & 0.000946 & 35.403 \\
\hline 2 & 0.000501 & 18.762 \\
\hline 3 & 0.000383 & 14.328 \\
\hline 4 & 0.000187 & 6.994 \\
\hline
\end{tabular}




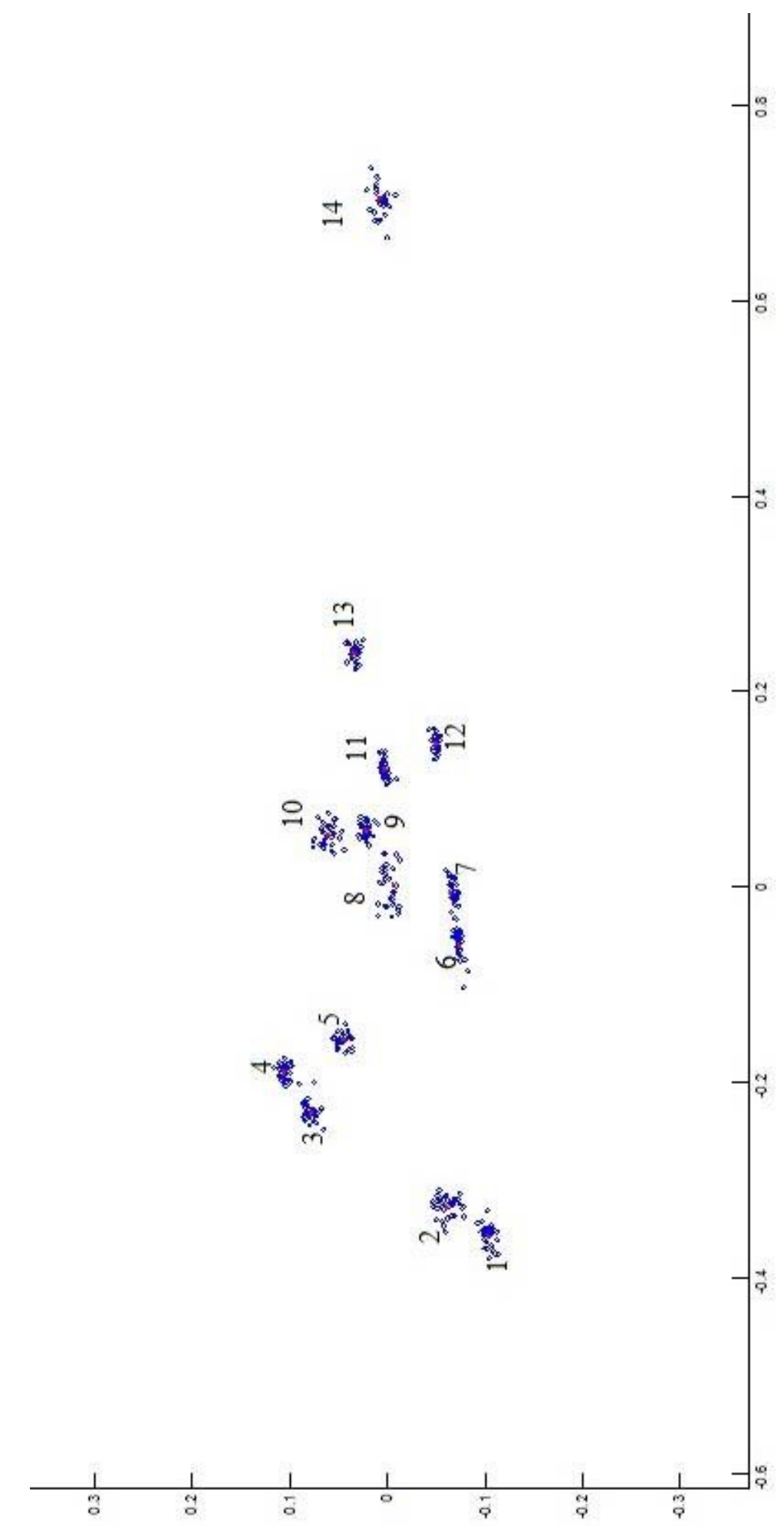

Figure 20: plot showing the distribution of all the landmarks digitized on the dorsal view of each gull skull. Each skull has been overlain on one graph to show the potential differences in morphologies among the species 
Figure 20 shows the distribution of all the landmarks digitized on the dorsal view of each specimen. The landmarks do not exhibit much variation in position. The landmarks appear to be uniform in their position. They all appear to be grouped together. The variation in the position of each landmark can most likely be attributed to individual variations in skull shape. The landmark coordinates were used to conduct further PCA tests. 


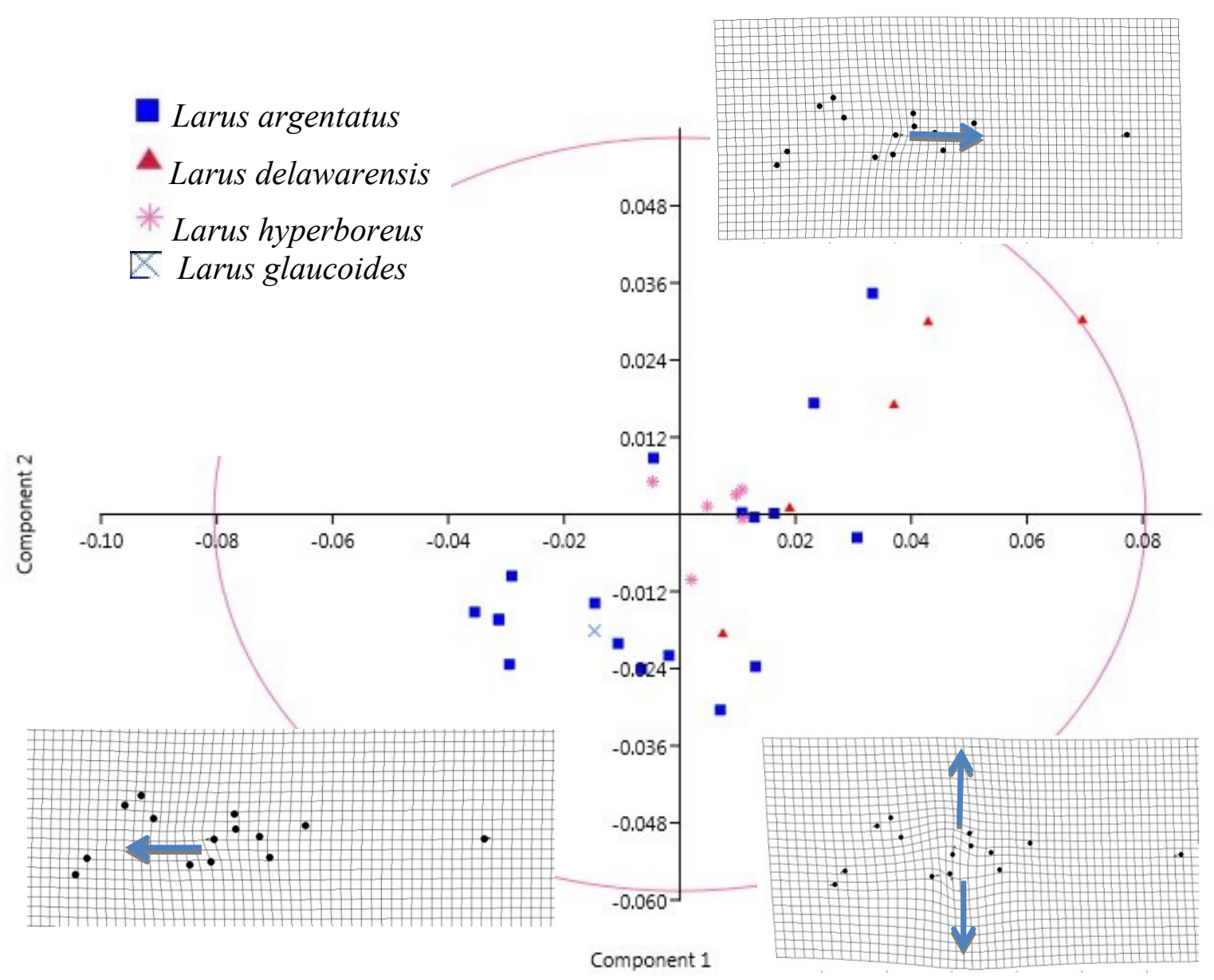

Figure 21: Scatter plot for the result of PCA for the gull dorsal cranial morphometrics analysis showing PC 1 and 2. 
Figure 21 shows the scatter plot of the first two components of the dorsal landmark analysis. PC 1 accounts for approximately $35.4 \%$ of the total variance in the analysis. PC 2 explains approximately $18.7 \%$ (Table 10) of the total sample variance. Most of the specimens that were measured fell inside the $95 \%$ confidence interval. Those that remained inside do not appear to show any distinct groupings although there is some noticeable asymmetry to the distributions. There is a lot of overlap between the species. Some specimens of $L$. argentatus (blue squares) and $L$. delawarensis (red triangles) are plotting on the upper right quadrant.

It appears that most of the $L$. argentatus specimens are plotting on the left side of the graph and most of the $L$. delawarensis specimens plot on the right hand side of the graph. The deformation grids show the displacement of the landmarks and approximate deformation of the skulls. Specimens that plot on the lower left exhibit a slight compaction towards the anterior portion of the skull. Specimens plotting on the upper right exhibit the opposite effect: a slight compaction towards the rostral end of the skull. Specimens that plot on the lower right exhibit a widening in the skull (at the nasal-frontal contact). 


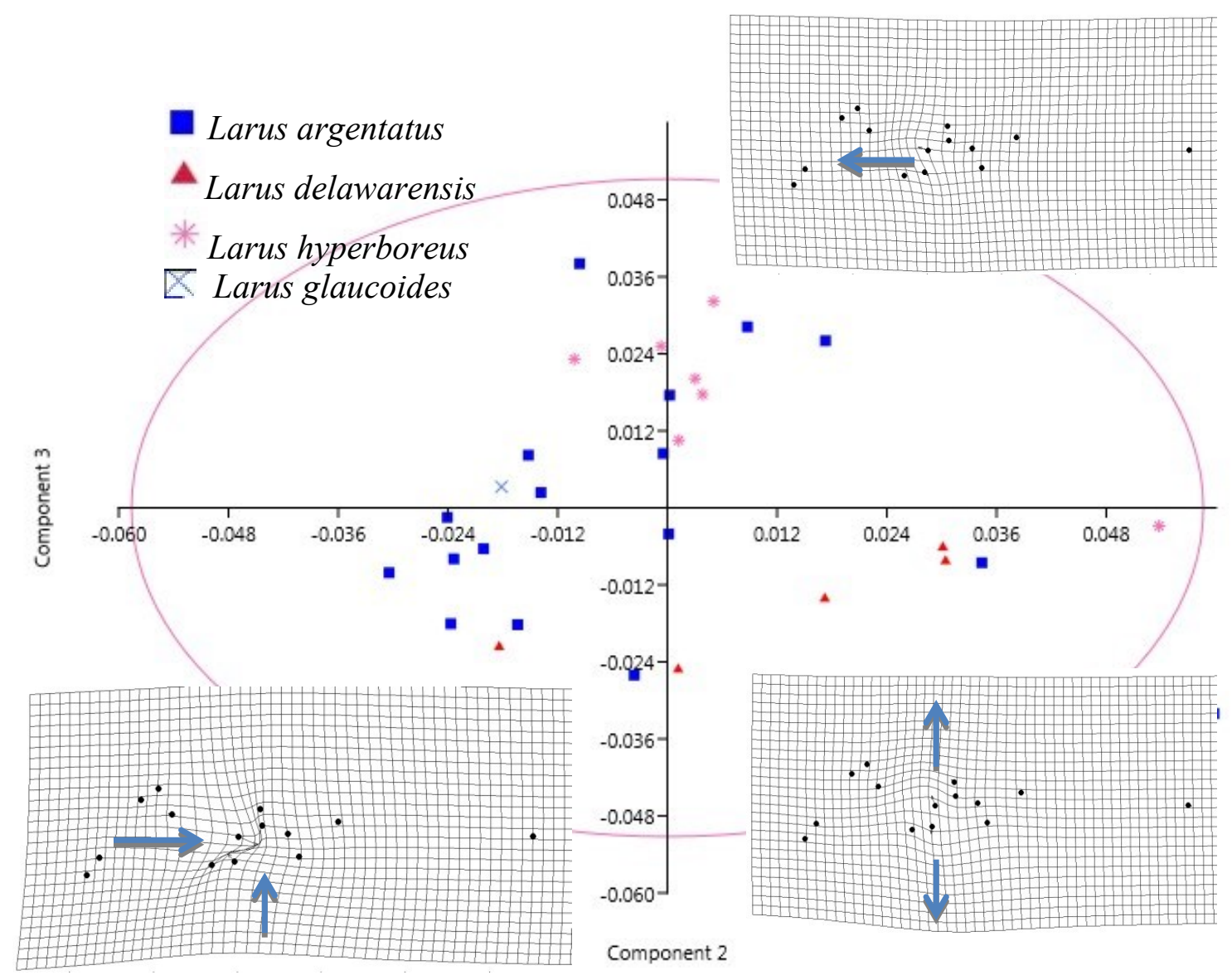

Figure 22: Scatter plot for the result of the PCA for the gull cranial morphometrics analysis. The graph shows the second and thirds components of the analysis. 
Figure 22 shows the scatter plot comparing components 2 and 3. PC 3 explains approximately $14.3 \%$ of the variance in the analysis. As per the previous result, the specimens included in the analysis fell inside the $95 \%$ confidence interval. There is extensive overlap between the species analyzed. There are three specimens of $L$. delawarensis and one specimen of $L$. argentatus plotting on the bottom right quadrant of the graph. One specimen of $L$. hyperboreus is plotting on the right side of the plot (positive side of PC 2). Specimens that plot on the bottom left quadrant of the graph exhibit in the central portion of the skull (at the contact of the frontal and nasal). Specimens that plot on the upper right exhibit compaction towards the anterior of the skull. Specimens that plot on the bottom right exhibit widening of the skull.

Figures 23 through 25 show the PCA results for the ventral view of the gull skulls. Figure 23 shows the distribution of all the landmarks digitized on the ventral view of each specimen. The landmarks digitized on each specimen have all superimposed in the graph. PC 1 explains $79.6 \%$ of the variance. PC 2 explains $10.9 \%$ of the variance and PC 3 explains $2.9 \%$ of the variance in the dataset.

Table 11: \% variance and eigenvalues of each component of the ventral geometric morphometric analysis

\begin{tabular}{|c|c|c|}
\hline PC & Eigenvalue & $\%$ variance \\
\hline 1 & 0.011982 & 79.668 \\
\hline 2 & 0.001646 & 10.943 \\
\hline 3 & 0.000438 & 2.9108 \\
\hline
\end{tabular}




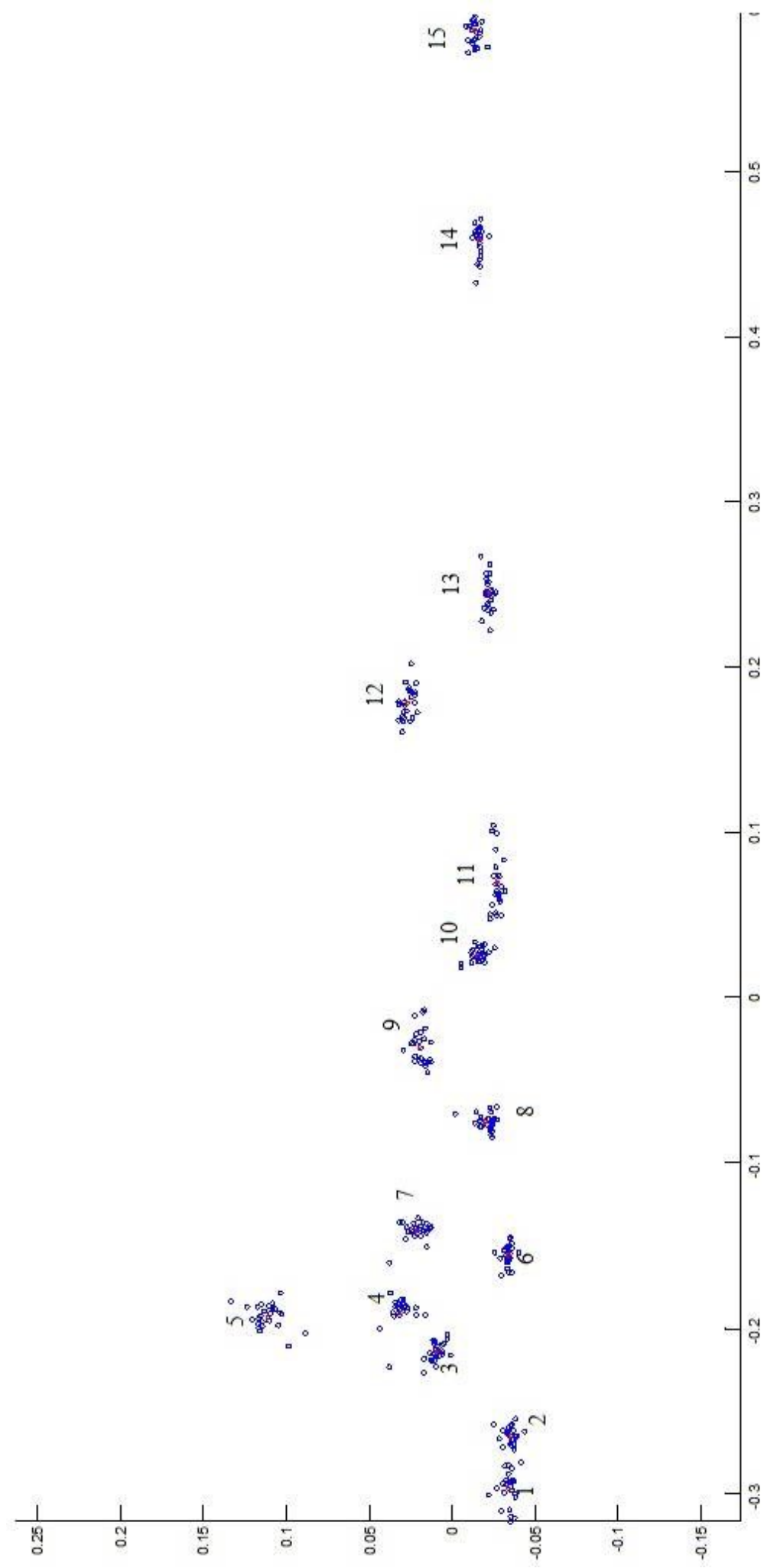

Figure 23: Plot showing all the digitized points on each gull skull in ventral view. 


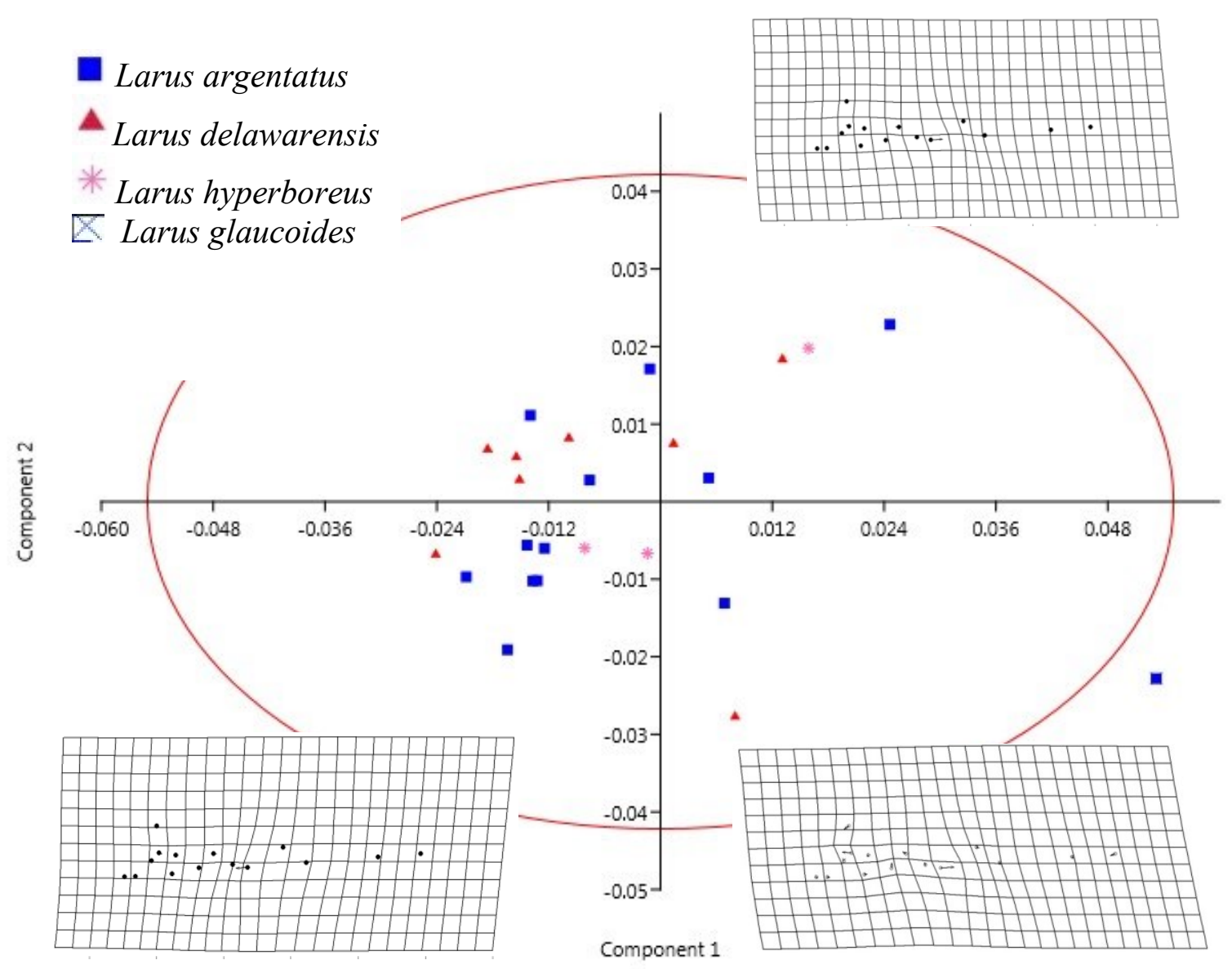

Figure 24: Scatter plot for the result of the PCA for the gull ventral cranial morphometrics analysis. The graph shows the results for PC 1 and PC 2. 
Figure 24 shows the scatter plot of principal components 1 and 2 of the analysis. Principal component 1 comprises $79.7 \%$ of the total sample variance. Component 2 explains $10.9 \%$ of the total variance. The specimens that were analyzed fell inside the $95 \%$ confidence interval. The specimens are scattered throughout the plot in a cloud. The deformation grids show the deformation in the skulls. Specimens plotting on the bottom right portion of the graph exhibit compression in their skulls. Specimens plotting on the upper right exhibit elongation in their skulls. The specimens plotting on the bottom right also exhibit elongation in their skulls. 


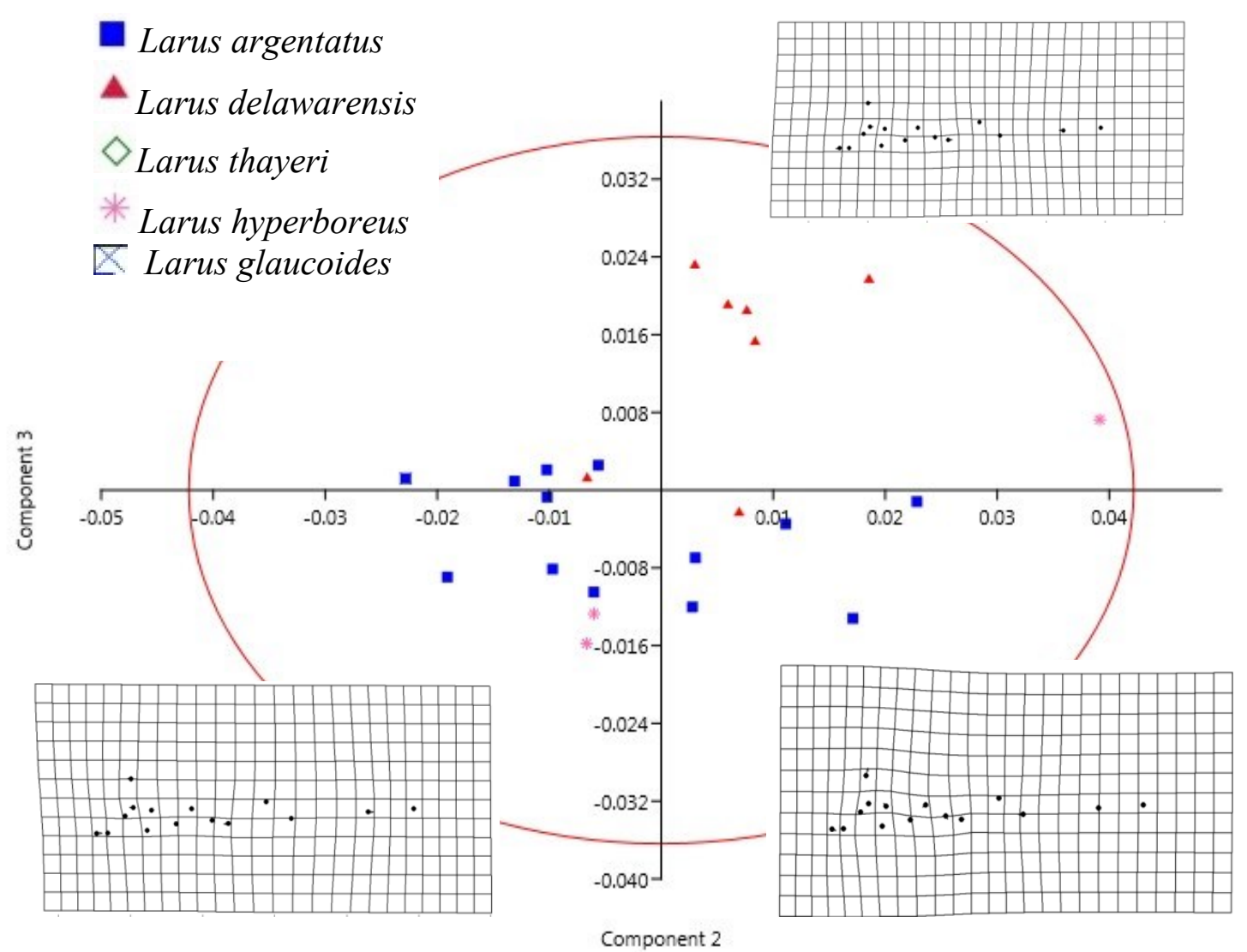

Figure 25: Scatter plot for the result of the PCA for the gull ventral cranial morphometrics analysis. The graph shows the results of components 2 and 3 
Figure 25 shows the scatter plot of PC 2 and PC 3 . Component 3 explains approximately $2.9 \%$ of the variance in the analysis. As per the previous result, the specimens included in the analysis fell inside the $95 \%$ confidence interval. Larus argentatus and Larus delawarensis are separated in this analysis. $L$. argentatus exhibits slight expansion and elongation of the skull and $L$. delawarensis exhibits slight compaction. Specimens plotting on the lower left exhibit slight compaction in the skulls. The specimens plotting on the upper right exhibit slight elongation. The ones plotting on the lower right exhibit slight narrowing of the skull.

\subsection{Theropod morphometrics analysis}

Four analyses were run were conducted on groups of fossil theropods: one includes all the tyrannosaurids ( $\mathrm{PC}_{\mathrm{ty}}$; Figs. 26 and 27), the second includes all early bird specimens ( $\mathrm{PC}_{\mathrm{m}}$; Figs. 28 and 29), the third includes all the maniraptorans ( $\mathrm{PC}_{\mathrm{b}}$; Figs. 30 and 31) and the final analysis includes all of the theropod specimens available ( $\mathrm{PC}_{\mathrm{th}}$; Figs. 32 and 33).

Table 10 shows the loadings of each component on the original variables. Table 11 shows the percent of variance that is explained by each principal component and the eigenvalues extracted from the PCA. The first component accounts for a large portion of the total variance (92.7\% Table 12). The second

component accounts for $3.6 \%$ (Table 12) of the total sample variance. The third PC explains 2.2\% (Table 12) of the variance. The element that has the highest 
positive loading $(0.76)$ on the first component is the femur length. The element with the second highest loading (0.56) is the tibiotarsus length. This means that $\mathrm{PC}_{\mathrm{ty}} 1$ is highly correlated with the increase in femur and tibiotarsus length. For component 2 , most of the variables have a correlation that is less than 0.5 . The only variable that meets this criterion is the femur length, with -0.62 . This means that $\mathrm{PC}_{\mathrm{ty}} 2$ is mainly characterized by a decrease in femur length. 
Table 12: loadings of each component for the Tyrannosaurid PCA

\begin{tabular}{|l|r|r|r|}
\hline & \multicolumn{1}{|c|}{$\mathbf{P C}_{\text {ty }} \mathbf{1}$} & $\mathbf{P C}_{\text {ty }} \mathbf{2}$ & $\mathbf{P C}_{\text {ty }} \mathbf{3}$ \\
\hline Humerus length & 0.1994 & 0.46507 & 0.44925 \\
\hline Radius length & 0.042251 & 0.37539 & 0.13324 \\
\hline Ulna length & 0.063304 & 0.42609 & 0.27403 \\
\hline Femur length & 0.75717 & 0.18166 & -0.61479 \\
\hline Tibia length & 0.55883 & -0.1955 & 0.50769 \\
\hline mt III & 0.26238 & -0.62452 & 0.26384 \\
\hline
\end{tabular}

Table 13: \% variance and eigenvalues of each component of the tyrannosaurid PCA

\begin{tabular}{|r|r|r|}
\hline \multicolumn{1}{|l|}{$\mathbf{P C}_{\text {ty }}$} & Eigenvalue & \multicolumn{1}{l|}{$\begin{array}{l}\text { \% } \\
\text { variance }\end{array}$} \\
\hline $\mathbf{1}$ & 130488 & 92.748 \\
\hline $\mathbf{2}$ & 5170.65 & 3.6752 \\
\hline $\mathbf{3}$ & 3105.97 & 2.2077 \\
\hline $\mathbf{4}$ & 1480.55 & 1.0523 \\
\hline $\mathbf{5}$ & 353.615 & 0.25134 \\
\hline $\mathbf{6}$ & 91.9703 & 0.065371 \\
\hline
\end{tabular}




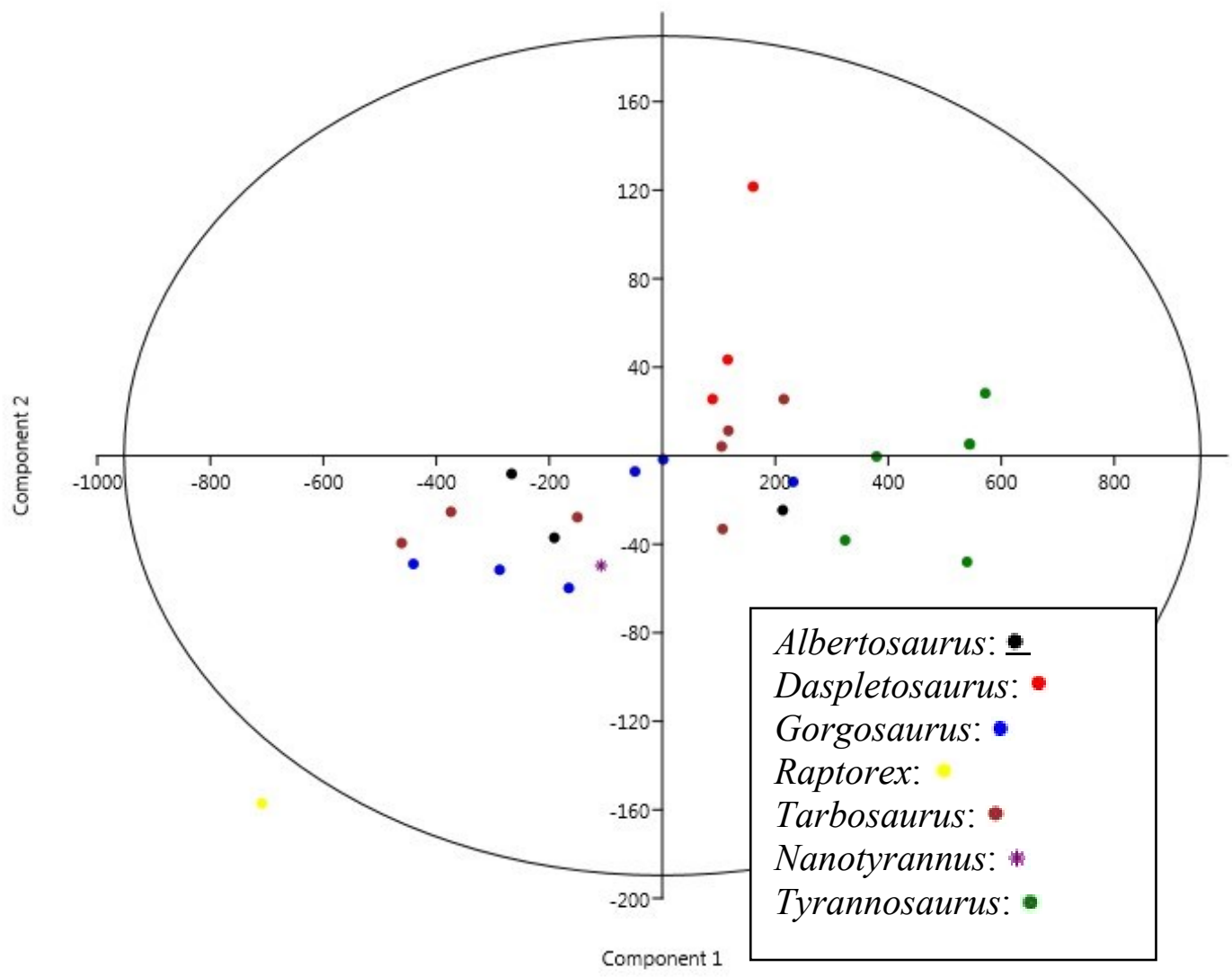

Figure 26: PCA results of the tyrannosaurid specimens showing $\mathrm{PC}_{\mathrm{ty}} 1$ and $\mathrm{PC}_{\mathrm{ty}} 2$. 
Figure 26 show the PCA results for the large bodied tyrannosaurids for $\mathrm{PC}_{\mathrm{ty}} 1$ and 2 . The specimens used for the analysis were selected based on the completeness of their measurements. Due to the incompleteness of several specimens in Currie's database, only a few specimens were utilized for the PCA. Raptorex appears to plot away from all the other specimens of tyrannosaurids falling outside of the $95 \%$ confidence interval. This may be due to the fact that only a limited number of measurements were available the specimen. There were also a limited number of complete specimens available for the analysis. A more complete set of measurements would be needed for further speculations.

Most of the specimens plot as one large group. There appears to be a group of specimens plotting on the right hand side of the graph, the Tyrannosaurus rex. Their position on the right hand side of $\mathrm{PC}_{t y} 1$ is due to their longer femora and tibiotarsi. Albertosaurus, Gorgosaurus, Tarbosaurus and Nanotyrannus and Daspletosaurus all show some separation, but have some overlap. Daspletosaurus is plotting on the positive part of component 2, suggesting it has larger metatarsi III. Their position to the left of Tyrannosaurus rex on the graph is indicative of their relatively shorter femora and tibiotarsi. It can also be seen that one of the specimens of Daspletosaurus is plotting away from the rest of the specimens, on the upper part of the second component. This indicates that the specimen has shorter metatarsi III than the rest of the Daspletosaurus specimens. 


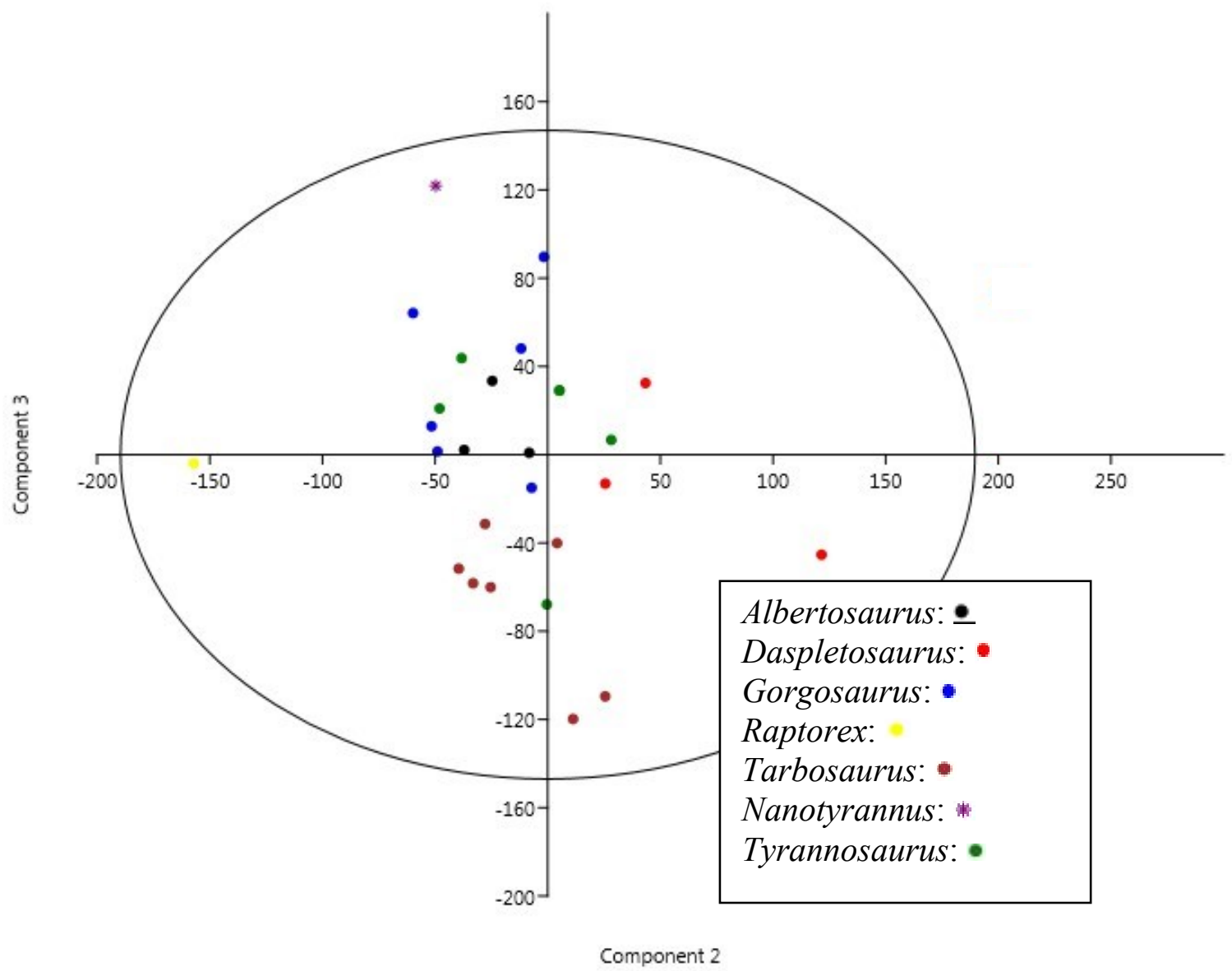

Figure 27: PCA results of the tyrannosaurid specimen showing $\mathrm{PC}_{\mathrm{ty}} 2$ and 3. 
Figure 27 shows the second and third principal components of the Tyrannosaurid PCA. $\mathrm{PC}_{t} 3$ represents $2.2 \%$ of the total sample variance (Table 12). The tibia length has a loading that is 0.5 and the femur length has a loading of -0.61 . This means that component 3 represents an increase in tibiotarsus length and a decrease in femur length. Specimens plotting on the upper portion of the graph will have shorter femurs and longer tibiotarsus. Interestingly, Nanotyrannus and Raptorex both plot away from the rest of the tyrannosaurid specimens. There is also a specimen of Daspletosaurus that is plotting away from the rest of the group. The Daspletosaurus plots far on the right hand side of the plot because it probably has a smaller length of the third Metatarsal. Raptorex, on the other hand, plots on the left hand side of component 2, which means it probably has a longer length of the third metatarsal. Nanotyrannus plots higher on the third component, which suggests that the specimen probably has longer tibiotarsus length and a shorter femur length. 
Figures 28 and 29 show the PCA results for the small to medium sized theropods. Table 12 shows the loading on each component of the analysis. Table 13 shows the eigenvalues and the percent variation of each component. PC1 explains $97.1 \%$ of the total sample variance and is highly and positively correlated with the femur length. PC 2 describes $1.2 \%$ of the total sample variance and PC 3 explains $0.7 \%$. Only the first two components will be considered.

Table 14: Loading of each component of the Maniraptora PCA $\left(\mathrm{PC}_{\mathrm{b}}\right)$

\begin{tabular}{|l|l|r|r|}
\hline & $\mathbf{P C}_{\mathbf{m}} \mathbf{1}$ & $\mathbf{P C}_{\mathbf{m}} \mathbf{2}$ & $\mathbf{P C}_{\mathbf{m}} \mathbf{3}$ \\
\hline H. length & 0.41131 & -0.25676 & 0.29586 \\
\hline R. length & 0.40863 & -0.44386 & 0.061207 \\
\hline U. length & 0.40781 & -0.47974 & -0.085235 \\
\hline F. length & 0.40994 & 0.25438 & -0.59584 \\
\hline T. length & 0.40813 & 0.4067 & -0.32997 \\
\hline mt III & 0.40363 & 0.52612 & 0.66147 \\
\hline
\end{tabular}

Table 15: \% variance and eigenvalue of each PC of the Maniraptora PCA

\begin{tabular}{|c|c|c|}
\hline $\mathbf{P C}_{\mathrm{b}}$ & Eigenvalue & $\%$ variance \\
\hline 1 & 5.75557 & 95.926 \\
\hline 2 & 0.149698 & 2.495 \\
\hline 3 & 0.0418648 & 0.69775 \\
\hline 4 & 0.0230166 & 0.38361 \\
\hline 5 & 0.0188049 & 0.31341 \\
\hline 6 & 0.0110432 & 0.18405 \\
\hline
\end{tabular}




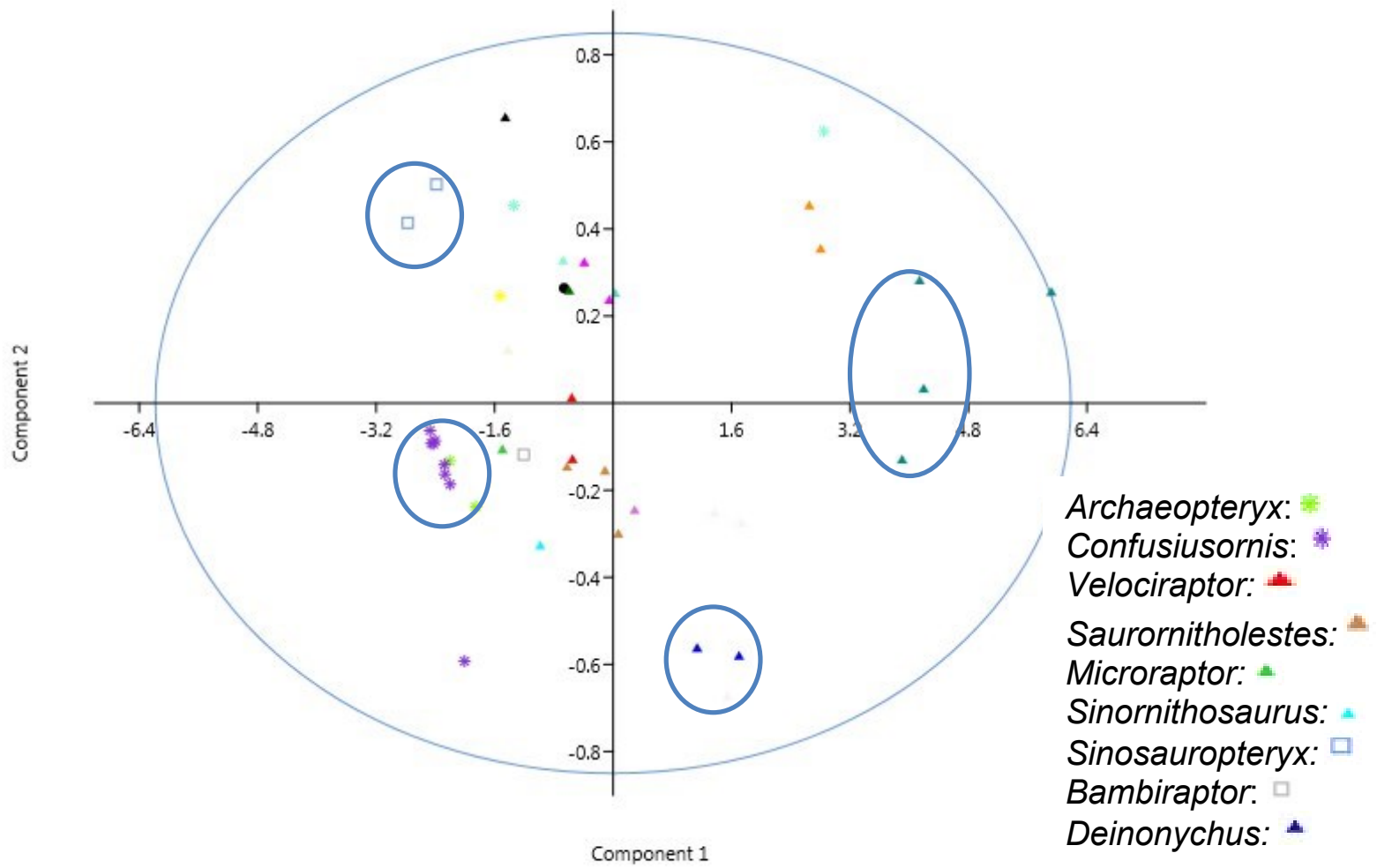

Figure 28: PCA results of the early bird specimen showing $P C_{b} 1$ and $P C_{b} 2$. 
Figure 28 shows the PCA result for the small to medium sized theropods and compares $\mathrm{PC}_{\mathrm{m}} 1$ and $\mathrm{PC}_{\mathrm{m}} 2 . \mathrm{PC}_{\mathrm{b}} 1$ represents $95.9 \%$ of the total variance. $\mathrm{PC}_{\mathrm{m}} 2$ represents $2.4 \%$ (Table 13). For component 1, all the variables show positive and nearly uniform loading, suggesting that $\mathrm{PC}_{\mathrm{m}} 1$ is a size variable. Some grouping can be seen in the plot. Archaeopteryx and Confuciusornis appear to group in a tight cluster on the negative side of component 1 , suggesting a smaller size compared to the other specimens.

The femur, tibia and metatarsus III lengths all have high positive loadings on the second component $\left(\mathrm{PC}_{\mathrm{m}} 2\right)$. The humerus, radius and ulna lengths all have negative loading on $\mathrm{PC}_{\mathrm{m}} 2$. There is an inverse correlation between the elements of the hindlimbs and elements of the forelimb (Table 14). Specimens that plot on the upper part of the $y$-axis will have longer hindlimbs and shorter forelimbs. Specimens plotting on the lower part of the $y$-axis will exhibit shorter hindlimbs and shorter forelimbs (Fig. 29). Deinonychus, Dromaeosaurus and Saurornitholestes plot on the right side of the graph, suggesting they are larger in size compared to the species plotting on the left side. Bambiraptor and Sinornithosaurus plot on the bottom left of the graph, suggesting that they are smaller in size and have proportionally longer forelimbs (Fig. 31).

Sinosauropteryx plots on the left side of the graph. This suggests that Sinosauropteryx was smaller in size compared to the other species examined and that it had larger hindlimbs. This is supported by previous analyses of skeletal anatomy of Sinosauropteryx (e.g., Ji and Ji, 1996). It also plots on the upper right, suggesting it has larger hindlimbs relative to forelimbs. 


\section{Combined theropod analysis}

Figures 30 and 31 show the results of the PCA conducted using all available theropod specimens $\left(\mathrm{PC}_{\mathrm{th}}\right)$. Table 16 shows the eigenvalues and percent of variance in each component of the PCA. Table 17 shows the loading of each variables on each $\mathrm{PC}_{\text {th }}$.

Table 16: Eigenvalues and percent variance for components 1 to 6 of the theropod PCA

\begin{tabular}{|c|c|c|}
\hline PC & Eigenvalue & $\begin{array}{l}\text { \% } \\
\text { variance }\end{array}$ \\
\hline 1 & 4.65692 & 77.615 \\
\hline 2 & 1.106 & 18.433 \\
\hline 3 & 0.14062 & 2.3437 \\
\hline 4 & 0.037662 & 0.6277 \\
\hline 5 & 0.035306 & 0.58844 \\
\hline 6 & 0.023496 & 0.3916 \\
\hline
\end{tabular}

Table 17: loading of the principal components of the theropod PCA

\begin{tabular}{|l|r|r|r|}
\hline & $\mathbf{P C}_{\text {th }} \mathbf{1}$ & $\mathbf{P C}_{\text {th }} \mathbf{2}$ & $\mathbf{P C}_{\text {th }} \mathbf{3}$ \\
\hline H. length & 0.96736 & 0.14083 & -0.14452 \\
\hline R. length & 0.79786 & 0.58806 & 0.0695 \\
\hline U. length & 0.84193 & 0.52477 & 0.028512 \\
\hline F. length & 0.88706 & -0.39879 & -0.19715 \\
\hline T. length & 0.91872 & -0.3621 & -0.00159 \\
\hline mt III & 0.863 & -0.41811 & 0.27426 \\
\hline
\end{tabular}




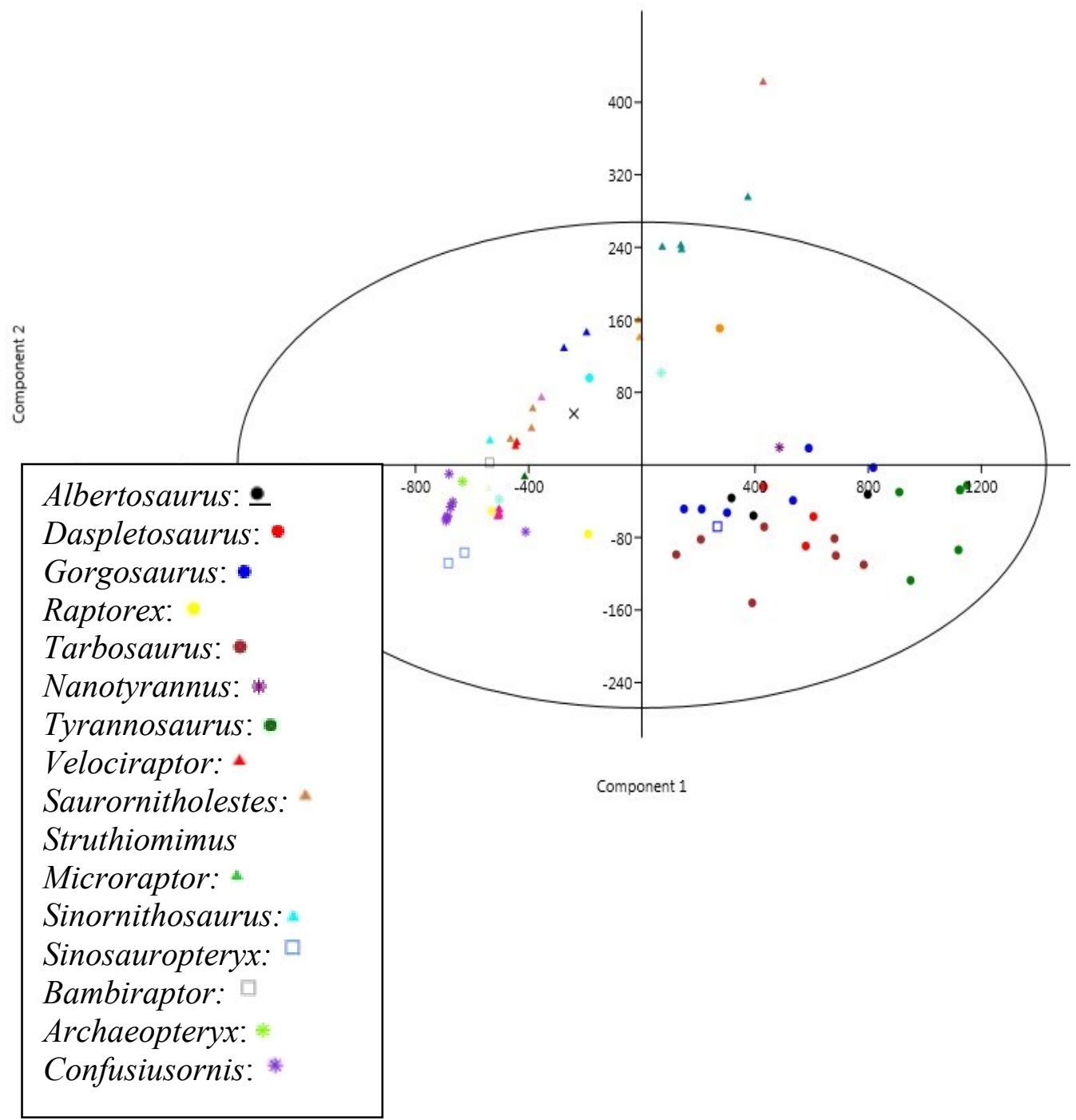

Figure 29: PCA results of all the theropod specimens showing PC 1 and 2. 
Figure 29 shows the plot of $\mathrm{PC}_{\text {th }} 1$ and $\mathrm{PC}_{\text {th }} 2$. $\mathrm{PC}_{\text {th }} 1$ accounts for $77.6 \%$ of the total sample variance. $\mathrm{PC}_{\mathrm{th}} 2$ accounts for $18.4 \%$ (Table16). Component 1 is highly, positively and uniformly correlated with all the variables (Table 17) suggesting that $\mathrm{PC}_{\mathrm{th}} 1$ represents the size variation in the dataset. The radius and ulna lengths show strong and positive loading on $\mathrm{PC}_{\mathrm{th}} 2$. The humerus length shows weak loading on $\mathrm{PC}_{\mathrm{th}} 2$. The femur, tibia and metatarsal III lengths are strongly and negatively correlated with $\mathrm{PC}_{\mathrm{th}} 2$ (Table 17). This shows an inverse correlation between elements of the hindlimb and elements of the forelimb. Two distinct groups can be seen in Figure 32. The small to mid-sized dinosaurs plot on the left-hand side of the graph (the early birds and maniraptorans). The right most group contains all the large bodied theropods (tyrannosaurids). There is some amount of overlap between the two groups. Raptorex plots closer to the left side of the graph, suggesting a smaller size compared to the other tyrannosaurids. The tyrannosaurids are also plotting in the bottom right portion of the graph (negative on the $\mathrm{Y}$ axis), which suggests that they have increased length of the hindlimb and decreased forelimb length. It is well documented that tyrannosaurids have highly reduced forelimbs and powerful hindlimbs (e.g., Sereno et al., 2009; Carpenter and Smith, 1995, Lipkin and Carpenter, 2008). 


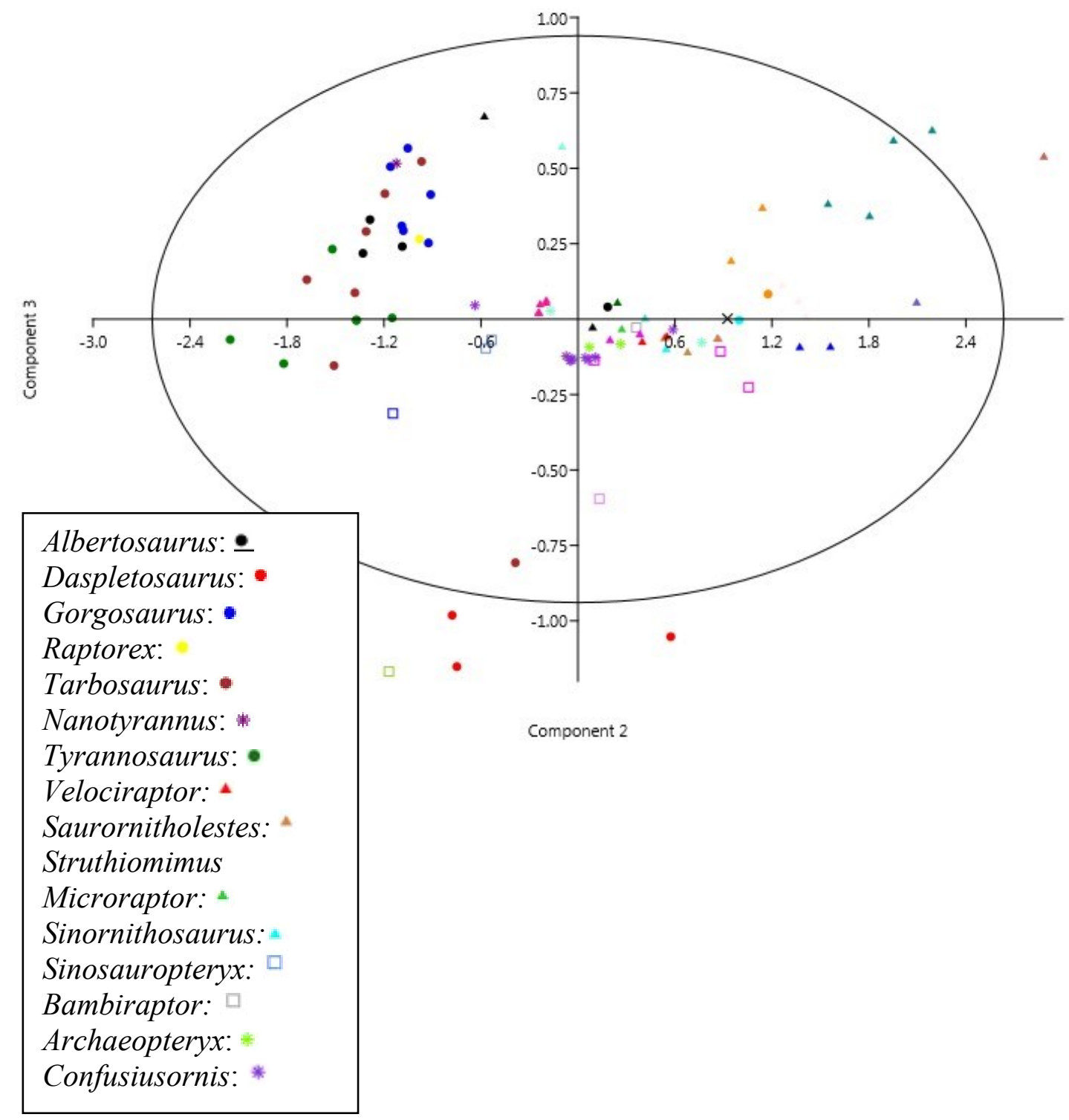

Figure 30: PCA results of all the theropod specimens showing PC 2 and 3. 
Figure 30 shows the results for the second and third components of the theropod PCA analysis. $\mathrm{PC}_{\text {th }} 3$ represents approximately $2.3 \%$ of the total sample variance (Table 16). Metatarsus III has a high and positive loading on $\mathrm{PC}_{\mathrm{th}} 3$. The femora and humeri length have a strong and negative loading on $\mathrm{PC}_{\mathrm{th}} 3$. The other variables do not exhibit significant loading on the component (Table17). This represents an inverse correlation between metatarsus III and the humerus and femur. Specimens plotting on the upper portion of the graph (positive on the $\mathrm{Y}$ axis) will have long metatarsus III and relatively shorter humerus and femurs. Two groups can be seen in Figure 33. Most of the tyrannosaurids (with the exception of Daspletosaurus) plot on the left side of the graph. The group on the right side is composed of the small theropods (maniraptorans and early birds). The tyrannosaurids show less variation along $\mathrm{PC}_{\mathrm{th}} 2$ compared to the small theropods. Most of the tyrannosaurids plot on the upper part of the graph (positive on the $\mathrm{Y}$ axis) suggesting that they exhibit longer metatarsus III. Daspletosaurus and one specimen of Tarbosaurus plot on the bottom part of the graph. The Daspletosaurus specimens plot outside the $95 \%$ confidence interval and are therefore outliers. The three specimens of Daspletosaurus had incomplete measurements of their metatarsus III, radius and ulna. Considering that metatarsus III has the highest loading on $\mathrm{PC}_{\text {th }} 3$ (Table 17), incomplete or missing measurements of metatarsus III would explain why they fall outside the confidence ellipse.

The group on the right side is composed of the smaller theropods (the maniraptorans and early birds). These exhibit higher amounts of variation along 
$\mathrm{PC}_{\mathrm{th}} 2$ compared to the tyrannosaurids. Maniraptorans (and early birds) show greater diversity of body plan compared to tyrannosaurids. This could explain their higher variation along $\mathrm{PC}_{\mathrm{th}} 2$, Some of the small theropod specimens, such as Struthiomimus and Saurornitholestes plot on the upper right portion of the graph. They exhibit larger metatarsus III and proportionally shorter humerus and femora. 


\section{Chapter 4: Discussion}

Most living Aves are taxonomically defined based on legacy diagnoses more than one hundred years old (e.g., Brooks, 1915, Ridgeway and Friedman, 1919). These diagnoses are primarily based on some combination of soft tissue (e.g., plumage/color), behavior (e.g., song type), or size (e.g., Sibley 2003, Edwards 2007, Colwell 2010). In contrast their closest relatives (extinct, nonavian theropods) are diagnosed entirely on hard tissue (skeletal) characters. Since these sets of parameters have almost no overlap between the living and extinct groups, I tested to see if a selected group of skeletal parameters - the basis of all dinosaur diagnoses - could be used to support the distinctions between closely related birds (members of Laridae) showing similar morphologies. The hypothesis was that if the skeletal parameters could not differentiate the examined gulls, then we may be able to hypothesize that closely related, morphologically similar, extinct, non-avian theropods can also not be fully distinguished without access to additional, non-hard tissue features. Thus, the diversity of these extinct clades might be predicted to be much higher than what can be determined from data available from the fossil record alone, assuming the biological species concept.

During this project, six species of gulls (L. argentatus, $L$. delawarensis, L. thayeri, L. glaucescens, L. glaucoides and L. hyperboreus) were analyzed using traditional PCA, as well as, geometric morphometrics to test if selected parameters of the skull and postcrania (femora lengths, width and midshaft 
radius, tarsometatarsi length and widths, tibiotarsi length and widths, humerus lengths and widths, radius length, ulna length and width) could be used to distinguish the taxa. A common explanation for the intraspecific shape variation seen is ontogeny (e.g., Carrier and Leon, 1990; Watanabe and Slice, 2014). As offspring grow to maturity, they undergo changes in the growth of their skeletal elements (e.g., Reece et al., 2013), with mature specimens having larger, betterdeveloped elements. Studies conducted on the ontogeny of terns (e.g., Cane, 1993) show that their hindlimbs grow at elevated rates and comprise higher percent of body weight than forelimbs (Cane, 1993).

The interspecific size variation seen in Figure 15 has been well documented (e.g., Sibley, 2003; Colwell, 2010): Larus delawarensis is known for being a smaller species of gull and $L$. hyperboreus are typically much larger than other species. The highest amount of shape variation $\left(\mathrm{PC}_{g} 3\right.$, Table 2$)$ is captured in the tibiotarsus and it most likely reflects ontogenetic growth (Cane, 1993).

Analysis of shape $\left(\mathrm{PC}_{\mathrm{g}} 2\right.$ and $\mathrm{PC}_{\mathrm{g}} 3$, Fig. 16) indicates that most of the variation is captured in the tarsometatarsus and the tibiotarsus. The results confirm that interspecific variation is very limited and these species are indistinguishable based on the shape of these parameters. Intraspecific shape variation is much more elevated, which may be caused by including varying ontogenetic stages in the analyses. L. delawarensis shows less variation than other species, but still has considerable overlap with the other species.

Separate analyses were then conducted on individual species $L$. argentatus, $L$. delawarensis and $L$. thayeri. The analysis for $L$. argentatus does 
recover its known sexual dimorphism (Figs. 17), with the males plotting on the upper right and females plotting on the lower left. The analysis of $L$. delawarensis and $L$. thayeri did not recover sexual dimorphism, even though it has been reported in these species. Again, in all analyses, most of the variation is recorded in overall size of the skeletal elements. The most significant shape variation (PC2) was recorded in the tarsometatarsus (in L. argentatus and L. thayeri) and in the ulna (in L. delawarensis). Sexual dimorphism has also been reported in other species of gulls, such as the yellow-legged gull (Larus michahellis) (Bosch 1996) and the California gull (Larus californicus) (Schnell et al., 1985). These authors reported that most of the dimorphism was recorded on the skull, specifically on bill depth (Schnell et al., 1985) and skull length (Bosch 1996). In order to further analyze potential dimorphism in gulls, future measurements and analyses should be focused on the cranial region of the specimens.

Select skulls of $L$. argentatus, $L$. delawarensis, $L$. thayeri and $L$. glaucoides were analyzed using landmark-based morphometrics (Figs. 20 - 25) using the dorsal and ventral views. In dorsal view, most of the shape change is seen in the compression and elongation of the skull (both in Figs. 21 and 22). This can be illustrated using deformation grids that show the relative displacement of the landmarks. Specimens plotting on the bottom left of the graph exhibit slight compression towards the anterior of the skull. Those plotting on the lower right shower slightly broader skulls. The specimens plotting on the upper right show slight compression towards the front of the skull (Fig. 21). These variations are very slight and there is considerable overlap between each 
species. Skull length and bill depth have been reported as a source of variation among species and have been used to sex gulls (e.g., Schnell et al., 1985; Bosch 1996).

The morphometrics analyses of the ventral view of the skull (Figs. 24 and 25) show the similar slight variations in shape as did the analysis of the dorsal view. Most of the variation is shown in the antero-posterior compression and expansion of the skull (skull length). The landmarks were selected to try and encompass as much of the shape of the skull as possible. A greater number of landmarks may be required to better show the skull variance. Different sets of landmarks might also be used to show the shape variation of different parts of the skull, such as the bill or the skull roof. Conducting geometric morphometrics on the lateral view of the skull might also show better species differentiation.

The postcranial analysis and cranial geometric morphometric analyses generated similar results indicating that the morphological parameters examined for the six gull species show very little appreciable morphological variation. This probably reflects that most of the gull species examined grow to similar adult sizes and share very similar lifestyles and habitats, e.g., gulls live near water bodies and all have skulls adapted to feed on small macroinvertebrates and fish (e.g., Sibley, 2003; Harris, 1964). Gulls are also very similar genetically and are known to interbreed where their breeding regions overlap (e.g., Hoffman et al., 1978; Mayr 1942). This project did not examine the issue of interbreeding, as the data was not recorded at the time of collection. Hybrids tend to show intermediate phenotypes and can be a significant source of uncertainty for 
taxonomists (e.g., Hoffman et al., 1978; King and Carey, 1999; Barton and Hewitt, 1985). According to the biological species concept, if two populations interbreed freely and successfully wherever they come into contact, then they should be classified as conspecific. L. hyperboreus has been known to hybridize with $L$. argentatus (Vigfúsdóttir, 2008). There is no way of accounting for that when performing morphometrics analyses, as gull hybrids are very similar in morphology to their parents (Chu 2008).

The results presented here show that once size is factored out, modern gull species are difficult to differentiate using the skeletal parameters examined in this project. No interspecific shape variation was identified in either the appendicular skeleton or skulls. My results are consistent with the skeletal analyses results of Chu (1998) and Crochet et al. (2000). Crochet et al., (2000) went a step further and analyzed the phylogenetic relationships of gulls using molecular and plumage data. In that study, most of the gull species (i.e., $L$. argentatus, L. hyperboreus, L. glaucoides, L. delawarensis and L. thayeri) analyzed during the project all group within a homogeneous assemblage known as the 'white headed' gull species, with $L$. delawarensis determined to have originated from a more recent split from this group. My results also indicate the separation of $L$. delawarensis from the other taxa based at least on size and on slight shape variation of the hindlimb (Fig. 15, 16).

Morphometric analyses were conducted on select taxa of theropods to determine the extent of their known skeletal morphological variations. Analyses of the tyrannosaurid subgroup (Figs. 26 and 27; Tables 10 and 11) showed that 
the highest variation was explained by the size of the animals $\left(\mathrm{PC}_{\mathrm{t} y} 1: 92 \%\right)$, which was primarily based on the lengths of their femurs and tibia (Table 10). Tyrannosaurus rex, which was the largest representative of the tyrannosaurids, plotted distinctly from other taxa in this theropod subgroup (e.g., Holtz et al., 2004). All other taxa exhibit significant overlap. In contrast, the shape analysis results indicate that all the theropod specimens, including the $T$. rex specimens plotted in one group with no clear distinction between individual species (Fig. 27). The highest loading is still represented by the femur and tibia (Table 10). Nanotyrannus is differentiated from the other theropod species in both analyses (Figs. 26 and 27). There has been considerable debate on the identity of Nanotyrannus, with most agreeing that it is a juvenile form of Tyrannosaurus rex (e.g., Yun, 2015). The position where this species plots suggests it had considerably longer tibia than femur (Fig. 27; Table 10), which is the immature condition in tyrannosaurids (Currie, 2008). Their tibia becomes proportionally shorter than the femur as their body size increases (Holtz, 2004 1995; Currie, 2008). Tyrannosaurid species are typically differentiated based on cranial characters and elements of the axial skeleton (e.g., Holtz, 2004). The tyrannosaurid species analyzed most likely shared the same ecological niches throughout their histories. Tyrannosaurids most likely filled the roll of top predators and may have occupied many predatory niches between hatchling and adulthood (Foster et al., 2001, Holtz, 2004).

Analysis of the limb elements of the small to medium sized theropods shows that they form relatively tight clusters (figure 28). Archaeopteryx and 
Confuciusornis cluster together on the lower left of the plot. Both taxa are thought to have had adapted either gliding or limited flight abilities (e.g., Zhou et al., 2001; Chatterjee and Templin, 2003). Deinonychus plots on the lower part of the graph, suggesting it had larger and longer forelimbs compared to other species. The compsonganthidSinosauropteryx plots on the upper left of the graph, suggesting it was smaller in size compared to the other species examined and had elongated hindlimbs ( $\mathrm{Ji}$ and $\mathrm{Ji}, 1996)$. The number of specimens for each species was, unfortunately, limited. Most of the specimens in Currie's database were incomplete and had very few measurements taken on them. Only the most complete specimens were analyzed.

The analysis of all theropods (Figs. 29 and 30 ) showed discrimination between the tyrannosaurids and the rest of the theropods (maniraptorans and early birds) based on size and on elements of the forelimb (Table 16). The loading data show that the length of the femur and length of the tibiotarsus are highly correlated with component 1 . This not unexpected because the tyrannosaurids are orders of magnitude larger than the other theropods and have proportionally larger hind legs, explaining why the femora and tibiotarsi show highly positive loading. Tyrannosaurids rely heavily on their hindlimbs for locomotion and, therefore, the selective pressure would be greater on their hindlimbs, suggesting they would have higher morphological variations in their hindlimb elements (e.g., Lipkin and Carpenter, 2008; Sereno et al., 2009).

The smaller theropods (maniraptorans and early birds) plot on the left side of the graph, which is explained by their relatively smaller size. Struthiomimus is 
and ornithomimid and plots away from the other small-bodied theropod species (Fig. 30). The small early birds, Archaeopteryx and Confuciusornis, plot at the bottom part of the group, along with Sinosauropteryx and Velociraptor. It has been suggested that these small theropods used their hindlimbs for hunting prey (especially in Velociraptor) and may even be pack hunters (e.g., Li et al. 2007; Park et al., 2014; Manning et al., 2006). Although Archaeopteryx shares many features with modern birds, there is still debate as to whether it was capable of powered flight (e.g., Ruben, 1993; Speakman, 1993; Nudds et al., 2014; Burger and Chiappe, 1999). It has been suggested that it was capable of short distance flight by running and taking off from the ground (e.g., Speakman, 1993; Ruben, 1991; Longrich et al., 2012; Chatterjee and Templin, 2003). The specimens that plot on the upper part of the graph exhibit longer and differently shaped forearms. Struthiomimus, had highly developed, elongated forelimbs which it may have used for grasping prey (e.g., Nichols and Russell, 1985). The trend seen may indicate differing modes of locomotion or different feeding strategies in the theropod species analyzed. To further explore this, future analyses should include morphological measurements of the skulls (like measurements of jaw joints) to better reflect the lifestyles and feeding behaviour of each species.

Figure 33 shows the final PCA conducted using all theropod material and reflects shape variation. Again, the large bodied theropods were separated from the smaller theropods into two groups. The tyrannosaurids plot on the left side and the small theropods plot on the right. In a morphometrics analysis, comparing PC2 and 3 will typically show the shape variation in the dataset. This 
analysis shows that, as expected, the tyrannosaurids vary significantly in shape compared to the small bodied theropods in the elements measured. The large bodied theropods have significantly larger and more robust hindlimb elements (Gatesy and Middleton, 1997; Dodson, 2004) and appear to group more tightly together than the small bodied theropods. They exhibit variations in the ratios of their femora to humeri lengths. Ratios of femoral length to humerus length can vary from approximately 2.8 in Daspletosaurus to 4.0 in Tarbosaurus (e.g., Holtz, 2004). The loading on $\mathrm{PC}_{\mathrm{th}} 3$ (Table 16) shows that the femora and humeri exhibit the largest amount of variance. The species show significant overlap. However, the Gorgosaurus specimens and Tyrannosaurus plot together. Analyses conducted by Currie (2003) suggests that Gorgosaurus had slightly shorter and lower skulls, shorter ilia, longer tibiae, longer metatarsals and longer toes than tyrannosaurines of similar body sizes. Many studies support a split in Tyrannosauridae between the gracile Albertosaurinae (containing Gorgosaurus) and the more robust Tyrannosaurinae (containing Tyrannosaurus) (e.g., Currie, 2003; Holtz 2004; Paul, 1988). Tyrannosaurus and Gorgosaurus were split to account for these differences. The Daspletosaurus specimens all fell outside the $95 \%$ confidence interval. A lot of the measurements were missing from several elements, including the femur and humerus. This would explain why they are outliers.

The smaller maniraptorans plot together and show more variation in shape than the tyrannosaurids. As discussed previously, the species included in this analysis occupied varied ecological niches and had a wide variety of locomotor 
modes. Some, like Archaeopteryx and Confuciusornis, were quite small and were possibly fliers or gliders. Others, like Saurornitholestes, had elongated hindlimbs and forelimbs and had specialized grasping claws for catching prey. The Ornithomimids, Struthiomimus and Ornithomimus, are separated from the other small bodied theropods based on elements of the hindlimb (femur and metatarsus III). They both belong to the Ornithomimosauria clade (Makovicky et al., 2004, Nicholls 1984) and are characterized by having elongate and slender forelimbs with non-raptorial manus and elongated hindlimbs adapted for fast running (Makovicky et al., 2004). The specimens plotting below the origin are members of Dromaeosauridae (like Velociraptor and Deinonychus) and Avialae (like Archaeopteryx and Confuciusornis). These species exhibit morphological characters adapted for active, predatory behavior. For example, Velociraptor and Deinonychus have a hyper-extendable claw on the second toe, which was most likely used for attacking preys (e.g., Norell and Makovicky, 2004; KielanJaworwaska and Barsbold, 1972).

The results of the analyses show that shape variation in gulls is very conserved in the skeletal elements. They are genetically very similar and have very similar feeding behaviors. Gulls are morphologically too similar to be separated based on the shape of their elements. Analyzing similar elements in theropods show that size has a large impact on their variation (e.g., Fig. 27), but that shape of limb elements can distinguish more distantly related species (e.g., Fig. 33). These variations in limb shape and proportion have been attributed to different lifestyles and ecological niches (e.g., Holtz 2004; Makovicky, 2004; 
Gatesy and Middleton, 1997). Species that share very similar lifestyles will exhibit overlaps in their skeletal morphologies and adaptations (e.g., Gatesy and Middleton, 1997; McGowan and Dyke, 2007). Even so, skeletal elements in the fossils will most likely not be able to account for species that are genetically (and morphologically) very similar. If the reproductive and molecular information of the gulls analyzed was not provided (and if the identity of the skeletons were unknown), it would become very difficult to quantitatively differentiate them using the limb elements. Larus delawarensis would be the most apparent differentiation based on its smaller size (Fig. 15). In the fossil record, size differences in a fossil group is usually attributed to sexual dimorphism (e.g., Chapman et al., 1997; Molnar 2005; Raath et al., 1990). Clearly, soft tissue and breeding potential are key aspects in species recognition.

\section{Conclusions}

The hypothesis to be tested for this project was whether closely related species of gulls could be differentiated exclusively based on their skeletal morphology. Based on the results of the PCA, the null hypothesis cannot rejected; closely related gull species sharing similar morphologies in their appendicular skeleton and skulls cannot be differentiated based on skeletal parameters examined in this project. This result is supported by the recent work of Chamero et al. 2013 who conducted a geometric morphometric analysis of pectoral girdle and forelimb variation in several extant taxa of Crocodylia, the closest living relatives of extinct, non-avian+avian dinosaurs. Their results 
demonstrated that intraspecific variation in the limbs and pectoral element is very large, but that the interspecific variation is small or significant. They also show a high degree of overlap in forelimb shape between closely related crocodylians. Similar to modern birds, recognition of closely related crocodile species using skeletal anatomy has long been problematic (e.g., Eaton et al., 2009; King and Burke, 1989; Ross, 2006). Crocodiles have highly conserved morphology (e.g., Shirley et al., 2013) and taxonomic analyses rely more heavily on molecular data (e.g., Eaton et al., 2009; Dever et al., 2002; Hekkala, 2004).

My results show that gulls exhibit higher intraspecific variation in limbs and less interspecific variation (Figs. 15 and 16). Although this is a small data set, when combined with the results of the other avian, and non-avian dinosaur analyses (and from previous analyses of Crocodylia), it suggests that a percentage of modern archosaur diversity can actually only be recognized through the soft-tissue and behavioral characteristics that are not preserved in extinct dinosaurs. I would thus suggest that our understanding of the true diversity of non-avian theropods is hampered by our lack of non-skeletal characteristics for these animals. If the gulls being analyzed in this project were found as fossils, they would most likely not be recognized as separate taxa. The size difference of $L$. delawarensis would most likely be attributed to ontogeny or sexual dimorphism. Further analysis of the material is needed. Similar to the theropod analysis (e.g., Fig. 30), more distantly related species of shorebirds should be analyzed along with the gulls (e.g., the gulls and the skuas or terns). This analysis would give further insight into the extent of morphological variations 
of related species. Gulls should also be analyzed and compared with other, distantly related birds of similar size (e.g., ducks or mallards). 


\section{Appendices}

\section{Appendix A Averaged measurements for the gull specimens}

\begin{tabular}{|c|c|c|c|c|c|c|c|c|c|c|c|c|}
\hline & 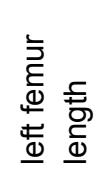 & 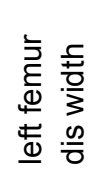 & 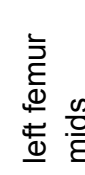 & 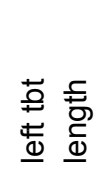 & 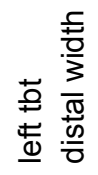 & 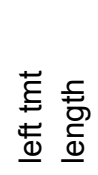 & 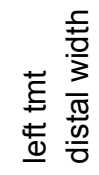 & 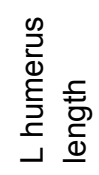 & 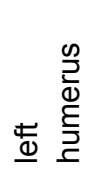 & 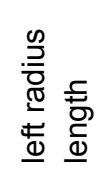 & 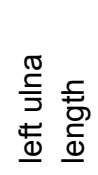 & 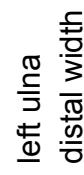 \\
\hline $\mathrm{z144}$ & 58.1 & 12.4 & 5.2 & 111.8 & 17.8 & 65.0 & 11.6 & 134.0 & 17.5 & 143.1 & 149.0 & 13.9 \\
\hline$s 5969$ & 56.0 & 11.2 & 4.8 & 109.4 & 16.4 & 62.8 & 10.5 & 129.3 & 16.8 & 138.8 & 143.9 & 13.8 \\
\hline s3784 & 57.4 & 11.9 & 5.0 & 113.1 & 17.0 & 67.8 & 10.6 & 129.9 & 17.8 & 140.7 & 145.9 & 14.1 \\
\hline s3787 & 57.1 & 11.5 & 4.8 & 106.7 & 17.2 & 63.7 & 11.3 & 126.6 & 17.3 & 135.4 & 140.2 & 13.9 \\
\hline s3790 & 59.6 & 11.7 & 5.0 & 113.4 & 17.0 & 66.6 & 10.7 & 131.6 & 17.2 & 143.5 & 145.0 & 13.5 \\
\hline s3789 & 0.6 & 11.6 & 5.0 & 14.7 & 16.3 & 68.5 & 10.5 & 131.4 & 17.6 & 145.1 & 148.4 & 13.6 \\
\hline s3788 & 7.2 & 11.3 & 4.6 & 77.1 & 15.7 & 61.4 & 10.7 & 131.0 & 17.5 & 136.7 & 141.5 & 13.3 \\
\hline s37k & 3.1 & .1 & 5.6 & .4 & 8.3 & 3.6 & 1.1 & 7.6 & 8.4 & 6 & 54.8 & 14.6 \\
\hline s484 & 0.5 & 12.4 & 5.0 & 1.7 & 6.8 & 4.0 & 11.4 & 33.9 & 7.4 & 39.6 & 44.3 & 13.5 \\
\hline S2153 & 62.5 & 12.5 & 5.3 & 15.9 & 18.6 & 70.0 & 12.6 & 133.5 & 17.8 & 144.3 & 148.9 & 14.4 \\
\hline $\mathrm{S} 1090$ & 56.2 & 12.0 & 5.1 & 108.3 & 17.3 & 62.1 & 12.8 & 125.8 & 17.6 & 135.4 & 140.9 & 14.2 \\
\hline S2152 & 64.5 & 13.5 & 4.7 & 122.3 & 19.1 & 72.8 & 12.6 & 130.0 & 17.5 & 145.0 & 142.0 & 15.3 \\
\hline S1099 & 60.1 & 11.0 & 4.7 & 107.5 & 16.6 & 65.1 & 10.9 & 131.6 & 17.2 & 139.8 & 144.8 & 14.1 \\
\hline S680 & 56.9 & 11.2 & 4.6 & 109.3 & 16.7 & 64.3 & 11.5 & 129.6 & 16.5 & 139.1 & 143.8 & 13.2 \\
\hline S1084 & 61.1 & 12.5 & 5.3 & 111.3 & 17.7 & 67.2 & 11.7 & 135.1 & 18.7 & 144.2 & 149.1 & 15.4 \\
\hline S3780 & 3.3 & 11.5 & 4.7 & 87.6 & 16.3 & 61.4 & 10.9 & 134.0 & 18.0 & 134.8 & 139.6 & 14.1 \\
\hline S5845 & 5.8 & 11.6 & 4.8 & 84.9 & 15.7 & 61.0 & 10.6 & 125.3 & 18.0 & 136.8 & 142.7 & 14.2 \\
\hline S5919 & 7.0 & 12.1 & 5.1 & 110.2 & 16.6 & 63.1 & 11.3 & 131.5 & 17.6 & 138.7 & 143.9 & 14.3 \\
\hline S5912 & 6.3 & 8.9 & 3.7 & 09.9 & 12.9 & 56.6 & 8.5 & 05.1 & 13.2 & 113.2 & 117.4 & 10.7 \\
\hline S6060 & .9 & 8.5 & 3.2 & 81.9 & 11.6 & 50.9 & 8.3 & 91.7 & 12.6 & 112.4 & 117.2 & 12.0 \\
\hline S5814 & 41.0 & 8.0 & 3.2 & 83.2 & 11.5 & 52.2 & 7.7 & 93.4 & 11.8 & 105.6 & 107.8 & 8.6 \\
\hline S5917 & 43.3 & 8.7 & 3.5 & 89.0 & 12.9 & 56.4 & 7.7 & 101.6 & 12.8 & 110.7 & 114.6 & 10.3 \\
\hline S5079 & 45.0 & 9.0 & 3.7 & 91.6 & 13.1 & 58.1 & 8.5 & 101.6 & 12.9 & 114.1 & 117.0 & 10.2 \\
\hline S5560 & 46.8 & 9.4 & 4.0 & 93.8 & 13.1 & 59.9 & 8.9 & 103.6 & 13.8 & 115.5 & 119.9 & 11.1 \\
\hline S5321 & 47.4 & 10.2 & 4.0 & 93.2 & 14.0 & 61.1 & 8.4 & 105.0 & 14.1 & 115.2 & 119.3 & 11.2 \\
\hline s6165 & 41.6 & 8.1 & 3.5 & 81.3 & 12.5 & 53.7 & 8.1 & 93.0 & 12.4 & 104.6 & 108.2 & 10.3 \\
\hline S3766 & 43.3 & 8.4 & 3.5 & 86.5 & 12.8 & 53.3 & 7.6 & 96.0 & 12.1 & 105.3 & 108.9 & 10.3 \\
\hline S3769 & 48.1 & 9.2 & 3.6 & 93.2 & 13.6 & 59.1 & 8.8 & 105.7 & 14.0 & 115.8 & 120.9 & 10.8 \\
\hline S3777 & 46.2 & 9.1 & 3.5 & 90.2 & 12.9 & 56.9 & 8.4 & 99.7 & 13.0 & 109.0 & 112.9 & 10.8 \\
\hline S3737 & 44.4 & 8.7 & 3.4 & 87.0 & 13.1 & 54.9 & 8.8 & 99.4 & 13.3 & 110.3 & 113.7 & 10.7 \\
\hline S3758 & 44.3 & 7.7 & 3.3 & 85.6 & 12.2 & 54.0 & 7.9 & 96.7 & 12.2 & 104.1 & 107.8 & 12.6 \\
\hline
\end{tabular}




\begin{tabular}{|c|c|c|c|c|c|c|c|c|c|c|c|c|}
\hline & 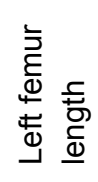 & 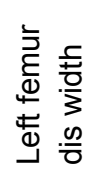 & 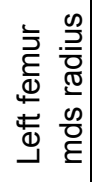 & 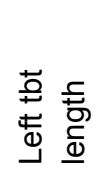 & 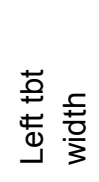 & 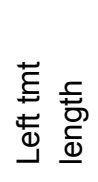 & 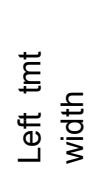 & 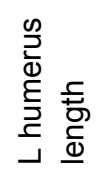 & 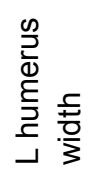 & 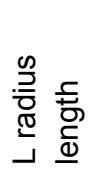 & 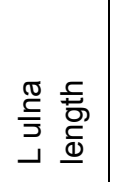 & 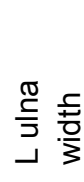 \\
\hline S3748 & 46.4 & 9.3 & 3.8 & 93.1 & 13.6 & 59.0 & 9.0 & 105.3 & 13.7 & 115.4 & 119.8 & 11.5 \\
\hline ROM108931 & 56.9 & 12.3 & 4.9 & 106.4 & 17.8 & 61.3 & 11.3 & 124.4 & 17.4 & 133.0 & 137.4 & 14.1 \\
\hline ROM108932 & 61.8 & 13.2 & 5.1 & 118.1 & 19.2 & 70.5 & 12.5 & 138.7 & 18.3 & 152.3 & 160.7 & 15.3 \\
\hline ROM015149 & 57.0 & 11.2 & 4.8 & 108.4 & 17.6 & 62.8 & 11.1 & 126.3 & 17.6 & 135.6 & 140.6 & 14.4 \\
\hline $\begin{array}{l}\text { ROM015125 } \\
2\end{array}$ & 56.1 & 11.4 & 4.6 & 106.1 & 17.3 & 60.9 & 11.2 & 122.6 & 16.6 & 128.6 & 132.4 & 13.7 \\
\hline Rom115403 & 58.5 & 12.0 & 5.2 & 110.2 & 17.8 & 65.2 & 10.9 & 126.1 & 17.4 & 137.2 & 140.9 & 14.4 \\
\hline ROM115408 & 58.4 & 12.1 & 4.7 & 112.7 & 18.1 & 66.3 & 11.6 & 128.4 & 17.7 & 136.1 & 141.4 & 14.7 \\
\hline ROM158134 & 55.2 & 11.1 & 4.3 & 104.5 & 15.3 & 59.1 & 9.9 & 119.8 & 15.9 & 129.3 & 134.2 & 13.6 \\
\hline $\begin{array}{l}\text { ROM015128 } \\
3\end{array}$ & 55.4 & 11.0 & 4.7 & 103.1 & 16.6 & 54.1 & 10.1 & 117.5 & 16.3 & 125.9 & 130.4 & 13.6 \\
\hline $\begin{array}{l}\text { ROM015126 } \\
2\end{array}$ & 52.6 & 10.9 & 4.5 & 102.0 & 14.4 & 56.5 & 10.7 & 113.4 & 16.3 & 120.3 & 125.3 & 14.1 \\
\hline ROM124926 & 60.0 & 12.0 & 4.8 & 114.2 & 17.6 & 66.2 & 10.2 & 130.0 & 18.0 & 139.4 & 145.0 & 14.8 \\
\hline ROM124924 & 53.5 & 10.9 & 4.9 & 104.3 & 15.6 & 60.9 & 10.5 & 121.8 & 16.5 & 129.6 & 134.3 & 14.0 \\
\hline ROM125735 & 55.4 & 11.2 & 4.6 & 104.1 & 16.3 & 60.5 & 10.3 & 118.7 & 15.9 & 127.4 & 130.8 & 13.2 \\
\hline ROM124925 & 57.0 & 11.4 & 4.6 & 105.2 & 16.7 & 60.6 & 10.5 & 121.4 & 16.5 & 130.5 & 134.6 & 13.9 \\
\hline ROM125437 & 55.0 & 10.7 & 4.3 & 102.2 & 16.2 & 58.3 & 10.2 & 118.7 & 16.2 & 126.6 & 131.3 & 13.1 \\
\hline ROM125436 & 58.3 & 11.7 & 4.8 & 110.9 & 15.9 & 66.6 & 11.0 & 127.4 & 17.8 & 136.9 & 141.6 & 14.7 \\
\hline S2154 & 55.5 & 11.6 & 4.4 & 104.3 & 16.3 & 59.3 & 10.8 & 124.0 & 16.8 & 132.1 & 136.9 & 14.0 \\
\hline S6055 & 59.3 & 12.0 & 4.6 & 113.4 & 17.9 & 65.8 & 11.0 & 130.9 & 17.4 & 138.0 & 142.7 & 14.0 \\
\hline S1785 & 57.9 & 11.4 & 4.5 & 107.0 & 16.2 & 64.1 & 10.7 & 124.4 & 16.7 & 133.2 & 136.1 & 13.8 \\
\hline S563 & 66.8 & 13.7 & 5.9 & 126.8 & 19.3 & 70.4 & 13.6 & 155.1 & 21.5 & 165.8 & 170.5 & 17.5 \\
\hline S2151 & 67.0 & 14.0 & 5.3 & 122.1 & 16.2 & 71.7 & 12.7 & 141.2 & 19.6 & 149.7 & 155.5 & 17.1 \\
\hline S5853 & 60.6 & 13.3 & 5.5 & 117.7 & 18.4 & 64.2 & 12.3 & 144.5 & 18.2 & 156.5 & 155.5 & 16.0 \\
\hline $\begin{array}{l}\text { ROM015126 } \\
0\end{array}$ & 72.2 & 14.7 & 5.5 & 132.6 & 21.4 & 76.2 & 14.0 & 154.4 & 21.5 & 165.8 & 172.4 & 17.6 \\
\hline $\begin{array}{l}\text { ROM015126 } \\
6\end{array}$ & 70.4 & 15.1 & 6.5 & 132.3 & 22.3 & 74.6 & 13.7 & 155.1 & 21.5 & 167.5 & \begin{tabular}{|l|}
170.0 \\
\end{tabular} & 17.5 \\
\hline $\begin{array}{l}\text { ROM015126 } \\
3\end{array}$ & 70.5 & 14.8 & 5.9 & 132.1 & 21.3 & 74.8 & 13.2 & 153.6 & 20.9 & 162.2 & 165.7 & 17.1 \\
\hline S930 & 69.4 & 14.8 & 5.5 & 130.8 & 21.3 & 74.9 & 13.4 & 149.7 & 19.7 & 156.5 & 170.5 & 15.6 \\
\hline S564 & 66.7 & 13.7 & 5.5 & 127.7 & 20.1 & 70.4 & 13.5 & 144.3 & 18.2 & 155.0 & 155.5 & 15.2 \\
\hline S2155 & 66.9 & 13.9 & 5.3 & 122.7 & 16.4 & 71.9 & 12.6 & 141.2 & 19.5 & 149.7 & 155.5 & 16.2 \\
\hline S5586 & 64.1 & 13.1 & 5.6 & 119.2 & 18.8 & 66.5 & 11.9 & 140.2 & 19.2 & 152.1 & 155.5 & 15.9 \\
\hline S3791 & 58.5 & 11.9 & 4.5 & 107.1 & 17.5 & 60.8 & 11.1 & 124.7 & 17.3 & 130.4 & 134.2 & 14.5 \\
\hline S893 & 61.8 & 10.9 & 4.8 & 96.2 & 16.4 & 56.8 & 10.4 & 113.1 & 16.0 & 117.8 & 122.5 & 13.3 \\
\hline S7955 & 66.9 & 13.8 & 5.5 & 130.3 & 20.9 & 75.6 & 12.3 & 142.6 & 18.7 & 150.1 & 154.7 & 15.3 \\
\hline S5532 & 56.9 & 11.3 & 4.5 & 108.0 & 16.9 & 63.2 & 10.5 & 119.5 & 16.4 & 129.0 & 133.7 & 13.5 \\
\hline S5531 & 62.5 & 12.7 & 5.3 & 120.8 & 19.6 & 68.9 & 12.0 & 131.2 & 18.0 & 139.9 & 145.0 & 14.0 \\
\hline
\end{tabular}




\begin{tabular}{|l|l|l|l|l|l}
\hline 56.9 & 11.7 & 4.6 & 108.5 & 17.3 & 62.8 \\
\hline
\end{tabular}

\begin{tabular}{|l|l|}
\hline 62.8 & 10 \\
\hline
\end{tabular}

\begin{tabular}{|l|l|l|l|l}
\hline 0.9 & 117.5 & 15.0 & 125.0 & 12 \\
\hline
\end{tabular}




\section{Appendix B Standardized gull measurements}

\begin{tabular}{|c|c|c|c|c|c|c|c|c|c|c|c|c|}
\hline & 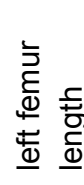 & 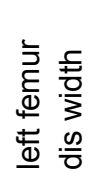 & 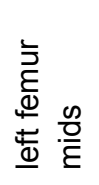 & 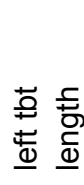 & 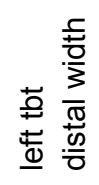 & $\begin{array}{l}\vec{E} \\
\underline{F} \\
\underline{\underline{E}} \\
\underline{\underline{\omega}}\end{array}$ & 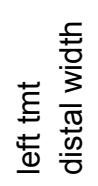 & & 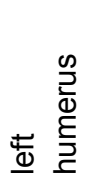 & 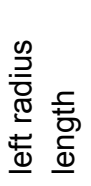 & 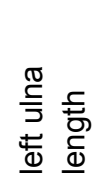 & 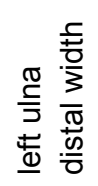 \\
\hline z144 & 0.2 & 0.2 & 0.7 & 0.3 & 0.5 & 0.3 & 0.5 & 0.6 & 0.3 & 0.5 & 0.6 & 0.1 \\
\hline s5969 & -0.1 & -0.5 & 0.2 & 0.1 & -0.1 & -0.1 & -0.2 & 0.3 & 0.0 & 0.3 & 0.3 & 0.1 \\
\hline s3784 & 0.1 & 0.2 & 0.4 & 0.4 & 0.2 & 0.7 & -0.1 & 0.3 & 0.4 & 0.4 & 0.5 & 0.2 \\
\hline s3787 & 0.0 & 0.0 & 0.1 & -0.1 & 0.2 & 0.0 & 0.3 & 0.1 & 0.2 & 0.1 & 0.1 & 0.1 \\
\hline s3790 & 0.4 & 0.1 & 0.4 & 0.4 & 0.2 & 0.5 & -0.1 & 0.4 & 0.2 & 0.6 & 0.4 & -0.1 \\
\hline s3789 & 0.5 & 0.0 & 0.4 & 0.5 & -0.1 & 0.8 & -0.2 & 0.4 & 0.4 & 0.7 & 0.6 & -0.1 \\
\hline s3788 & 0.1 & -0.1 & -0.1 & -0.1 & -0.4 & -0.3 & -0.1 & 0.4 & 0.3 & 0.2 & 0.2 & -0.3 \\
\hline s3783 & 0.8 & 0.7 & 1.1 & 0.7 & 0.7 & 1.6 & 0.2 & 0.8 & 0.7 & 0.9 & 1.0 & 0.5 \\
\hline s484 & 0.5 & 0.5 & 0.4 & 0.3 & 0.1 & 0.1 & 0.4 & 0.6 & 0.3 & 0.3 & 0.4 & -0.1 \\
\hline S2153 & 0.7 & 0.6 & 0.8 & 0.6 & 0.8 & 1.0 & 1.1 & 0.5 & 0.4 & 0.6 & 0.6 & 0.3 \\
\hline S1090 & -0.1 & 0.3 & 0.6 & 0.0 & 0.3 & -0.2 & 1.3 & 0.1 & 0.4 & 0.1 & 0.2 & 0.2 \\
\hline S2152 & 1.0 & 1.1 & 0.0 & 1.1 & 1.0 & 1.5 & 1.1 & 0.3 & 0.3 & 0.7 & 0.2 & 0.8 \\
\hline S1099 & 0.4 & -0.3 & 0.0 & 0.0 & 0.0 & 0.3 & 0.1 & 0.4 & 0.2 & 0.3 & 0.4 & 0.2 \\
\hline S680 & 0.0 & -0.2 & -0.1 & 0.1 & 0.0 & 0.1 & 0.5 & 0.3 & -0.1 & 0.3 & 0.3 & -0.3 \\
\hline S1084 & 0.6 & 0.5 & 0.8 & 0.3 & 0.5 & 0.6 & 0.6 & 0.6 & 0.8 & 0.6 & 0.7 & 0.9 \\
\hline S3780 & 0.2 & 0.0 & 0.0 & 0.0 & -0.1 & $\begin{array}{l}-0.3 \\
\end{array}$ & 0.1 & 0.6 & 0.5 & 0.0 & 0.1 & 0.2 \\
\hline S5845 & 0.0 & 0.0 & 0.1 & -0.2 & -0.3 & -0.4 & -0.1 & 0.0 & 0.5 & 0.2 & 0.3 & 0.2 \\
\hline S5919 & 0.0 & 0.3 & 0.5 & 0.2 & 0.0 & -0.1 & 0.3 & 0.4 & 0.4 & 0.3 & 0.3 & 0.3 \\
\hline S5912 & -1.4 & -1.4 & -1.3 & -1.4 & -1.5 & -1.1 & -1.4 & -1.2 & -1.5 & -1.3 & -1.3 & -1.6 \\
\hline S6060 & -2.1 & $\begin{array}{l}-1.7 \\
\end{array}$ & $\begin{array}{l}-2.0 \\
\end{array}$ & -2.0 & -2.0 & $\begin{array}{l}-2.0 \\
\end{array}$ & $\begin{array}{l}-1.6 \\
\end{array}$ & $\begin{array}{l}-2.0 \\
\end{array}$ & -1.7 & $\begin{array}{l}-1.3 \\
\end{array}$ & $\begin{array}{l}-1.3 \\
\end{array}$ & $\begin{array}{l}-0.9 \\
\end{array}$ \\
\hline S5814 & -2.1 & -2.0 & -2.0 & -1.9 & -2.0 & $\begin{array}{l}-1.8 \\
\end{array}$ & -1.9 & -1.9 & -2.1 & -1.7 & -1.9 & -2.7 \\
\hline S5917 & -1.8 & -1.6 & -1.6 & -1.4 & -1.5 & -1.1 & -1.9 & -1.4 & -1.6 & -1.4 & -1.5 & -1.8 \\
\hline S5079 & -1.5 & -1.4 & -1.3 & -1.2 & -1.4 & -0.9 & -1.4 & -1.4 & -1.6 & -1.2 & -1.3 & -1.8 \\
\hline S5560 & $\begin{array}{l}-1.3 \\
\end{array}$ & $\begin{array}{l}-1.2 \\
\end{array}$ & -0.9 & -1.1 & $\begin{array}{l}-1.4 \\
\end{array}$ & $\begin{array}{l}-0.6 \\
\end{array}$ & $\begin{array}{l}-1.2 \\
\end{array}$ & $\begin{array}{l}-1.3 \\
\end{array}$ & $\begin{array}{l}-1.2 \\
\end{array}$ & $\begin{array}{l}-1.1 \\
\end{array}$ & -1.1 & $\begin{array}{l}-1.4 \\
\end{array}$ \\
\hline S5321 & -1.2 & -0.7 & -0.9 & -1.1 & -1.0 & -0.4 & -1.5 & -1.2 & -1.1 & -1.2 & -1.2 & -1.3 \\
\hline s6165 & -2.0 & -1.9 & -1.7 & -2.0 & -1.7 & -1.6 & -1.7 & -1.9 & -1.8 & -1.8 & -1.9 & -1.8 \\
\hline S3766 & $\begin{array}{l}-1.8 \\
\end{array}$ & $\begin{array}{l}-1.8 \\
\end{array}$ & $\begin{array}{l}-1.6 \\
\end{array}$ & -1.6 & $\begin{array}{l}-1.5 \\
\end{array}$ & $\begin{array}{l}-1.6 \\
\end{array}$ & $\begin{array}{l}-2.0 \\
\end{array}$ & $\begin{array}{l}-1.8 \\
\end{array}$ & $\begin{array}{l}-2.0 \\
\end{array}$ & $\begin{array}{l}-1.8 \\
\end{array}$ & -1.8 & $\begin{array}{l}-1.8 \\
\end{array}$ \\
\hline S3769 & -1.1 & -1.3 & -1.5 & -1.1 & $\begin{array}{l}-1.2 \\
\end{array}$ & -0.7 & -1.2 & -1.2 & $\begin{array}{l}-1.2 \\
\end{array}$ & $\begin{array}{l}-1.1 \\
\end{array}$ & -1.1 & $\begin{array}{l}-1.5 \\
\end{array}$ \\
\hline S3777 & -1.4 & -1.4 & -1.6 & -1.4 & -1.5 & -1.0 & -1.5 & -1.5 & -1.6 & -1.5 & -1.6 & -1.5 \\
\hline S3737 & -1.6 & -1.6 & -1.8 & -1.6 & -1.4 & -1.4 & -1.3 & -1.6 & -1.4 & -1.5 & -1.5 & -1.6 \\
\hline S3758 & -1.6 & -2.1 & -1.9 & -1.7 & -1.8 & -1.5 & -1.8 & -1.7 & -1.9 & -1.8 & -1.9 & -0.6 \\
\hline S3748 & -1.4 & -1.2 & $\begin{array}{l}-1.2 \\
\end{array}$ & -1.1 & -1.2 & -0.7 & -1.1 & -1.2 & $\begin{array}{l}-1.3 \\
\end{array}$ & $\begin{array}{l}-1.1 \\
\end{array}$ & -1.1 & $\begin{array}{l}-1.2 \\
\end{array}$ \\
\hline ROM108931 & 0.0 & 0.4 & 0.2 & -0.1 & 0.5 & -0.4 & 0.3 & 0.0 & 0.2 & -0.1 & -0.1 & 0.2 \\
\hline ROM108932 & 0.6 & 1.0 & 0.6 & 0.8 & 1.0 & 1.1 & 1.0 & 0.9 & 0.6 & 1.1 & 1.4 & 0.8 \\
\hline
\end{tabular}




\begin{tabular}{|c|c|c|c|c|c|c|c|c|c|c|c|c|}
\hline ROM015149 & 0.0 & -0.2 & 0.1 & 0.0 & 0.4 & -0.1 & 0.2 & 0.1 & 0.3 & 0.1 & 0.1 & 0.3 \\
\hline & 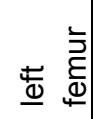 & 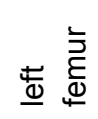 & 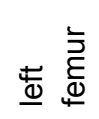 & 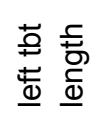 & 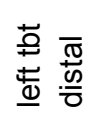 & $\begin{array}{l}\overrightarrow{\underline{\xi}}=5 \\
\underline{\underline{0}} \\
\underline{\underline{\omega}} \underline{\underline{\sigma}}\end{array}$ & 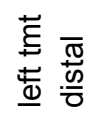 & 比 & 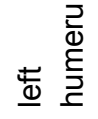 & 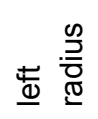 & $\underline{\frac{\mathbb{W}}{\omega}} \frac{\sigma}{5}$ & $\stackrel{\mathbb{E}}{\underline{\mathbb{E}}} \frac{\mathbb{\sigma}}{J}$ \\
\hline $\begin{array}{l}\text { ROM015125 } \\
2\end{array}$ & -0.1 & -0.1 & -0.1 & -0.1 & 0.3 & -0.4 & 0.3 & -0.1 & -0.1 & -0.3 & -0.4 & 0.0 \\
\hline Rom115403 & 0.2 & 0.3 & 0.7 & 0.2 & 0.5 & 0.3 & 0.0 & 0.1 & 0.3 & 0.2 & 0.1 & 0.3 \\
\hline ROM115408 & 0.2 & 0.3 & 0.0 & 0.4 & 0.6 & 0.4 & 0.5 & 0.2 & 0.4 & 0.1 & 0.2 & 0.5 \\
\hline ROM158134 & -0.2 & -0.3 & -0.5 & -0.3 & -0.5 & -0.7 & -0.6 & -0.3 & -0.4 & -0.3 & -0.3 & -0.1 \\
\hline $\begin{array}{l}\text { ROM015128 } \\
3\end{array}$ & -0.2 & -0.3 & 0.0 & -0.4 & 0.0 & -1.5 & -0.5 & -0.4 & -0.2 & -0.5 & -0.5 & -0.1 \\
\hline $\begin{array}{l}\text { ROM015126 } \\
2\end{array}$ & -0.5 & -0.3 & -0.3 & -0.4 & -0.9 & -1.1 & -0.1 & -0.7 & -0.2 & -0.8 & -0.8 & 0.2 \\
\hline ROM124926 & 0.4 & 0.3 & 0.1 & 0.5 & 0.4 & 0.4 & -0.4 & 0.3 & 0.5 & 0.3 & 0.4 & 0.6 \\
\hline ROM124924 & -0.4 & -0.3 & 0.2 & -0.3 & -0.4 & -0.4 & -0.2 & -0.2 & -0.1 & -0.3 & -0.3 & 0.1 \\
\hline ROM125735 & -0.2 & -0.1 & -0.1 & -0.3 & -0.1 & -0.5 & -0.3 & -0.4 & -0.4 & -0.4 & -0.5 & -0.3 \\
\hline ROM124925 & 0.0 & -0.1 & -0.1 & -0.2 & 0.1 & -0.5 & -0.2 & -0.2 & -0.1 & -0.2 & -0.2 & 0.1 \\
\hline ROM125437 & -0.2 & -0.5 & -0.6 & -0.4 & -0.1 & -0.8 & -0.4 & -0.4 & -0.2 & -0.5 & -0.4 & -0.3 \\
\hline ROM125436 & 0.2 & 0.1 & 0.1 & 0.2 & -0.3 & 0.5 & 0.1 & 0.2 & 0.5 & 0.2 & 0.2 & 0.5 \\
\hline S2154 & -0.2 & 0.0 & -0.3 & -0.3 & -0.1 & -0.7 & 0.0 & 0.0 & 0.0 & -0.1 & -0.1 & 0.1 \\
\hline S6055 & 0.3 & 0.3 & -0.1 & 0.4 & 0.5 & 0.4 & 0.1 & 0.4 & 0.3 & 0.2 & 0.3 & 0.1 \\
\hline S1785 & 0.1 & 0.0 & -0.3 & -0.1 & -0.2 & 0.1 & -0.1 & 0.0 & 0.0 & -0.1 & -0.1 & 0.0 \\
\hline S563 & 1.3 & 1.2 & 1.5 & 1.5 & 1.1 & 1.1 & 1.7 & 1.9 & 2.0 & 1.9 & 2.0 & 2.0 \\
\hline S2151 & 1.3 & 1.4 & 0.8 & 1.1 & -0.2 & 1.3 & 1.2 & 1.0 & 1.2 & 1.0 & 1.0 & 1.7 \\
\hline S5853 & 0.5 & 1.0 & 1.0 & 0.8 & 0.7 & 0.1 & 1.0 & 1.2 & 0.6 & 1.4 & 1.0 & 1.2 \\
\hline $\begin{array}{l}\text { ROM015126 } \\
0\end{array}$ & 2.0 & 1.8 & 1.1 & 1.9 & 2.0 & 2.0 & 2.0 & 1.8 & 2.0 & 1.9 & 2.1 & 2.0 \\
\hline $\begin{array}{l}\text { ROM015126 } \\
6\end{array}$ & 1.8 & 2.0 & 2.4 & 1.9 & 2.3 & 1.8 & 1.8 & 1.9 & 2.0 & 2.0 & 1.9 & 2.0 \\
\hline $\begin{array}{l}\text { ROM015126 } \\
3\end{array}$ & 1.8 & 1.9 & 1.6 & 1.9 & 1.9 & 1.8 & 1.5 & 1.8 & 1.7 & 1.7 & 1.7 & 1.7 \\
\hline S930 & 1.6 & 1.9 & 1.0 & 1.8 & 1.9 & 1.8 & 1.6 & 1.5 & 1.3 & 1.4 & 2.0 & 1.0 \\
\hline S564 & 1.3 & 1.2 & 1.1 & 1.5 & 1.4 & 1.1 & 1.7 & 1.2 & 0.6 & 1.3 & 1.0 & 0.8 \\
\hline S2155 & 1.3 & 1.4 & 0.8 & 1.2 & -0.1 & 1.4 & 1.1 & 1.0 & 1.2 & 1.0 & 1.0 & 1.3 \\
\hline S5586 & 0.9 & 0.9 & 1.2 & 0.9 & 0.9 & 0.5 & 0.7 & 0.9 & 1.0 & 1.1 & 1.0 & 1.1 \\
\hline S3791 & 0.2 & 0.2 & -0.3 & -0.1 & 0.4 & -0.4 & 0.2 & 0.0 & 0.2 & -0.2 & -0.3 & 0.4 \\
\hline S893 & 0.7 & -0.4 & 0.1 & -0.9 & -0.1 & -1.1 & -0.3 & -0.7 & -0.3 & -1.0 & -1.0 & -0.2 \\
\hline S7955 & 1.3 & 1.3 & 1.0 & 1.7 & 1.7 & 1.9 & 1.0 & 1.1 & 0.8 & 1.0 & 1.0 & 0.8 \\
\hline S5532 & 0.0 & -0.1 & $\begin{array}{l}-0.3 \\
\end{array}$ & 0.0 & 0.1 & 0.0 & -0.2 & $\begin{array}{l}-0.3 \\
\end{array}$ & -0.2 & -0.3 & -0.3 & -0.1 \\
\hline S5531 & 0.7 & 0.7 & 0.7 & 1.0 & 1.2 & 0.9 & 0.7 & 0.4 & 0.5 & 0.4 & 0.4 & 0.1 \\
\hline S5553 & 0.1 & 0.1 & -0.1 & 0.1 & 0.3 & -0.1 & 0.1 & -0.4 & -0.8 & -0.6 & -0.5 & -0.4 \\
\hline
\end{tabular}




\section{Appendix C Measurements of Theropod Specimens}

\begin{tabular}{|c|c|c|c|c|c|c|c|c|}
\hline$\frac{\mathscr{E}}{\mathscr{E}}$ & 苞 & $\underset{D}{\stackrel{D}{0}}$ & 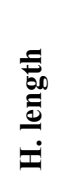 & 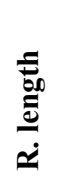 & 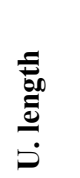 & $\frac{5}{50}$ & 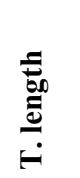 & $\underset{\Xi}{\Xi}$ \\
\hline $\begin{array}{l}\text { Albertosaurus } \\
\text { sarcophagus }\end{array}$ & NMC 11315 & $\begin{array}{l}\text { Currie pers. obs. and } \\
\text { Russell } 1970\end{array}$ & 222 & 96.2 & $\begin{array}{l}119 . \\
5\end{array}$ & 680 & 690 & 445 \\
\hline $\begin{array}{l}\text { Albertosaurus } \\
\text { sarcophagus }\end{array}$ & ROM 807 & $\begin{array}{l}\text { Parks 1928; Currie } \\
\text { pers. obs. }\end{array}$ & 305 & 134 & 165 & 1020 & 980 & 595 \\
\hline $\begin{array}{l}\text { Albertosaurus } \\
\text { sarcophagus }\end{array}$ & TMP 1986.64.1 & Currie pers. obs. & 209 & 99 & 114 & 729 & 750 & 475 \\
\hline $\begin{array}{l}\text { Daspletosaurus } \\
\text { torosus }\end{array}$ & TMP 2001.36.1 & $\begin{array}{l}\text { Currie pers. obs., some } \\
\text { from field }\end{array}$ & 360 & 135 & 169 & 960 & 905 & 486 \\
\hline $\begin{array}{l}\text { Daspletosaurus } \\
\text { torosus }\end{array}$ & UALVP 52981 & field measurements & 305 & 125 & 175 & 965 & 870 & 456 \\
\hline $\begin{array}{l}\text { Gorgosaurus } \\
\text { libratus cf. }\end{array}$ & $\begin{array}{l}\text { Children's } \\
\text { Museum } \\
2001.89 .1\end{array}$ & Currie pers. obs., cast & 303 & 94 & 182 & 830 & 885 & 538 \\
\hline $\begin{array}{l}\text { Gorgosaurus } \\
\text { libratus }\end{array}$ & $\begin{array}{l}\text { NMC } 2120 \text { (type } \\
\text { Gorgo) }\end{array}$ & Currie pers. obs. & 324 & 156 & 180 & 1030 & 980 & 615 \\
\hline $\begin{array}{l}\text { Gorgosaurus } \\
\text { libratus }\end{array}$ & TMP 91.36.500 & Currie pers. obs. & 167 & 96 & 120 & 645 & 714 & 456 \\
\hline $\begin{array}{l}\text { Raptorex } \\
\text { kriegsteini }\end{array}$ & $\begin{array}{l}\text { Long Hao Inst. } \\
\text { Geol. Pal. LH } \\
\text { PV18 }\end{array}$ & Sereno et al. 2009 & 99 & 52 & 56.8 & 338 & 382 & \\
\hline $\begin{array}{l}\text { Tarbosaurus } \\
\text { baatar }\end{array}$ & $\begin{array}{l}\text { CMMD1 (Central } \\
\text { Museum of } \\
\text { Mongolian } \\
\text { Dinosaurs) }\end{array}$ & $\begin{array}{l}\text { P. Currie pers. Obs. } \\
120605\end{array}$ & 212 & 98.6 & $\begin{array}{l}120 . \\
5\end{array}$ & 785 & 740 & 486 \\
\hline $\begin{array}{l}\text { Tarbosaurus } \\
\text { baatar }\end{array}$ & $\begin{array}{l}\text { MPC 940823-Bgt- } \\
1\end{array}$ & Currie pers. obs. & 130 & 126 & 92 & 630 & 615 & 412 \\
\hline $\begin{array}{l}\text { Tarbosaurus } \\
\text { baatar }\end{array}$ & MPC-D107/02 & Currie pers. obs. & 285 & 123 & 135 & 1120 & 890 & 530 \\
\hline $\begin{array}{l}\text { Tarbosaurus } \\
\text { baatar }\end{array}$ & $\begin{array}{l}\text { PIN 552-1/Ulan } \\
\text { Batar }\end{array}$ & Maleev 1974 & 255 & 110 & 115 & 995 & 870 & 550 \\
\hline $\begin{array}{l}\text { Tyrannosaurus } \\
\text { rex }\end{array}$ & $\begin{array}{l}\text { FMNH PR2081 } \\
\text { (Sue) }\end{array}$ & $\begin{array}{l}\text { Currie pers. obs. \& } \\
\text { Brochu } 2003\end{array}$ & 385 & 175 & 222 & 1321 & 1140 & 671 \\
\hline $\begin{array}{l}\text { Tyrannosaurus } \\
\text { rex }\end{array}$ & $\begin{array}{l}\text { MOR } 0555 \\
\text { "Wankel" }\end{array}$ & Currie pers. obs. & 385 & 161 & 201 & 1280 & 1150 & 670 \\
\hline Guanlong wucaii & $\begin{array}{l}\text { IVPP V14531 } \\
\text { holotype }\end{array}$ & $\begin{array}{l}\text { Miyashita pers.obs. } \\
2013\end{array}$ & 217 & 160 & 179 & 343 & 380 & $\begin{array}{l}189 . \\
2\end{array}$ \\
\hline Yutyrannus huali & $\begin{array}{l}\text { ZCDM V5001, } \\
\text { IVPP FV1961 }\end{array}$ & $\begin{array}{l}\text { Xu et al., 2012; cast } \\
\text { from SVP auction }\end{array}$ & 320 & 219 & 255 & 650 & 655 & 350 \\
\hline Aucasaurus & MCF-PBPH-236 & Currie pers. obs. & 248 & 79 & 92 & 700 & 640 & 346 \\
\hline $\begin{array}{l}\text { Carnotaurus } \\
\text { sastrei }\end{array}$ & MACN-CH 894 & $\begin{array}{l}\text { Bonaparte et al, } \\
\text { Currie pers. obs. }\end{array}$ & 284 & 76 & 82 & 1024 & & \\
\hline $\begin{array}{l}\text { Acrocanthosaurus } \\
\text { atokensis }\end{array}$ & NCSM 14345 & Currie pers. obs. & 370 & 220 & 255 & 1277 & 952 & $439 \mathrm{e}$ \\
\hline
\end{tabular}




\begin{tabular}{|c|c|c|c|c|c|c|c|c|}
\hline Allosaurus fragilis & MOR 693 & Currie pers. obs. & 318 & 200 & 254 & 742 & 702 & 345 \\
\hline Allosaurus fragilis & $\begin{array}{l}\text { Wyoming } \\
\text { Dinosaur Center } \\
\text { baby (Pohl) }\end{array}$ & $\begin{array}{l}\text { Currie pers. obs. } \\
120813 \text {, cast }\end{array}$ & 176 & 110 & 137 & 450 & 407 & 205 \\
\hline Allosaurus fragilis & $\begin{array}{l}\text { USNM } 4734 \\
\text { (topotype) }\end{array}$ & $\begin{array}{l}\text { Gilmore } 1920, \\
\text { Carrano database }\end{array}$ & 310 & 222 & 263 & 850 & 690 & 327 \\
\hline Suchomimus & BM R16013 & cast at BMHN & 545 & 257 & 327 & 1037 & 945 & \\
\hline $\begin{array}{l}\text { Sinosauropteryx } \\
\text { prima }\end{array}$ & $\begin{array}{l}\text { NIGP } \\
127586 / \text { NGNC } \\
2123\end{array}$ & Currie pers. obs. & 20.3 & 12.4 & 16.9 & 53.2 & 61 & 40 \\
\hline $\begin{array}{l}\text { Sinosauropteryx } \\
\text { prima }\end{array}$ & NIGP 127587 & Currie pers. obs. & 35.5 & 20.1 & 28.2 & 86.4 & 97 & 63.9 \\
\hline Bambiraptor & $\begin{array}{l}\text { AMNH FARB } \\
30556 \text { (FIP } \\
000001)\end{array}$ & Currie pers. obs. & 103 & 85 & 93 & 118 & $\begin{array}{l}165 . \\
7\end{array}$ & 80 \\
\hline $\begin{array}{l}\text { Deinonychus } \\
\text { antirrhopus }\end{array}$ & AMNH 3015 & Ostrom 1976 & 237 & 172 & 186 & 284 & 312 & 151 \\
\hline $\begin{array}{l}\text { Deinonychus } \\
\text { antirrhopus }\end{array}$ & MCZ 4371 & Ostrom 1976 & 254 & 192 & 208 & 336 & 368 & $\begin{array}{l}164 . \\
4\end{array}$ \\
\hline $\begin{array}{l}\text { Dromaeosaurid } \\
\text { Sayn Shand }\end{array}$ & MPC-D100/22 & PJC2002, 150901 & 186 & 134 & 146 & 228 & 278 & $\begin{array}{l}132 . \\
4\end{array}$ \\
\hline Microraptor gui & Wendy 1 & Currie pers. obs. & 88.3 & 78.7 & 79.4 & $\begin{array}{l}105 . \\
7\end{array}$ & $\begin{array}{l}132 . \\
7\end{array}$ & 70.3 \\
\hline $\begin{array}{l}\text { New IVPP from } \\
\text { Tugumu }\end{array}$ & & Currie pers. obs. & 119 & 87.5 & 96 & 192 & 211 & $\begin{array}{l}136 . \\
5\end{array}$ \\
\hline $\begin{array}{l}\text { Saurornitholestes } \\
\text { langstoni }\end{array}$ & MOR 660 & Currie pers. obs. & 162 & $\begin{array}{l}122 . \\
8\end{array}$ & $\begin{array}{l}123 . \\
1\end{array}$ & 225 & $\begin{array}{l}245 . \\
5\end{array}$ & 113 \\
\hline Julieraptor & ROM 53680 & Currie pers. obs. & 140 & $\begin{array}{l}105 . \\
6\end{array}$ & $\begin{array}{l}107 . \\
5\end{array}$ & 165 & 207 & $\begin{array}{l}101 . \\
4\end{array}$ \\
\hline $\begin{array}{l}\text { Saurornitholestes } \\
\text { langstoni }\end{array}$ & UALVP 55700 & field measurements & 170 & 129 & 144 & 220 & 249 & 120 \\
\hline $\begin{array}{l}\text { Sinornithosaurus } \\
\text { millenii }\end{array}$ & IVPP V12811 & $\begin{array}{l}\text { Xu Xing, Currie pers. } \\
\text { obs. }\end{array}$ & 139 & 89 & 110 & 137 & 125 & 92 \\
\hline $\begin{array}{l}\text { Velociraptor } \\
\text { mongoliensis }\end{array}$ & MPC-D100/0025 & $\begin{array}{l}\text { Barsbold \& Osmolska } \\
1999\end{array}$ & 145 & 96 & 106 & 172 & 229 & $\begin{array}{l}112 . \\
5\end{array}$ \\
\hline $\begin{array}{l}\text { Velociraptor } \\
\text { mongoliensis }\end{array}$ & $\begin{array}{l}\text { MPC-D100/0054 } \\
\text { skull }\end{array}$ & $\begin{array}{l}\text { Currie pers. } \\
\text { obs. } 150829\end{array}$ & $\begin{array}{l}130 . \\
3\end{array}$ & $\begin{array}{l}104 . \\
4\end{array}$ & $\begin{array}{l}117 . \\
3\end{array}$ & 187 & 214 & $\begin{array}{l}100 . \\
9\end{array}$ \\
\hline Wendy 2 & $\begin{array}{l}\text { Wendy 2; } \\
\text { poached, ?in } \\
\text { Korea }\end{array}$ & Currie pers. obs. & 84 & 68 & 75 & 92 & 141 & \\
\hline $\begin{array}{l}\text { Protarchaeoptery } \\
x\end{array}$ & GMV 2125 & Ji\&Ji, Currie pers. obs. & 88 & 71 & 73 & 122 & 160 & 85 \\
\hline Avimimus & $\begin{array}{l}\text { Complete Currie } \\
\text { pers. obs. on } \\
\text { display }\end{array}$ & Currie pers. obs. & 99 & 93 & 105 & 210 & 239 & 124 \\
\hline Caudipteryx zhoui & NGMC 97-9-A & Currie pers. obs. & 70 & 56 & 59 & 149 & 188 & 107 \\
\hline Caudipteryx zoui & NGMC 98-7-8 & Currie pers. obs. & 68.5 & 55 & 59 & 145 & 182 & 105 \\
\hline Caudipteryx zoui & private collection & cast in Fukui & 71.3 & 60 & 62 & $\begin{array}{l}142 . \\
5\end{array}$ & 187 & 113 \\
\hline Caudipteryx zoui & BPM 0001 & $\begin{array}{l}\text { Zhou, Wang, Zhang, } \\
\text { Xu, 2000; Currie pers. }\end{array}$ & 72 & 59 & 63.5 & $\begin{array}{l}145 . \\
4\end{array}$ & 188 & 113 \\
\hline
\end{tabular}




\begin{tabular}{|c|c|c|c|c|c|c|c|c|}
\hline & & obs. & & & & & & \\
\hline Caudipteryx sp. & IVPP 12430 & $\begin{array}{l}\text { Zhou, Wang, Zhang, } \\
\text { Xu, 2000; Currie pers. } \\
\text { obs. }\end{array}$ & 69 & 56 & 61.8 & 146 & 187 & 112 \\
\hline Anzu wyliei & $\begin{array}{l}\text { CM } 78000 \\
\text { Triebold \& Nus \#1 }\end{array}$ & $\begin{array}{l}\text { Lamanna et al. 2014, } \\
\text { casts, Carnegie } \\
150115\end{array}$ & 338 & 274 & 280 & 533 & 650 & \\
\hline Citipati n.sp. & MPC-D100/42 & $\begin{array}{l}\text { Currie pers. obs. in } \\
\text { Denmark }\end{array}$ & 205 & 180 & 188 & 305 & 380 & 180 \\
\hline Citipati osmolskae & $\begin{array}{l}\text { MPC-D100/978 } \\
\text { holotype }\end{array}$ & Currie pers. obs. & 230 & 189 & 200 & 345 & 397 & 192 \\
\hline Citipati osmolskae & MPC-D100/979 & Currie pers. obs. & 215 & 198 & 214 & 405 & & 177 \\
\hline $\begin{array}{l}\text { Conchoraptor } \\
\text { gracilis }\end{array}$ & MPC-D110/21 & Currie pers. obs. & 61.3 & 54.6 & 55 & 131 & 164 & \\
\hline Heyuannia huangi & $\begin{array}{l}\text { HYMV1-2 } \\
\text { (Heyuan Museum) }\end{array}$ & Lu 2005 & 130 & 110 & 127 & 255 & 315 & 135 \\
\hline Ingenia yanshini & MPC-D100/32 & Currie pers. obs. & 140 & $\begin{array}{l}110 . \\
5\end{array}$ & $\begin{array}{l}115 . \\
2\end{array}$ & 254 & 294 & 132 \\
\hline Ingenia yanshini & MPC-D100/33 & Currie pers. obs. & 128 & 94.7 & 99 & 233 & 267 & $\begin{array}{l}124 . \\
5\end{array}$ \\
\hline Khaan mckennai & $\begin{array}{l}\text { MPC D-100/1127 } \\
\text { holotype, "Sid" }\end{array}$ & $\begin{array}{l}\text { Currie pers. obs. } \\
120315\end{array}$ & $\begin{array}{l}110 . \\
2\end{array}$ & 87 & 95.5 & 183 & 215 & \\
\hline $\begin{array}{l}\text { Deinocheirus } \\
\text { mirificus } \\
\text { Therizino } 3\end{array}$ & $\begin{array}{l}\text { MPC-D100/127 } \\
\text { KID447 }\end{array}$ & Currie pers. obs. & 993 & 650 & 655 & 1150 & 1140 & 655 \\
\hline $\begin{array}{l}\text { Gallimimus } \\
\text { bullatus }\end{array}$ & MPC-D100/11 & $\begin{array}{l}\text { Osmolska et al, Currie } \\
\text { pers. obs. }\end{array}$ & 530 & 350 & 380 & 665 & 695 & 530 \\
\hline $\begin{array}{l}\text { Ornithomimus } \\
\text { edmontonicus }\end{array}$ & ROM 851 & $\begin{array}{l}\text { Parks 1933, Clive } \\
\text { Coy, Russell 72, PJC } \\
\text { 2005; Carrano } \\
\text { database }\end{array}$ & 279 & 177 & 206 & 435 & 475 & 310 \\
\hline $\begin{array}{l}\text { Ornithomimus } \\
\text { edmontonicus }\end{array}$ & TMP 95.110.1 & Currie pers. obs. & 275 & 200 & 211 & 425 & 465 & 332 \\
\hline $\begin{array}{l}\text { Struthiomimus } \\
\text { altus }\end{array}$ & AMNH 5257 & Currie pers. obs. & 358 & 261 & 261 & 512 & 555 & 370 \\
\hline $\begin{array}{l}\text { Struthiomimus } \\
\text { altus }\end{array}$ & BHI 1266 "Claws" & Currie pers. obs. & 395 & 313 & 326 & 655 & 700 & 475 \\
\hline $\begin{array}{l}\text { Struthiomimus } \\
\text { altus }\end{array}$ & TMP 90.26.1 & Currie pers. obs. & 310 & 260 & 280 & 467 & 506 & 375 \\
\hline $\begin{array}{l}\text { Struthiomimus } \\
\text { altus }\end{array}$ & $\begin{array}{l}\text { UCMZ (VP) } \\
1980.1\end{array}$ & Currie pers. obs. & 362 & 239 & 256 & 502 & 556 & 398 \\
\hline $\begin{array}{l}\text { Sinornithoides } \\
\text { youngi }\end{array}$ & IVPP V9612 & Currie pers. obs. & 83 & 59.1 & 65 & 137 & 194 & 111 \\
\hline $\begin{array}{l}\text { Limusaurus } \\
\text { inextricabilis }\end{array}$ & $\begin{array}{l}\text { IVPP V15923 } \\
\text { holotype }\end{array}$ & $\begin{array}{l}\text { Xu et al., 2009; Currie } \\
\text { pers. Obs. } 120807\end{array}$ & 82.2 & 45 & 44.3 & 208 & 245 & 157 \\
\hline $\begin{array}{l}\text { Sinosaurus } \\
\text { triassicus }\end{array}$ & $\begin{array}{l}\text { ZLJ0057 } \\
\text { (Previously LDM } \\
\text { L10) }\end{array}$ & Currie pers. obs. & 285 & 155 & 218 & 545 & 482 & 295 \\
\hline Eoraptor & PVSJ 512 & Currie pers. obs. & 81.5 & 61 & 62 & 152 & 155 & 73.5 \\
\hline $\begin{array}{l}\text { Herrerasaurus } \\
\text { ischigualestensis }\end{array}$ & PVSJ 373 & Currie pers. obs. & 175 & 152 & 167 & 345 & 315 & 164 \\
\hline
\end{tabular}




\begin{tabular}{|l|l|l|l|l|l|l|l|l|}
\hline $\begin{array}{l}\text { Archaeopteryx } \\
\text { lithographica }\end{array}$ & Berlin & Wellnhofer 74 & 63.5 & 54.4 & 55 & 52.6 & 68.5 & 37 \\
\hline $\begin{array}{l}\text { Archaeopteryx } \\
\text { lithographica }\end{array}$ & Solnhofen & Wellnhofer 93, 95 & 83 & 69 & 72 & 70 & 89.5 & 47.8 \\
\hline $\begin{array}{l}\text { Confuciusornis } \\
\text { sanctus }\end{array}$ & GMV 59a & Currie pers. obs. & 63 & 50 & 56 & 55 & 59 & 29 \\
\hline $\begin{array}{l}\text { Confuciusornis } \\
\text { sanctus }\end{array}$ & GMV 59b & Currie pers. obs. & 66 & 54 & 59 & 55.8 & 66.5 & 30.4 \\
\hline $\begin{array}{l}\text { Confuciusornis } \\
\text { sanctus }\end{array}$ & $\begin{array}{l}\text { IVPP V11374 bird } \\
1\end{array}$ & $\begin{array}{l}\text { cast (check original } \\
\text { later) }\end{array}$ & 53.1 & 42.6 & 45.3 & 44.8 & 50.5 & 24.3 \\
\hline $\begin{array}{l}\text { Confuciusornis } \\
\text { sanctus }\end{array}$ & $\begin{array}{l}\text { Nathan, right one } \\
\text { of pair }\end{array}$ & Currie pers. obs. & 55.4 & 44.6 & 46.1 & 47.8 & 54.4 & 27.7 \\
\hline $\begin{array}{l}\text { Confuciusornis } \\
\text { sanctus }\end{array}$ & $\begin{array}{l}\text { Nathan, left one of } \\
\text { pair }\end{array}$ & Currie pers. obs. & 53.9 & 43.9 & 46.1 & 48.3 & 51.3 & 25.7 \\
\hline $\begin{array}{l}\text { Confuciusornis } \\
\text { sanctus }\end{array}$ & TMP 98.14.1 & Currie pers. obs. & 64 & 51.3 & 51.5 & 51.6 & 60.4 & 30.9 \\
\hline $\begin{array}{l}\text { Confuciusornis } \\
\text { sanctus }\end{array}$ & TMP 98.14.2 & Currie pers. obs. & 49.8 & 42.5 & 42.7 & 44.6 & 50.2 & 26.2 \\
\hline Protopteryx? & IVPP V11665 & Currie pers. obs. & 26.8 & 26.4 & 27.4 & 19.8 & 28.8 & 16.5 \\
\hline
\end{tabular}




\section{Appendix D Loading of PC 1 and 2 of each analysis}

PC1

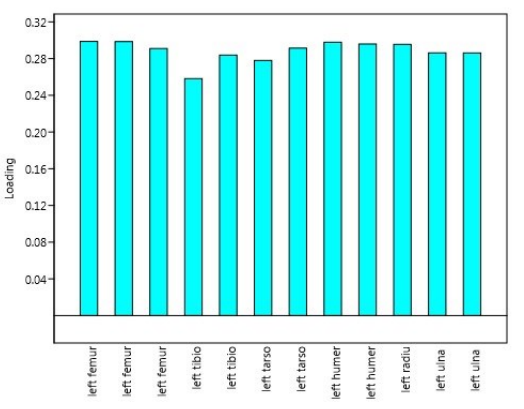

Gulls

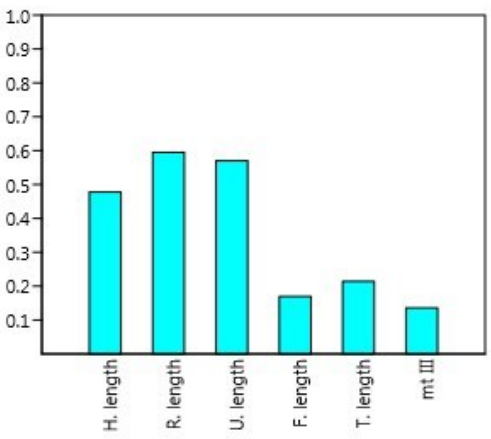

Small bodied theropods

Tyrannosaurid

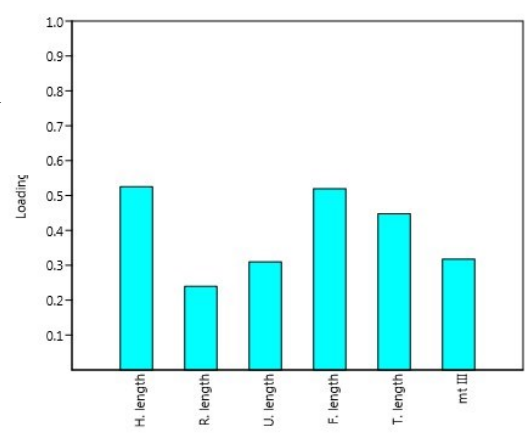

All

Theropods
PC2
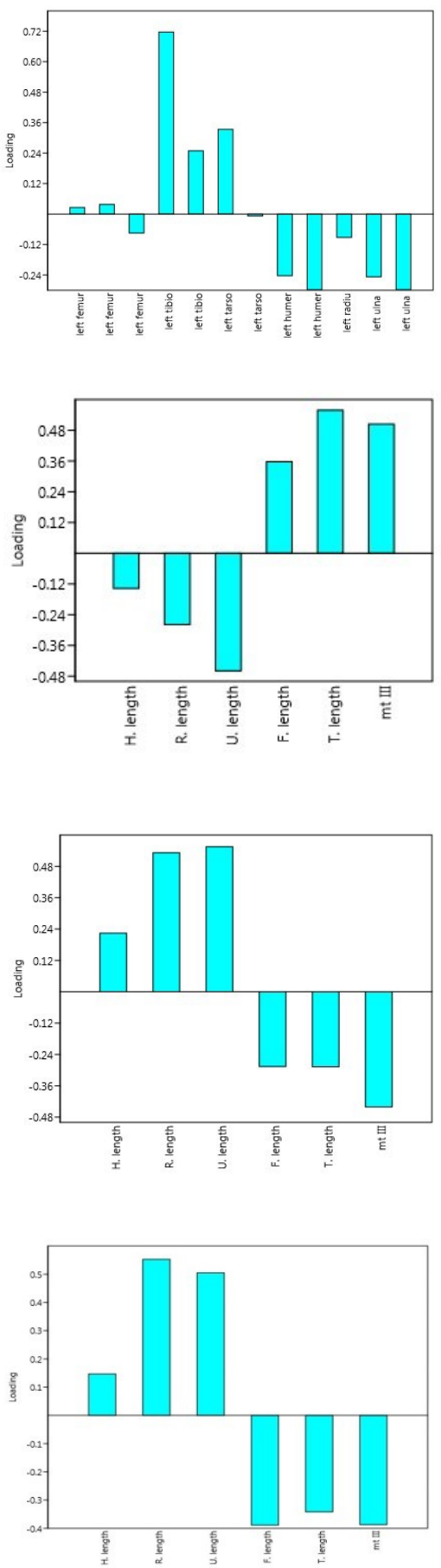
Appendix E Landmarks digitized on Larus skulls

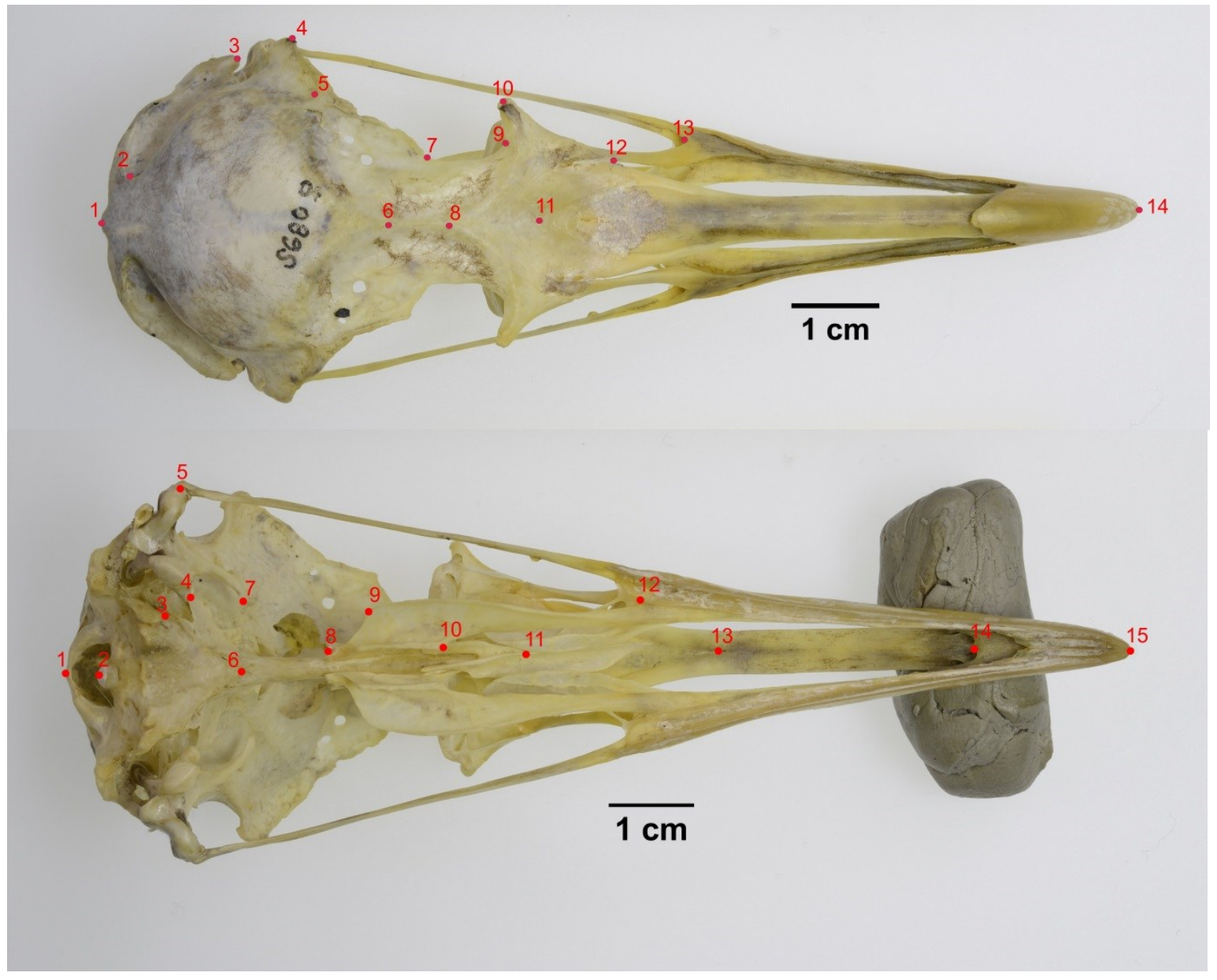




\section{Appendix F Landmark location}

\begin{tabular}{|l|l|}
\hline Number & Dorsal Landmarks \\
\hline 1 & Foramen magnum dorsal extreme \\
\hline 2 & 'Highest' curvature of fossa temporalis \\
\hline 3 & Distal end of the occipital process \\
\hline 4 & 'point' of the postorbital process \\
\hline 5 & Edge of the frontal \\
\hline 6 & Tip of frontal crest \\
\hline 7 & Sharpest curvature of orbit \\
\hline 8 & Tip of nasal crest \\
\hline 9 & Sharpest curvature of the lacrimal \\
\hline 10 & Tip of the lacrimal bone \\
\hline 11 & Suture of nasals and premaxilla \\
\hline 12 & posterior curvature of nasal opening \\
\hline 13 & Sharpest curvature of jugal \\
\hline 14 & Tip of beak \\
\hline
\end{tabular}

\begin{tabular}{|l|l|}
\hline Number & Ventral Landmarks \\
\hline 1 & Foramen magnum ventral extreme \\
\hline 2 & Occipital condyle tip \\
\hline 3 & Edge of basioccipital \\
\hline 4 & Suture of quadrate and pterygoid \\
\hline 5 & Suture of quadratojugal and jugal \\
\hline 6 & suture of parasphenoid and Basitemporal \\
\hline 7 & Tip of squamosal \\
\hline 8 & Contact of pterygoid and palatine \\
\hline 9 & Sharpest curvature of external edge of palatine \\
\hline 10 & Contact of vomer and palatine \\
\hline 11 & Contact of vomer and palatine \\
\hline 12 & $\begin{array}{l}\text { Contact of premaxillary process of palatine and palatine process of } \\
\text { premaxilla }\end{array}$ \\
\hline 13 & Ventral suture of premaxilla and nasal \\
\hline 14 & Choanal fossa \\
\hline 15 & Tip of beak \\
\hline
\end{tabular}




\section{References}

Agnolin, F. L., \& Novas, Fernando E. (2013), Avian ancestors: a review of the phylogenetic relationships of the theropods Unenlagiidae, Microraptoria, Anchiornis and Scansoriopterygidae, Springer Science \& Business Media

Bada, J. L., Wang, X. S., Poinar, H. N., Paabo, S. and Poinar, G. O. (1994), Amino acid racemization in amber-entombed insects: Implications for DNA preservation, Geochimica et cosmochimica acta, vol. 58, No. 14, pp. 3131-3135

Bakker, R. J. and Bradley, R. D. (2006), Speciation in mammals and the genetic species concept, Journal of Mammalogy, vol. 87 (4), pp. 643-662

Bakker, R. J. and Bradley, R. D. (2006), Speciation in mammals and the genetic species concept, Journal of Mammalogy, vol. 87 (4), pp. 643-662

Bakker, R. T. (1986), The dinosaur heresies, William Morrow.

Barrett, P. M. (2009), The affinities of the enigmatic dinosaur Eshanosaurus deguchiianus from the Early Jurassic of Yunnan Province, People's Republic of China, Palaeontology, 52(4), 681-688

Barton, N. H., \& Hewitt, G. M. (1985), Analysis of hybrid zones, Annual review of Ecology and Systematics, 113-148.

Benson, R. B. (2009), An assessment of variability in theropod dinosaur remains from the Bathonian (Middle Jurassic) of Stonesfield and New Park Quarry, UK and taxonomic implications for Megalosaurus bucklandii and Iliosuchus incognitus, Palaeontology, 52(4), 857-877

Benson, R. B., Carrano, M. T., \& Brusatte, S. L. (2010), A new clade of archaic large-bodied predatory dinosaurs (Theropoda: Allosauroidea) that survived to the latest Mesozoic. Naturwissenschaften, 97(1), 71-78

Benton, M. and Harper, D. (2009), Introduction to paleobiology and the fossil record, Blackwell publishing

Benton, M. J. (2004), Origin and relationships of Dinosauria, The Dinosauria, $2^{\text {nd }}$ edition, pp. 7-19.

Bookstein, F. L. (1997), Landmark methods for forms without landmarks: morphometrics of group differences in outline shape. Medical image analysis, 1(3), 225-243. 
Bosch, M. (1996), Sexual Size Dimorphism and Determination of Sex in YellowLegged Gulls (Dimorfismo Sexual de Tamaño y Determinación del Sexo en Gaviotas Patiamarillas), Journal of Field Ornithology, 534-541.

Brett-Surman, Michael K., Thomas R. Holtz, and James O. Farlow, eds. (2012) The complete dinosaur, Indiana University Press

Brooks, W. S. (1915), Notes on birds from east Siberia and arctic Alaska, Mus. Comp. Zool. Vol. LIX, No. 5. pp. 361-413

Bryant, H. N., \& Russell, A. P. (1992), The role of phylogenetic analysis in the inference of unpreserved attributes of extinct taxa. Philosophical Transactions of the Royal Society of London B: Biological Sciences, 337(1282), 405-418.

Burgers, P., \& Chiappe, L. M. (1999), The wing of Archaeopteryx as a primary thrust generator, Nature, 399(6731), 60-62.

Burnham, D. A., Derstler, K. L., Currie, P. J., Bakker, R. T., Zhou, Z. and Ostrom, J. H., (2000), Remarkable new birdlike dinosaur (Theropoda: Maniraptora) from the upper Cretaceous of Montana, The University of Kansas Paleontological Contributions, number 13

Cane, W. P. (1993), The ontogeny of postcranial integration in the common tern, Sterna hirundo, Evolution, 1138-1151

Cane, W. P. (1994), ontogenetic evidence for relationships within the Laridae, the auk 111(4):873-880

Carpenter, K. (2013), A Closer Look at the Hypothesis of Scavenging versus Predation by Tyrannosaurus rex, Tyrannosaurid Paleobiology, 265-77.

Carpenter, K., \& Smith, M. B. (1995), Osteology and functional morphology of the forelimb in tyrannosaurids as compared with other theropods (Dinosauria), Journal of Vertebrate Paleontology, 15, 530.

Carrano, M. T., \& Sampson, S. D. (2008), The phylogeny of Ceratosauria (Dinosauria: Theropoda), Journal of Systematic Palaeontology, 6(02), 183-236

Carrano. M. T., Benson, R. B. J. and Sampson, S. D. (2012), The phylogeny of Tetanurae (Dinosauria: Theropoda), Journal of Systematic paleontology, 10(2), pp. 211-300

Carrier, D., \& Leon, L. R. (1990), Skeletal growth and function in the California gull (Larus californicus), Journal of Zoology, 222(3), 375-389. 
Chamero, B., Buscalioni, Á. D. and Marugán-Lobón, J. (2013), Pectoral girdle and forelimb variation in extant Crocodylia: the coracoid-humerus pair as an evolutionary module, Biological Journal of the Linnean Society, 108, 600-618 Chatterjee, S. (1997). The rise of birds. Baltimore: Johns Hopkins Univ. Pr. Chatterjee, S., \& Templin, R. J. (2003), The flight of Archaeopteryx, Naturwissenschaften, 90(1), 27-32.

Chiappe, L. M. and Dyke, Gareth J. (2002), The Mesozoic Radiation of Birds, Annual Review of Ecology and Systematics, 33, pp. 91-124

Chiappe, L. M., Norell, M. A., \& Clark, J. M. (1996), Phylogenetic position of Mononykus (Aves: Alvarezsauridae) from the Late Cretaceous of the Gobi desert, Memoirs-Queensland Museum, 39, 557-582.

Chu, P. (1998), A Phylogeny of the Gulls (Aves: Larinae) Inferred from Osteological and Integumentary Characters, Cladistics 14, 1-43

Codd, J. R., Manning, P. L., Norell, M. A. and Perry, S. F. (2008), Avian-like breathing mechanics in maniraptoran dinosaurs, Proceedings of the Royal Society of London B: Biological Sciences, 275(1631), pp. 157-161

Colwell, M. A. (2010), Shorebird ecology, conservation, and management, University of California press

Cooper, A. and Penny, D. (1993), Mass Survival of Birds Across the CretaceousTertiary Boundary: Molecular Evidence, Science, 275(5303), pp. 1109-1113

Crochet, P.-A., Bonhomme, F., and Lebreton, J. D., (2000), Molecular phylogeny and plumage evolution in gulls (Larini), Journal of Evolutionary Biology, 13 (1), pp. $47-57$

Cullen, T. M., Fraser, D., Rybczynski, N., \& Schröder-Adams, C. (2014), Early evolution of sexual dimorphism and polygyny in Pinnipedia. Evolution, 68(5), 1469-1484.

Currie, P. J. (2003), Allometric growth in tyrannosaurids (Dinosauria: Theropoda) from the Upper Cretaceous of North America and Asia, Canadian Journal of Earth Sciences, 40(4), 651-665.

Dever, J. A., Strauss, R. E., Rainwater, T. R., McMurry, S. T., \& Densmore, L. D. (2002), Genetic diversity, population subdivision, and gene flow in Morelet's 
crocodile (Crocodylus moreletii) from Belize, Central America, Copeia, 2002(4), 1078-1091.

Dodson, P. (1993), Comparative craniology of the Ceratopsia, American Journal of Science, 293, pp. 200-234

Dodson, P. (2003). Allure of El Lagarto-Why do dinosaur paleontologists love alligators, crocodiles, and their kin? The Anatomical Record Part A: Discoveries in Molecular, Cellular, and Evolutionary Biology, 274(2), 887-890.

Dwight, J. (1925). The gulls (Laridae) of the world; their plumages, moults, variations, relationships, and distribution, Bulleting of the American Museum of Natural History, 52, pp. 63-408

Eaton, M. J., Martin, A., Thorbjarnarson, J., \& Amato, G. (2009), Species-level diversification of African dwarf crocodiles (Genus Osteolaemus): a geographic and phylogenetic perspective, Molecular Phylogenetics and Evolution, 50(3), 496-506.

Edwards, S. V., Jennings, B. W., Shedlock, A. M., (2005), Phylogenetics of modern birds in the era of genomics, Proceedings of the Royal Society B, 272, pp. 979-992

Eernisse, D. J. and Kluge, A. G. (1993), Taxonomic Congruence versus Total Evidence, and Amniote Phylogeny Inferred from Fossils, Molecules, and Morphology, Molecular Biology and Evolution, 10 (6), pp. 1170-1195

Erickson, G. M., Currie, P. J., Inouye, B. D., \& Winn, A. A. (2006), Tyrannosaur life tables: an example of nonavian dinosaur population biology.Science, 313(5784), 213-217.

Foth, C. and Rauhut, W. M. (2013), Macroevolutionary and Morphofunctional Patterns in Theropod Skulls: A Morphometric Approach, Acta Palaeontologica Polonica, 58(1):1-16

Fountaine, T. M. R., Benton, M. J., Dyke, G. J. and Nudds, R. L. (2005), The quality of the fossil record of Mesozoic birds, Proceedings of the Royal Society of London B, 272, 289-294

Fowler, D. W., Woodward, H. N., Freedman, E. A., Larson, P. L., \& Horner, J. R. (2011), Reanalysis of "Raptorex kriegsteini": a juvenile tyrannosaurid dinosaur from Mongolia. PLoS One, 6(6), e21376. 
Gatesy, S. M. (1991), Hind Limb Scaling in Birds and Other Theropods: Implications for Terrestrial Locomotion, Journal of Morphology, 209, pp. 83-96

Gauthier, J. (1986), Saurischian monophyly and the origin of birds, Memoirs of the California Academy of Sciences, 8, pp. 1-55

Gianechini, F. A. and Apesteguía, S. (2011), Unenlagiinae revisited: dromaeosaurid theropods from South America, Anais da Academia Brasileira de Ciências, 83(1), pp. 163-195

Godefroit, P., Sinitsa, S. M., Dhouailly, D., Bolotsky, Y. L., Sizov, A. V., McNamara, M. E., Benton, M. J., Spagna, P. (2014), A Jurassic ornithischian dinosaur from Siberia with both feathers and scales, Science, 345(6195), pp. 451-455

Griffiths, R., Double, M. C., Orr, K. and Dawson, R. J. G. (1998), A DNA test to sex most birds, Molecular Ecology, 7, pp. 1071 - 1075

Gündüz, İ., Jaarola, M., Tez, C., Yeniyurt, C., Polly, P. D., \& Searle, J. B. (2007). Multigenic and morphometric differentiation of ground squirrels (Spermophilus, Scuiridae, Rodentia) in Turkey, with a description of a new species. Molecular phylogenetics and evolution, 43(3), 916-935.

Gunnerus, J. E. (1767), Leem, K. (1975). Larus albus gunnerus in Leem's Beskrivelse over Finmarkens Lapper, 1767. Rosenkilde og Bagger, International Boghandel og Forlag.

Hackett, S. J. (1989), Effects of varied electrophoretic conditions on detection of evolutionary patterns in the Laridae, Condor, 91, 73-90.

Hackett, S. J., Kimball, R. T., Reddy, S., Bowie, R. C. K., Braun, E. L., Braun, M. J., Chojnowski, J. L., Cox, W. A., Han, K.-L., Harshman, J., Huddleston, C. J., Ben D. Marks, Kathleen J. Miglia, William S. Moore, Frederick H. Sheldon, David Steadman, W., Witt, C. C., Yuri, T., (2008). A phylogenomic study of birds reveals their evolutionary history. science, 320(5884), 1763-1768.

Haddrath, O. and Baker, A. J. (2001), Complete mitochondrial DNA genome sequences of extinct birds: ratite phylogenetics and the vicariance biogeography hypothesis, Proceedings of the Royal Society of London, 268, pp. $939-945$

Harris, M. P. (1965), The food of some Larus gulls, Ibis, 107(1), 43-53.

Hayman, P., Marchant, J. and Prater, T. (1986), Shorebirds, an identification guide to the waders of the world, Houghton Mifflin 
Hebert, P. D. N., Stoeckle, M. Y., Zemlak, T. S., Francis, C. M. (2004), Identification of Birds through DNA Barcodes, PLoS Biology, 2(10), pp. 16571663

Hedrick, B. P. and Dodson, P. (2013), Lujiatun Psittacosaurids: Understanding Individual and Taphonomic Variation Using 3D Geometric Morphometrics, 8(8), e69265

Hekkala, E. R. (2004), Conservation genetics at the species boundary: case studies from African and Caribbean crocodiles (Genus: Crocodylus), New York, NY: Columbia University.

Hendrickx, C., Hartman, S. A., \& Mateus, O. (2015), An overview of non-avian theropod discoveries and classification, PalArch's Journal of Vertebrate Palaeontology, 12(1)

Hoffman, W. (1984), Phylogeny, feeding behavior, and wing structure in gulls, terns, and allies (Laroidea), Ph.D. thesis, University of South Florida, Tampa Hoffman, W., Wiens, J. A., \& Scott, J. M. (1978), Hybridization between gulls (Larus glaucescens and L. occidentalis) in the Pacific Northwest, The Auk, 441458

Holliday, C. M. and Witmer, L. M. (2008), Cranial kinesis in dinosaurs: intracranial joints, protractor muscles, and their significance for cranial evolution and function in diapsids, Journal of Vertebrate Paleontology, 28(4), pp. 10731088

Holtz Jr, T. R. (2000), A new phylogeny of the carnivorous dinosaurs, Gaia, 15, 5-61

Holtz, T. R. (2004), Tyrannosauroidea, in The Dinosauria 2004

Holtz, T. R. (2012) Theropods, in The Complete Dinosaur, Indiana University press

Holtz, T. R. and Osmolska, H. (2004), Saurischia, The Dinosauria, 2004, pp. 2124

Hoyo, J., Elliott, Andrew, Sargatal, Jordi, Christie, David A. (2013), Handbook of the birds of the world, Lynx Edicion 
Hu, D., Hou, Lianhai, Zhang, Lijun \& Xu, Xing (2009), A pre-Archaeopteryx troodontid theropod from China with long feathers on the metatarsus, Nature, 461 (7264), pp. 640-643

Hudson, G. E., Hoff, K. M., Vanden Berge, J. M., and Trivette, E. C. (1969), A numerical study of the wing and leg muscles of Lari and Alcae. Ibis , 111, 459524

Hugot, J. P., Morand, S. and Vassart, M. (1991), Morphological study of Contracaecum magnicollare (Nematoda, Anisakidae) from Anous minutus (Aves, Laridae), Systematic Parasitology, 20, pp. 229-236

Hurum, J. H., \& Sabath, K. (2003), Giant theropod dinosaurs from Asia and North America: skulls of Tarbosaurus bataar and Tyrannosaurus rex compared. Acta Palaeontologica Polonica, 48(2).

Hutson, J. D., \& Hutson, K. N. (2015), An examination of forearm bone mobility in Alligator mississippiensis (Daudin, 1802) and Struthio camelus Linnaeus, 1758 reveals that Archaeopteryx and dromaeosaurs shared an adaptation for gliding and/or flapping, Geodiversitas, 37(3), 325-344

Ingolfsson, A. (1970), Hybridization of glaucous gulls Larus hyperboreus and herring gulls $L$. argentatus in Iceland, Ibis, 112(3), 340-362

Irmis, R. B. (2010), Evaluating hypotheses for the early diversification of dinosaurs, Earth and Environmental Science Transactions of the Royal Society of Edinburgh, 101, pp. 397-426

Janke, A. and Ulfir Amason (1997), The Complete Mitochondrial Genome of Alligator mississippiensis and the separation Between Recent Archosauria (Birds and Crocodiles), Molecular Biology and Evolution, 14(2), 1266-1272

Jetz, W., Thomas, G. H., Joy, J. B., Hartmann, K. and Mooers, A. O. (2012), The global diversity of birds in space and time, Nature, 491, pp. 444-448

Ji, Q. and Ji, S. (1996), On the Discovery of the earliest fossil bird in China (Sinosauropteryx gen. nov.) and the origin of birds, Chinese Geology, 233, pp. 30-33

Ji, Q., Ji, S. A., Lü, J., You, H., Chen, W., Liu, Y. and Liu Y. (2005), first avialan bird from China, Geological bulleting of china, 24, 197-210

Ji, Q., Norell, M. A., Gao, K. Q., Ji, S. A., \& Ren, D. (2001), The distribution of integumentary structures in a feathered dinosaur, Nature, 410(6832), 1084-1088. 
Kielan-Jaworowska, Z., and Barsbold, R. (1972) Narrative of the PolishMongolian paleontological expeditions 1967-1971, Palaeontologia Polonica 27: 5- 13

King, J. R., \& Carey, G. J. (1999), Slaty-backed Gull hybridization and variation in upperparts colour, Birder's Journal, 8, 88-93.

Kischlat, E. E. (2000), Tecodoncios: A aurora dos Arcosaurios no Triassico. in Holz and De Rose (eds.), Paleontologia do Rio Grande do Sol. 273-316.

Kubetzki, U. and Garthe, S. (2003), Distribution, diet and habitat selection by four sympatrically breeding gull species in the south-eastern North Sea, Marine Biology, 143, pp. 199-207

Langer, M. C., Rincón, A. D., Ramezani, J., Solórzano, A., \& Rauhut, O. W. (2014), New dinosaur (Theropoda, stem-Averostra) from the earliest Jurassic of the La Quinta formation, Venezuelan Andes, Royal Society open science, 1(2), 140184.

Larson, D. (2008), Diversity and variation of theropod dinosaur teeth from the uppermost Santonian Milk River Formation (Upper Cretaceous), Alberta: a quantitative method supporting identification of the oldest dinosaur tooth assemblage in Canada, Canadian Journal of Earth Sciences, 45, pp. 1455-1468

Larson, P. (2013), The case for Nanotyrannus, Tyrannosaurid Paleobiology, pp. $15-53$

Larsson, H. C., Sereno, P. C., \& Wilson, J. A. (2000), Forebrain enlargement among nonavian theropod dinosaurs, Journal of Vertebrate Paleontology, 20(3), $615-618$

Lemme, I., and Erbacher, M., (2013), Molecules and morphology suggests cryptic species diversity and an overall complex taxonomy of fish scale geckos, genus Geckolepis, Organisms Diversity and Evolution, 13(1), pp. 87-95

Li, R., Lockley, M. G., Makovicky, P. J., Matsukawa, M., Norell, M. A., Harris, J. D., \& Liu, M. (2008), Behavioral and faunal implications of Early Cretaceous deinonychosaur trackways from China, Naturwissenschaften, 95(3), 185-191

Linnaeus, C. (1758). Systema Naturae, Ed. 10, Vol. 1. 824 pp. Salvii, Holmiae.

Lipkin, C., \& Carpenter, K. (2008), Looking again at the forelimb of Tyrannosaurus rex, Tyrannosaurus rex, the tyrant king, 166-189. 
Livezey, B. C. (2010), Phylogenetics of modern shorebirds (Charadriiformes) based on phenotypic evidence: analysis and discussion, Zoological Journal of the Linnean Society, 160 (3), pages 567-618

Livezey, B. C., \& Zusi, R. L. (2007), Higher-order phylogeny of modern birds (Theropoda, Aves: Neornithes) based on comparative anatomy. II. Analysis and discussion, Zoological Journal of the Linnean Society, 149(1), 1-95

Longrich, N. (2006), Structure and function of hindlimb feathers in Archaeopteryx lithographica. Paleobiology, 32(03), 417-431.

Longrich, N. R., Vinther, Jakob, Meng, Qingjin, Li, Quangguo, and Russell, Anthony P. (2012) Primitive Wing Feather Arrangement in Archaeopteryx lithographica and Anchiornis huxleyi, Current Biology, 22, 2262-2267

Maiorino L., Farke, A. A., Piras, P., Ryan M. J., Terris, K. M. and Kotsakis, T. (2013), Journal of Vertebrate Paleontology, 33(6), pp. 1385-1393

Makovicky P. J., Apesteguía S. and Agnolín F. L. (2005), The earliest dromaeosaurid theropod from South America, Nature, 437: 1007-1011

Makovicky, P. J., Kobayashi, Y. and Currie, P. J. (2004), Ornithomimosauria, in The Dinosauria: second edition, University of California Press

Manning, P. L., Payne, D., Pennicott, J., Barrett, P. M., \& Ennos, R. A. (2006), Dinosaur killer claws or climbing crampons? Biology Letters, 2(1), 110-112.

Martin, L. D., Zhou, Z. H., Hou, L., \& Feduccia, A. (1998), Confuciusornis sanctus compared to Archaeopteryx lithographica, Naturwissenschaften, 85(6), pp. 286289.

Mayden, R. L. (1997), A hierarchy of species concepts: the denouement in the saga of the species problem, In Species, The Units of Biodiversity, ed. MF

Mayr, E. (1942), Systematics and the origin of species, from the viewpoint of a zoologist, Harvard University Press.

Mayr, E. (1957), Species concepts and definitions, pp. 1- 22. In E. Mayr (ed.), The Species Problem, American Association for the Advancement of Science Publ. 50, Washington, D.C

Mayr, E. (1982), The growth of biological thought: Diversity, evolution, and inheritance, Harvard University Press. 
Mayr, E. (1963), Animal species and evolution (Vol. 797), Cambridge, Massachusetts: Belknap Press of Harvard University Press.

McGowan, A. J. \& Dyke, G. J. (2007), A morphospace-based test for competitive exclusion among flying vertebrates: did birds, bats and pterosaurs get in each other's space? Trustees of the Natural History Museum, 20, pp. 1230-1236

Meganathan, P. R., Dubey, B., \& Haque, I. (2009), Molecular Identification of Indian Crocodile Species: PCR-RFLP Method for Forensic Authentication, Journal of forensic sciences, 54(5), 1042-1045.

Meyer, B., \& Wolf, J. (1822), Taschenbuch der deutschen Vögelkunde (Vol. 1). F.

Moyniham, M. (1959), A revision of the family Laridae (aves) American Museum Novitates, no. 1958

Naish D., (2012) Birds, in The Complete Dinosaur, Indiana University press

Naumann, J. A., \& Naumann, J. F. (1822), Naturgeschichte der Vögel Deutschlands: nach eigenen Erfahrungen entworfen, 10, p 351. Fleischer

Nesbitt, J. S., Irmis, R. B. and Parker, W. G. (2007), A critical re-evaluation of the Late Triassic dinosaur taxa of North America, Journal of Systematic Paleontology, 5, issue 2, pp. 209-243

Nicholls, E. L., \& Russell, A. P. (1985), Structure and function of the pectoral girdle and forelimb of Struthiomimus altus (Theropoda: Ornithomimidae), Palaeontology, 28(4), 643-677.

Norell, M. A. and Makovicky. P. J. (2004) Dromaeosauridae, in The Dinosauria, second edition, University of California press

Norell, M. and Xu, Xing (2005), Feathered Dinosaurs, Annual Review in Earth and Planetary Science, 33, pp. 277-299

Nudds, R. L. (2014), Reassessment of the wing feathers of Archaeopteryx lithographica suggests no robust evidence for the presence of elongated dorsal wing coverts, PloS one, 9(4), e93963. 
O'Connor, J. and Zhou, Z. (2015), Early evolution of the biological bird: perspectives from new fossil discoveries in China, Journal of Ornithology, 73(1) pp. $1-10$

Ord, G. (1815), North American Zoology, in Guthrie, W., A New Geographical, Historical and Commercial Grammar: Philadelphia, Johnson and Warner, 2nd American edition, 2, 292.

Ostrom, J. H. (1976), Archaeopteryx and the origin of birds, Biological Journal of the Linnean Society. 8: 91-182

Padian, K. (2004) Basal Avialae, The Dinosauria second edition, pp. 210-231

Park, J., Lee, J., Lee, J., Kim, K. S., \& Kim, S. (2014), Raptor: Fast bipedal running and active tail stabilization, In Ubiquitous Robots and Ambient Intelligence (URAI), 2014 11th International Conference on (pp. 215-215). IEEE.

Paul G. S. (1988), Predatory Dinosaurs of the World: A Complete Illustrated Guide. Simon and Schuster,

Pons, J. M., Hassanin, A., \& Crochet, P. A. (2005), Phylogenetic relationships within the Laridae (Charadriiformes: Aves) inferred from mitochondrial markers, Molecular phylogenetics and evolution, 37(3), 686-699.

Pontoppidan, E. (1763), Den Danske Atlas eller Konge-Riget Dannemark, Trykt hos Kongelig Universitets Bogtrykker AH Godiche.

Prum, R. O., Berv, J. S., Dornburg, A., Field, D. J., Townsend, J. P., Lemmon, E. M. and Lemmon, A. R. (2015), A comprehensive phylogeny of birds (Aves) using targeted next-generation DNA sequencing, Nature, 526, pp. 569-573

Rauhut, O. W. (2003), Special Papers in Palaeontology, The Interrelationships and Evolution of Basal Theropod Dinosaurs, 69. Blackwell Publishing

Reece, J. B., Urry, Lisa A., Cain, Michael L., Wasserman, Steven A., Minorsky, Peter V., Jackson, Robert B. (2011), Campbell biology, ninth edition, Pearson Higher Education AU.

Reynolds, S. J., Martin, G. R., Wallace, L. L., Wearn, C. P. \& Hughes, B. J. (2008), Sexing sooty terns on Ascension Island from morphometric measurements, Journal of Zoology, 274, 2-8

Reynolds, S. J., Martin, G. R., Wallace, L. L., Wearn, C. P. \& Hughes, B. J. 
Ridgway, R., \& Friedmann, H. (1919), The birds of North and Middle America: a descriptive catalogue of the higher groups, genera, species, and subspecies of birds known to occur in North America, from the Arctic lands to the Isthmus of Panama, the West Indies and other islands of the Caribbean sea, and the Galapagos Archipelago, 50(8) Govt. Print. Off.

Rising, J. D. and Somers, Keith M. (1989), The Measurement of Overall Body Size in Birds, The Auk, 106(4), pp. 666-674

Ruben, J. (1993), Powered flight in Archaeopteryx: response to Speakman, Evolution, 47(3), 935-938.

Ryan, M. J., Evans, D., C., Currie, P. J., Brown, C. M., Brinkman, D. (2012), New leptoceratopsids from the Upper Cretaceous of Alberta, Canada, Cretaceous Research, 35, pp. 69-80

Schmidt-Nielsen, K. (1984), Scaling, why is animal size important? Cambridge University press

Schnell, G. D. (1970a), A phenetic study of the suborder Lari (Aves) I. Methods and results of principal components analyses, Systematic Zoology, 19, pp. 35 57

Schnell, G. D. (1970b), A phenetic study of the suborder Lari (Aves) II. Phenograms, discussion, and conclusions, Systematic Zoology, 19, pp. 264 302

Schnell, G. D., Worthen, G. L. and Douglas, M. E. (1985), Morphometric Assessment of Sexual Dimorphism in Skeletal Elements of California Gulls, The Condor, 87(4) (Nov., 1985), pp. 484-493

Sereno, P. C. (1997), The origin and evolution of dinosaurs, Annual Review of Earth and Planetary Sciences, 25(1), 435-489.

Sereno, P. C., \& Brusatte, S. L. (2008), Basal abelisaurid and carcharodontosaurid theropods from the Lower Cretaceous Elrhaz Formation of Niger, Acta Palaeontologica Polonica, 53(1), 15-46.

Sereno, P. C., Forster, C. A., Rogers, R. R. and Monetta, A. M. (1993), Primitive dinosaur skeleton from Argentina and the early evolution of Dinosauria, Nature, 361 , pp. 64-66 
Sereno, P. C., Tan, L., Brusatte, S. L., Kriegstein, H. J., Zhao, X., \& Cloward, K. (2009), Tyrannosaurid skeletal design first evolved at small body size, Science, 326(5951), 418-422.

Shirley, M. H., Vliet, K. A., Carr, A. N., \& Austin, J. D. (2014), Rigorous approaches to species delimitation have significant implications for African crocodilian systematics and conservation, Proceedings of the Royal Society of London B: Biological Sciences, 281(1776), 20132483.

Sibley, D. A. (2003) The Sibley field guide to birds of Eastern North America, Knopf Doubleday Publishing group

Sibley, D. A. (2003) The Sibley field guide to birds of Eastern North America, Knopf Doubleday Publishing group

Sibley, J., C. G. and Ahlquist, J. E. (1990), Phylogeny and Classification of Birds: A Study in Molecular Evolution, Yale University Press, New Haven

Simpson, G. G. (1951), The species concept, Evolution, 5(4), 285-298.

Smith, J. B., Vann, D. R., \& Dodson, P. (2005), Dental morphology and variation in theropod dinosaurs: implications for the taxonomic identification of isolated teeth. The Anatomical Record Part A: Discoveries in Molecular, Cellular, and Evolutionary Biology, 285(2), 699-736.

Snell, R. R. (1989), Status of Larus Gulls at Home Bay, Baffin Island, Colonial Waterbirds, 12(1), pp. 12-23

Snively, E., \& Russell, A. P. (2007), Functional variation of neck muscles and their relation to feeding style in Tyrannosauridae and other large theropod dinosaurs, The Anatomical Record, 290(8), 934-957

Speakman, J. R. (1993), Flight capabilities in Archaeopteryx, Evolution, 47(1), 336-340.

Starrfelt, J., \& Liow, L. H. (2016), How many dinosaur species were there? Fossil bias and true richness estimated using a Poisson sampling model. Phil. Trans. $R$. Soc. B, 371(1691), 20150219

Strauch, J. G., JR. (1978), The phylogeny of the Charadriiformes (Aves): A new estimate using the method of character compatibility analysis, Transcripts of the Zoological Society of London, 34:263-345 
Thomas, G. H., Wills, M. A., Szekely, T. (2004), Phylogeny of shorebirds, gulls, and alcids (Aves: Charadrii) from the cytochrome-b gene: Parsimony, Bayesian inference, minimum evolution, and quartet puzzling, Molecular Phylogeny and Evolution, 30, pp. 516-526

Thomas, G. H., Wills, Matthew A., Szekely, Tamas (2004), A supertree approach to shorebird phylogeny, BMC Evolutionary Biology, 4 (28), pp. 1-18

Timmennann, G. (1957), Studien zu einer vergleichenden Parasitologie der Charadriiformes oder Regenpfeifervogel. 1: Mallophaga, Parasitologische Schriftenreihe 8(204), p 1-15

Tuinen, M. (2009), Birds (Aves), The Timetree of Life, Oxford University Press, New York, pp. 409-411

Vigfúsdóttir, F., Pálsson, S., \& Ingolfsson, A. (2008), Hybridization of glaucous gull (Larus hyperboreus) and herring gull (Larus argentatus) in Iceland: mitochondrial and microsatellite data, Philosophical Transactions of the Royal Society of London B: Biological Sciences, 363(1505), 2851-2860.

Wang, S. C. and Dodson, Peter (2006), Estimating the diversity of dinosaurs, Proceedings of the National Academy of Sciences of the United States of America, vol. 103 (37), pp. 13601-13605

Watanabe, A., \& Slice, D. E. (2014), The utility of cranial ontogeny for phylogenetic inference: a case study in crocodylians using geometric morphometrics, Journal of evolutionary biology, 27(6), 1078-1092.

Webster, M., \& Sheets, H. D. (2010), A practical introduction to landmark-based geometric morphometrics, Quantitative Methods in Paleobiology, 16, 168-188

Weishampel, D. B. Dodson, P., Osmólska, H. (2004), The Dinosauria: Second Edition, University of California Press

Wellhnofer, P. (1992), A new specimen of Archaeopteryx from the Sonlnhofen Limestone, Natural History Museum of Los Angeles County, 36, pp. 3-23

Wellnhofer, P. (1993), The seventh specimen of Archaeopteryx from the Solnhofen Limestone. Archaeopteryx, 11, pp. 1-47

Wetmore, A. (1960), A classification for the birds of the world, Smithsonian Miscellaneous Collection, 139(11), pp. 1-37 
Witmer, L. M. (1990). The craniofacial air sac system of Mesozoic birds (Aves), Zoological Journal of the linnean Society, 100(4), 327-378.

Witmer, L. M. (1995), The Extant phylogenetic Bracket and the importance of reconstructing soft tissues in fossils, Functional morphology in vertebrate paleontology, first edition, pp. 19-33

Witmer, L. (2002) The debate on avian ancestry: phylogeny, function, and fossils. In: Chiappe, L. \& Witmer, L. (eds.), Mesozoic Birds: Above the Heads of Dinosaurs, 3-30.

Wold, S., Esbensen, K., \& Geladi, P. (1987), Principal component analysis, Chemometrics and intelligent laboratory systems, 2(1-3), 37-52.

Xing, L., Buckley, L. G., McCrea, R. T., Lockley, M. G., Zhang, J., Piñuela, L., Klein, H., Wang, F. (2015), Reanalysis of Wupus agilis (Early Cretaceous) of Chongqing, China as a Large Avian Trace: Differentiating between Large Bird and Small Non-Avian Theropod Tracks, PLOS One

Xu, X. and Pol, D. (2014), Archaeopteryx, paravian phylogenetic analyses, and the use of probability-based methods for palaeontological datasets, Journal of Systematic Palaeontology, 12 (3), 323-334

Xu, X., Wang, K., Zhang, K., Ma, Q., Xing, L., Sullivan, C., Hu, D, Cheng, S \& Wang, S. (2012), A gigantic feathered dinosaur from the Lower Cretaceous of China.Nature, 484(7392), 92-95.

Xu, X., You, H., Du, K. \& Han, F. (2011), An Archaeopteryx-like theropod from China and the origin of Avialae, Nature, 475, pp. 465-470

Xu, X., Zhao, Qi, Norell, M., Sullivan, C., Hone, D., Erickson, G., Wang, X., Han, F. \& Guo, Y. (2008), A new feathered maniraptoran dinosaur fossil that fills a morphological gap in avian origin, Chinese Science Bulletin, 54(3), pp. 430-435

Yun, C.-C., (2015), Evidence points out that Nanotyrannus is juvenile Tyrannosaurus rex, PeerJ Preprints, 3, e1052

Zelditch, M. L., Swiderski, D. L., \& Sheets, H. D. (2012), Geometric morphometrics for biologists: a primer, Academic Press.

Zhang, F., Kearns, Stuart L., Orr, Patrick J., Benton, Michael J., Zhou, Zhonghe, Johnson, Diane, Xu, Xing \& Wang, Xiaolin (2010), Fossilized melanosomes and the colour of Cretaceous dinosaurs and birds, Nature, 463, pp. 1075-1078 
Zheng, X., O'Connor, Jingmai, Wang, Xiaoli, Wang, Min, Zhang, Xiaomei, and Zhou, Zhonghe (2014), On the absence of sternal elements in Anchiornis (Paraves) and Sapeornis (Aves) and the complex early evolution of the avian sternum, PNAS, 111(38), pp. 13900-13905

Zheng, X.-T., You, Hai-Lu, Xu, Xing \& Dong, Zhi-Ming (2009), An Early Cretaceous heterodontosaurid dinosaur with filamentous integumentary structures, Nature, 458(19), pp. 333-336 